\title{
)eutsche MedizinischeWochenschrift
}

W. Bargmann, Kiel

R. Bauer, Tübingen

W. Bickenbach, München

H. E. Bock, Tübingen

A. Butenandt, München

E. Derra, Düsseldorf
H. A. Gottron, Mainz.

G. R. Graham, London

N. Henning, Erlangen

F. Hoff, Frankfurt

K. Kolle, München

H. Leicher, Mainz.
E. Letterer, "Tübingen

H. Meessen, Dïsseldorf

R. Nissen, Basel

K. H. Schäfer, Hamburg

W. Scheid, Köln

G. Schettler, Heidelberg
M. Schneider, Köln

R. Schoen, Göttingen

W. Schönfeld, Heidelberg

K. Spang, Stuttgart

A. Windorfer, Erlangen

Schriftleitung: Prof. Dr. F. Grosse-Brockhoff Disseldorf

Prof. Dr. F. Kümmerle Mainz.

Dr. R. H. Rosie stutgart

Inhaltsverzeichnis für den 98. Jahrgang

I. Halbjahr 1973 Hefte 1-26

686 Abbildungen in 850 Einzeldarstellungen und 438 Tabellen

Georg Thieme Verlag · Stuttgart 


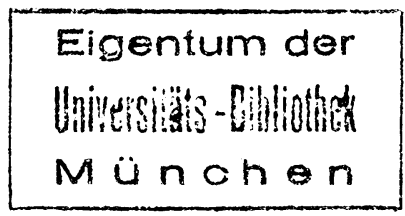

Diejenigen Bezeichnungen, die zugleich eingetragene Warenzeichen sind, wurden nicht besonders kenntlich gemacht. Es kann also aus der Bezeichnung einer Ware mit dem für diese eingetragenen Warenzeichen nicht geschlossen werden, daß die Bezeichnung ein freier Warenname ist. Ebensowenig ist zu entnehmen, ob Patente oder Gehrauchsmuster vorliegen.

Alle Rechte, insbesondere das Recht der Vervielfältigung und Verbreitung sowie der Ubersetzung, vorbehalten. Kein Teil des Werkes darf in irgendeiner Form (durch Photokopie, Mikrofilm oder ein anderes Verfahren) ohne schriftliche Genehmigung des Verlages reproduziert oder unter Verwendung elektronischer Systeme verarbeitet vervielfältigr oder verbreitet werden.

Some of the product names, patents and registered designs referred to are in fact registered trademarks or proprietary names even though specific reference to this fact is not always made in the text. Therefore, the appearance of a name without designation as proprietary is not to be construed as a representation by the publisher that it is in the public domain.

All rights, including the rights of publication, distribution and sales, as well as the right to translation, are reserved. No part of this work covered by the copyrights hereon may be reproduced or copied in any form or by any means - graphic, electronic or mechanical including photocopying, recording, taping, or information and retrieval systems - without written permission of the publisher.

(C) Georg Thieme Verlag, Stuttgart 1973 - Printed in Germany - Druckhaus Dörs, Ludwigsburg. 


\section{Sachverzeichnis ${ }^{1}$}

A

AB0-System, Antikörper im Nabelschnurblut, Immunspezifität $\mathbf{7 0 3}$

Acetylsalicylsäure, Einfluß auf perkutane Rekanalisation arterieller Obliterationen nach Dotter 1285

- und Prostaglandine 521

-, Wirkungsmechanismus 521

Acetylsalicylsäureanhydrid, Einfluß auf immunkompetente Zellen $\mathbf{3 8 4}$

Achalasie der Speiseröhre, pneumatische Dilatation 814

Achillessehnenreflexzeit und Schilddrüsendiagnostik 1048

Acinuszellkarzinom 523

Acrel-Medaille 292

Adenokarzinom, metastasierendes 1149

Adhäsivität von Blutplättchen, Bestimmung 164

Adipositas durch Psychopharmaka 1306

-, Therapie 568

Adolf-Harnack-Medaille 748

Aggregationshemmer, quantitative Bestimmung der antithrombogenen Wirkung 1004

Aggregationsneigung von Blutplättchen, Bestimmung 164

Akromegalie, Therapie $\mathbf{4 4 4}$

Akupunktur in USA 1091

Aldosteronismus, primärer, und Pathogenese der Hypertonie $\mathbf{1 0 0}$

Alfons-Fischer-Medaille 128

Alkohol bei Diabetikern 1088

- und Leberschä digung, akute 983

Alkoholismus und Arzt 637

Alloalbuminämie, Nachweis 210

Altersosteoporose, Therapie mit Natriumfluorid 1241

$\gamma$-Aminobuttersäuregehalt im Gehirn bei Chorea Huntington 1193

Amnioskop, modifiziertes, zu Filmaufnahmen des Fetus in utero 849

Amphotericin B bei systemischer Candida-albicansInfektion und ClotrimazolResistenz 1207

Ampicillin, Anwendung, orale, nach UUberlagerung 845

-, bakterizider paradoxer Effekt auf Enterokokken 611

Amyloidose, generalisierte, mit Paraproteinämie, Knochenmarksplasmozytose und Lungenamyloidose 614
Anämie, aplastische, Therapie mit Oxymetholon 1026

- durch Blutentnahmen, diagnostische 849

-, hypoplastische kongenitale 966

-, immunhämolytische und Leukozytopenie mit Autozytotoxinen $\mathbf{5 3 2}$

-, perniziöse, und chronischatrophische Gastritis, Immunpathogenese $\mathbf{1 6 9}$

-, renale, Pathogenese 217

,-- , Prophylaxe und Therapie 1040

Anaphylaxie nach Schutzimpfungen 1047, 1238

- - Tetanusimmunisierung, aktiver 110, 517, 682

- - Tetanustoxoid-Injektion 517, 682

Anapolon bei aplastischen Anämien 1026

Angina pectoris, Indikationen zur chirurgischen Therapie 893

Anoxie-Syndrom, perinatales, morphologische Substrate 665

Antiandrogen-Behandlung und Hodenveränderungen 1013

Antibiotika, Wirkung gegen Meningokokken $\mathbf{8 6}$

Anticholinergika bei Glaukom 795

Antidiabetika, orale, Maximaldosis 1307

Antiepileptika und Calciumstoffwechselstörungen 1043

-, Langzeittherapie, und rachitische Osteopathie 1036

Antikörper des AB0-Systems im Nabelschnurblut, Immunspezifität $\mathbf{7 0 3}$

-, antimitochondriale, bei Lupus-erythematodesähnlichem Syndrom 131

-, komplette und inkomplette, bei Harnwegsinfektionen des Kindes 904

-, mitochondriale, bei nicht hepatischen Krankheiten 1186

Antilymphozytenglobulin, Einfluß auf menschlichen Lymphozyt $\mathbf{5 7 8}$

Antioxidantiengehalt des Frühstücks und Magenkrebs 33

$u_{1}$-Antitrypsin-Mangel mit juvenilem Lungenemphysem 255

Anurie, akute, bei Plasmozytom 318

Aortenisthmusstenose 1054
Aphasie bei Hirnkranken und Sprachverständniss:örungen 139

Apoplexie und Flüssigkeitszufuhr 122

Aquaeductus cereb-i, Größe bei Kindern 232

Arbeitsbelastung durch Treppensteigen 1008

Arterienfibrose, obititerierende 593

Arterienobliterationen, perkutane Rekanalisation nach Dotter und Einflufs von Acetylsalicylsäure $\mathbf{1 2 8 5}$

Arteriitis temporalis, Immunhistologie 283

Arteriosklerose und Thrombangiitis obliterans. pathologischanatomische Aburenzung $\mathbf{1 5 8}$

Arthur-Weber-Stifungspreis 1052

Arvo-Ylppö-Medail!e 292

Arzneimittel, rezentereie, Unschädlichkeit und W $\mathrm{W}$ irksamkeit 1243

Arzneimittc thedingte Taubheit 1309

Arzneispezialititen, Zahl der Zulassungen in BRI) 1972 1133

Arzt, Ärıtebedarf fi, $r$ Südafrika 1006

-, Arrtegewerkschaten in USA 127

-, Aufklärungspflicht bei Verordnung phenacetinhaltiger Medikamente :0ro8

-, Auskunftscrteilui g an private Krankenversicterung 1049

-, Auskunftspflicht gegenüber Berufsgenossers schaften 1307

-, EDV und Schveigepflicht 797

-, Eigenerkrankung 637

-, Einsichtnahme ir. Gutachten durch die begutachtete Person 176

-, Entlassungsbe-ichte, Ubersendung an Krarkenkassen 909, 1190

-, Hilfeleistungsnflicht des Krankenhausarytes außerhalb der Klinik 518

-, Kusten bei Be'andilung von Arztangehöriger, Beihilfefähigkeit 685

-, Mitteilungspfich bisher nicht bekannter Befunde durch Gutachter 635

-, Notfalldienst $2: 1$

- und Psvchosen 637

-, Zahl bei Renterversicherungsträgern faanar 1972 850
-, Sachverständiger, Erstattung von Unkosten für Benutzung fremder Einrichtungen 456

-, Schweigepflicht gegenüber

Berufsgenossenschaften 1307

-, - bei Gutachten 286

-, Unterlagenherausgabe an nachbehandelnde Ärzte 1241

-, - - Werksärzte 847

-, Verwertung fremder Befunde bei amtsärztlichem Gutachten 125

Arztangehörige, Beihilfefähigkeit von Arztkosten 685

Arztwahl durch Kassenpatienten und Uberweisung an Facharzt 32

Aspirationsbiopsie, Aussagekraft 1147

Asthma bronchiale bei Hausstaub-Allergie $\mathbf{3 2 0}$

Aszites bei Leberzirrhose und Hydrothorax 669

- - inoperablem Malignom, Therapie 175

Aufbewahrungspflicht des Gesundheitsamts für Röntgenfilme 581

Aufklärungspflicht, ärztliche, bei Verordnung phenacetinhaltiger Medikamente 1008

Auskunftspflicht gegenüber Berufsgenossenschaften und ärztliche Schweigepflicht 1307

Australia-Antigen bei Diabetes 301

-, Nachweis, fluoreszenzserologischer, in Leber 93

- -Persistenz und ärztliche Arbeitsfähigkeit 908

-, Stimulation der Lymphozyten in vitro von HB-Antikörper-Trägern 262

Autozytotoxine bei immunhämolytischer Anämie und Leukozytopenie $\mathbf{5 3 2}$

Azathioprin, Therapie der Enteritis regionalis Crohn 1270

\section{B}

B-Partikel-ähnliche Strukturen in Mammagewebe $\mathbf{1 6 2}$

Baastrupsche Krankheit, Diagnose 1178

Bacteroides-Keime, pathogenetische Bedeutung 350

Bakteriologie, Harngewinnung zur bakteriologischen Untersuchung 845

Bartter-Syndrom bei Erwachsenem $\mathbf{7 2 3}$ 
Bauchlage, Einfluß auf Entwicklung 955

-, - - Gesichtsfeld 955

-, - - Hüftgelenke 955

-, - - verschiedene Krankheiten 955

-, - - Ruktation 955

-, _ - Wirbelsäule 955

BCG-Impfung und Tuberkulintest 125

- - Tuberkulose-Erkrankungen 941

Belastungsprüfungen, klinische, bei koronarer Herzerkrankung 891

Bence-Jones-Plasmozytom, akutes Nierenversagen $\mathbf{3 1 8}$

Bevölkerungsrückgang in $\mathrm{BRD}$ bis 1985748

Bierkonsum in BRD 1971338

- - - 19721091

Bilirubinenzephalopathie bei Neugeborenen und medikamentöse Therapie 1260

Bisalbuminämie, Nachweis 210

Blasenfunktionsstörungen bei Diabetes 1309

Bleivergiftung, Dauer der spezifischen Behandlung 747

Bleomycin, Lungenfibrose als Nebenwirkung 77

Blut, Fettklärung 335

-, Hämoglobinbestimmung 456

-, Unterscheidung von mütterlichem und fetalem Blut bei Vaginalblutungen 227

Blutdruck und Nierenfunktion bei nephrogener und essentieller Hypertonie $\mathbf{5 9 7}$

Blutentnahmen, diagnostische, und Anämie 849

Blutgasmuster, lokale, Einfluß pneumatischer Blutleeren 72

Blutgerinnung, Beeinflussung durch Clomethiazol 226

- , - - Propanidid 226

Blutleere, pneumatische, Einfluß auf lokale Blutgas- und Enzymmuster $\mathbf{7 2}$

Blutplättchen, Bestimmung der Adhäsivität und Aggregationsneigung 164

Blutsenkungsgeschwindigkeit, Beschleunigung nach Operationen 1144

-, Bestimmung mit MikroMethoden 175

- bei nephrotischem Syndrom 634

Bluttransfusion und Corticosteroide, Vorbehandlung 288

- - $\gamma$-Globulin-Prophylaxe 228

Blutung, vaginale, Unterscheidung von mütterlichem und fetalem Blut 227

Blutungsanomalien bei Trichomonas vaginalis $\mathbf{3 7 5}$

Brennwert der Nahrung, Verfügbarkeit bei Säuglingen, Kindern und Erwachsenen 901

Brill-Symmers-Lymphoblastom 335

Bromcarbamid, Intoxikation 398
Bromsulfalein-Test, Vergleichbarkeit verschiedener Modifikationen 934

Bronchialadenom 340

Bronchialasthma bei Hausstaub-Allergie $\mathbf{3 2 0}$

Bronchialkarzinom, retrospektive Studie über Behandlungsergebnisse 1099

Bronchialkarzinom, inoperables 347, 793

Bronchialtumor und Mittellappensyndrom 1095

Bronchitis, chronische, Chemotherapie 947

,-- , Sputumbefunde 673

Brustkrebs nach Mumpsorchitis 1278

-, Risikofaktoren 583

Budd-Chiari-Syndrom, Diagnostik 48

- nach Gravidität 398

C

Caerulein, Beeinflussung des unteren Osophagussphinkters 332

Caesium, radioaktives, zur Telecurietherapie 1306

Calcitonin, Einfluß auf Druckprofil des unteren Osophagussphinkters 1059

-, Hemmung der Gallenblasenkontraktion 957

Calciumoxalatsteine und Erkrankưngen von Dünndarm und Leber 335

-, Therapie 335

Calciumstoffwechselstörungen bei antiepileptischer Therapie 1043

Candida-albicans-Infektionen und humorale Antikörper 194

- - -Sepsis nach Nierentransplantation, Behandlung mit Clotrimazol und Miconazole 15

- - - mit interstitieller Pilzpneumonie, Therapie 1207

Candida-Myokarditis 79

Candida-Osophagitis 1.30

Candidiasis 799

-, granulomatöse und Immunabwehr $\mathbf{4 1 5}$

Carotissinusnerven-Stimulation 37

Carotissinus-Syndrom, Behandlung mit Schrittmacherstimulation $\mathbf{5 5 8}$

Cephalosporine, Steigerung der Toxizität durch Diuretika 459

Chemotherapie, Bronchitis, chronische 947

Chlor im Badewasser 580

Chlorkalk zur Stuhlentseuchung bei Hepatitis 1276

Chloroform in Zahnpasten 849

${ }^{197} \mathrm{Hg}$-Chlormerodrin, Einfluß auf EEG beim Kaninchen 284

Cholelithiasis und Pankreatitis bei primärem Hyperparathyreoidismus 426
Cholesteringranulomatose, pulmonale, bei Cholesterinpneumonie 503

Cholesterinpneumonie, idiopathische, mit Ubergang in pulmonale Cholesteringranulomatose $\mathbf{5 0 3}$

Cholezystektomie, Einfluß auf exkretorische Pankreasfunktion 930

Cholinmangeldiät und Penicillamin bei Ratten und Lipomatose des exokrinen Pankreas 1085

Chorea Huntington und $\gamma$-Aminobuttersäuregehalt im Gehirn 1193

Chromenteropathie und exokrine Pankreasfunktion 1268

Ciguatera-Vergiftung 1052

Clonethiazol, Einfluß auf Blutgerinnung 226

Clotrimazol, Behandlung von Candida-albicans-Sepsis nach Nierentransplantation 15

- -Resistenz bei systemischer Candida-albicans-Infektion, Therapie mit Amphotericin B 1207

Coecumperforation, "spontane " 671

Contusio cordis, und ventrikuläre Extrasystolen $\mathbf{8 8 5}$

Cor pulmonale, subakutes, durch tumoröse Pulmonalarterienummauerung und EKG 1034

Corticosteroide vor Bluttransfusionen 288

-, chronische Polyarthritis, alternierende Therapie 919

Corticosteroidtherapie, orale und parenterale, Dosierung 518

Coxarthrose, operative Behandlung 325

Cushing-Syndrom, Pathologie 1272

Cyclophosphamid zur Langzeittherapie bei Plasmozytom 496

\section{$\mathrm{D}$}

D-Penicillamin bei Ratten unter Cholinmangeldiät und Lipomatose des exokrinen Pankreas 1085

Datenverarbeitung, elektronische, Analyse mikrobiologischer Befunde 441

,,-- und ärztliche Schweigepflicht 797

Defektdysproteinämie mit juvenilem Lungenemphysem 255

Dekubitalulkus, Therapie mit Kristallzucker 1091

Depot-Penicilline beim Kleinkind 1276

Dermatitis exfoliativa Ritter, Differentialdiagnose 959

Dermatozoenwahn und periphere Nervenschädigung 1305

Desinfektion der Hände auf Infektionsstationen 124

- - Harnröhrenmündung mit Sublimat 1275

- , Haut- 517

,,-- vor Injektionen 909

Desinfektionsmaßnahmen bei Virushepatitis 176

Desodorant-Sprays, Wirkung und Nebenwirkungen 960

Diabetes insipidus, renaler, Therapie 74

- mellitus und Alkohol 1088

- - Australia-Antigen 301

- -, Blasenfunktionsstörungen bei 1309

- -, Glibornurid-Therapie 915

- -, $\gamma$-Globulin zur Infektionsprophylaxe 634

- -, Maximaldosis oraler Antidiabetika 1307

- -, Opticusatrophie und Innenohrschwerhörigkeit, fami. liäres Vorkommen $\mathbf{2 4 3}$

- -, psychische und vegetative Störungen 684

- - und Störungen der Speiseröhrenfunktion $\mathbf{1 1 5 1}$

Diät und Koronarsklerose 797

-, vollsynthetische fettfreie, und Bedeutung der Kohlenhydrate $\mathbf{1 1 5 6}$

Diättherapie der Fettsucht 26 , 741

Diagnose, Vorgehen 783

Diagnostik, Achillessehnenreflexzeit und Schilddrüsendiagnostik 1048

-, Alloalbuminämie, Nachweis 210

-, Aspirationsbiopsie, Aussagekraft 1147

-, Australia-Antigen in Leber, fluoreszenzserologischer Nachweis 93

-, Baastrupsche Krankheit 1178

-, Belastungsprüfungen bei koronarer Herzerkrankung 891

-, Bisalbuminämie, Nachweis 210

- , Blut, Unterscheidung von mütterlichem und fetalem bei Vaginalblutungen 227

-, Blutentnahmen und Anämie 849

-, Blutplättchen, Bestimm ung der Adhäsivität und Aggrega. tionsneigung 164

-, Bromsulfalein-Test, Vergleichbarkeit verschiedener Modifikationen 934

-, Budd-Chiari-Syndrom 48

-, Candida-Infektionen und humorale Antikörper 194

-, Dermatitis exfoliativa Ritter 959

-, Doppelradionuklid-Pankreasszintigraphie 1019 
-, Echoenzephalographie (B-Scan), zweidimensionale 1234

-, EEG bei Schizophrenie 1074

-, Endoskopie, gastroenterologische, Risiken 386

-, Enzymbestimmungen, Wertigkeit bei Myokarditis 1297

-, Epidermolysis necroticans 959

-, Fettleberhepatitis $\mathbf{6 2 5}$

-, Glucosewerte bei unterschiedlicher Blutentnahme 124

-, Hämiglobincyanid-Methode zur Hämoglobinbestimmung 456

-, Hämoglobinbestimmung 456

-, Hepatitis, chronisch-aggressive, Differentialdiagnostik 580

-, Hirnszintigraphie, statische, bei zerebrovaskulären $\mathrm{Er}$ krankungen 973

-, - bei zerebrovaskulärer Insuffizienz 627

-, Hyperaldosteronismus, primärer, Seitenlokalisation und Diagnose 506

-, Hypercalcurie, idiopathische 683

-, Immunelektrophorese bei Paraproteinosen $\mathbf{7 3 1}$

-, Karzinome und Malignität, Histologie 683

-, Kern- und MitochondrienAntikörpernachweis, simultaner, in der Immunfluoreszenz 1223

-, Kohlenhydratstoffwechsel und Myokardinfarkt 270

-, Leberfunktionsproben, pathologische, Häufigkeit bei anikterischen Drogenabhängigen 1022

-, Leberkeilexzision, pathologisch-anatomische Folgen 81

-, Leberzirrhose, immunologische und morphologische Differentialdiagnose $\mathbf{4 7 2}$

-, Leukämie-Frühveränderungen, Differentialdiagnose 895, 945

-, Lupus erythematodes und LE-Antiglobulinkonsumptionstest 1048

-, Lymphogranulomatose 836

-, Magensekretionsanalyse, Dur chführung und Beurteilung 938

-, Mammatumoren, gut- und bösartige, Tripeldiagnostik 691

-, Mammographie, vermeidbare Irrtïmer $\mathbf{2 7 2}$

-, Mellanomverdacht, Biopsie 123:9

-, Mikro-Blutsenkungsmethoden 175

-, Mo rbus Crohn des oberen Verdauungstrakts $\mathbf{4 8 1}$

-, Nierendystopie 1169

-, Nierenfunktionsstörungen 684.
-, Nierentraumen 1137

-, Oberbauchsyndrom, Evokationstest mit Sekretin und Pankreozymin $\mathbf{8}$

-, Pankreaserkrankungen, durch Lipasebestimmung im Serum 364

-, Pankreas, und Evokationstest 579

-, Plasmazellenleukämie 874

-, Polypektomie, endoskopische, im proximalen Kolon 219

-, Porphyrinnachweis im Liquor bei chronischer hepatischer Porphyrie 513

-, Pseudotumor cerebri 17

-, Sonographie der Niere 361

-, - - Pankreasregion 429

-, Sputumbefunde bei chronischer Bronchitis 673

-, Ugen-Teststreifen zum Nachweis von Urobilinogen im Harn 112

-, Ultraschalltomographie der Pankreasregion $\mathbf{4 2 9}$

Dialyse, Heimbehandlung und -Training 641

Dickdarm, submuköse Lipome 1064

Dickdarmpolypen, koloskopische Polypektomie $\mathbf{6 7 5}$

Di-Guglielmo-Syndrom 355

Dilatation, pneumatische, zur Behandlung der Achalasie der Speiseröhre $\mathbf{8 1 4}$

Diuretika, Steigerung der Toxizität von Cephalosporinen 459

Divertikulitis des Kolon, Behandlungsergebnisse $\mathbf{1 1 0 9}$

Dokumentationsassistenten, Verein Medizinischer 1309

Doppelradionuklid-Pankreasszintigraphie 1019

DPT-Grundimmunisierung nach Wiederimpfung 74

Drogenabhängige, anikterische, Häufigkeit pathologischer Leberfunktionsproben 1022

Drogenabhängigkeit, Entwicklungsstadien bei Jugendlichen 327

Drogenkonsum bei Jugendlichen, Psychodynamik von Weckaminen 295

Drogenverzicht, Motivation 1247

Druckprofil im unteren Osophagussphinkter, Beeinflussung durch Gastrin, Calcitonin und Glucagon 1059

Drüsen, endokrine, Hypertrophie, durch Immunisierung gegen das Effekthormon 469

,-- , Induktion biologisch frustraner Hyperfunktion durch Immunisierung gegen das Effekthormon 469

Dünndarmschleimhautbilder, pathologische, Klassifizierung 998

Dïsenzerstäuber, bakteriologische Probleme 227
Duodenalzerreißung 524

Durchfälle, intermittierende, und Skelettschmerzen als Leitsymptome $\mathbf{7 3 7}$

Durchzugsmethode, kontinuierliche, zur Funktionsdiagnostik des unteren Ösophagussphinkters $\mathbf{1 0 5 9}$

Dysplasie, fibröse 914

Dystrophia adiposogenitalis, Therapie 31

\section{E}

Eagle-Effekt von Penicillin G 611

Echoenzephalographie (B-Scan), zweidimensionale 1234

Edens-Preis 77

EDV, Analyse mikrobiologischer Befunde 441

- und ärztliche Schweigepflicht 797

Eingriffe, ärztliche, Einwilligungsformulare und Patientenreaktion 1147

Eisenmangelanämie 35

Eiweißstoffwechsel und orale Kontrazeptiva 829

E.-K.-Frey-Preis 1092

EKG-Artefakt infolge Parkinsonismus 342

EKG-Muskelartefakte 586

Elektrokardiogramm, Einfluß von ${ }^{117} \mathrm{Hg}$-Chlormerodrin beim Kaninchen $\mathbf{2 8 4}$

- bei subakutem Cor pulmonale durch tumoröse Pulmonalarterienummauerung 1034

- bei Rauschgiftsüchtigen 1047

- und Schizophrenie $\mathbf{1 0 7 4}$

Elektrotherapic bei schweren Herzrhythmusstörungen $\mathbf{6 7 5}$

Elliptozytose, hereditäre 1053

Endokarditis, Pilz-, nach prothetischem Herzklappenersatz 201

Endokrinopathie, paraneoplastische, bei Leberzellkarzinom 322

Endometriose und Ischialgie 179

-, extragenitale 239

Endoskopie, gastroenterologische, Risiken $\mathbf{3 8 6}$

Enteritis regionalis Crohn, Therapie mit Azathioprin 1270

Enterokokken, paradoxer bakterizider Effekt von Penicillinen 611

Entlassungsberichte, ärztliche, Ubersendung an Krankenkassen 909, 1190

Entwicklung, kindliche, und Bauchlage 955

Enzephalitis bei Herpes-simplex und Glioblastom 1010

- im Kindesalter 235

Enzephalopathie, Bilirubin-, bei Neugeborenen und medikamentöse Therapie 1260

-, portocavale pulmonale, venöse Beimischung 769

Enzymbestimmungen, diagnostische Wertigkeit bei Myokarditis 1297

Enzymdefekte bei Biosynthese der Steroidhormone 1299

Enzymmuster, lokale, Einfluß pneumatischer Blutleeren 72

Epidemiologie der Toxoplasmose $\mathbf{5 3 5}$

Epidermoid, extradurales 1280

Epidermolysis necroticans, Differentialdiagnose 959

Episiotomie, zunehmende Häufigkeit 400

-, Indikationen 401

Ergometrie, Untersuchungen zur körperlichen Belastbarkeit chronisch Leberkranker 528

Ergotamintartrat und Spasmen der Extremitätenstammarterien 825

Erich-Lexer-Preis 1278

Ernährungsfaktoren, Einfluß auf Entstehung von Fettsucht und Hyperinsulinismus $\mathbf{1 2 5 6}$

Ernst-von-Bergmann-Plakette 128

Erysipel, chronisch-rezidivierendes, und Nagelmykose, Therapie 846

Erythema perstans 585

Erythrämie 355

Erythroleukämie 355

European Reticulo-Endothelial Society 638

- Sleep Research Society 232

Evans-Syndrom 1163

Evokationstest zur Pankreasdiagnostik 579

- mit Sekretin und Pankreozymin beim Oberbauchsyndrom 8

Extrasystolen, ventrikuläre, Dauerfolge nach traumatischer Herzschädigung $\mathbf{8 8 5}$

Extremitätenstammarterien, Spasmen durch ergotamintartrathaltige Medikamente 825

\section{F}

Facharzt, Uberweisung in Kassenpraxis 32

Fahrtiichtigkeit und Ovulationshemmer 1191

Faktor-XII-Mangel 267

Fett im Unterhautfettgewebe und Herzinfarkt in Israel und Deutschland 637

-, verdampftes, und Lipoidpneumonie 337

Fettklärung im Blut 335

Fettleber, Pathogenese, Klinik und Biochemie 733

- -Hepatitis, Diagnose 625

Fettsäuren und Myokardinfarkt 
Fettstoffwechsel und orale Kontrazeptiva 829

Fetus in utero, Filmaufnahmen mit modifiziertem Amnioskop 849

Fibel der rheumatischen Erkrankungen 1309

Fibrinolyse, Kurzzeit-, bei akutem Myokardinfarkt 861

Fibroadenom der Mamma, Einfluß oraler Steroidkontrazeptiva 698

Fieber, rezidivierendes $\mathbf{4 5 1}$

Fingergelenkersatz nach Swanson 44

Fingergelenksluxation, alte, Therapie 1005

Flüssigkeitszufuhr bei zerebralem Insult 122

Fluglotsen und stressbedingte Krankheiten 1278

Fluor zur Therapie der Altersosteoporose 1241

Fluoreszenzserologie, Nachweis von Australia-Antigen in Leber 93

Fluoride zur Kariesprophylaxe 123,751

Fluoridierung des Trinkwassers, Toxikologie $\mathbf{7 7 8}$

Franceschetti-Liebrecht-Preis 34

Friedrich-Miescher-Preis 1194

Fructose, Bilanz- und Stoffwechselverhalten bei Gesunden und parenteraler Ernährung 602, 1006

-, Nebenwirkungen bei Infusion 839

-, parenteral, postoperative Verwertung 809

Furosemid, Wirkung bei chronischer Niereninsuffizienz 977

\section{G}

Gallenblasenkontraktion, Hernmung durch Calcitonin 957

Gastrin, Einfluß auf Druckprofil des unteren Osophagussphinkters 1059

Gastritis, chronisch-atrophische, und perniziöse Anämie, Immunpathogenese 169

Gastroenterologie, Endoskopie, Risiken 386

Gehirn, $\gamma$-Aminobuttersäuregehalt bei Chorea Huntington 1193

-, Aquaeductus cerebri, Größe bei Kindern 232

-, Echoenzephalographie (B-Scan), zweidimensionale 1234

-, ischämischer Insult und

Schlafmittel 1089

-, Pseudotumor cerebri, Diagnose 17

$=-,-$, Therapie 19

-, Schlaganfälle, jahreszeitliche Häufung 1144

- -Szintigraphie bei zerebrovaskulären Erkrankungen 973
-, zerebrovaskuläre Insuffizienz, akute, Therapie 123

-, falsche Uberträgerstoffe 574

Gehirnerkrankungen und Poliomyelitisschluckimpfung 1049

Gelbfieberimpfung in Praxis 1088

Geriatrie, Glucosetoleranz 908

-, Osteoporose, Therapie mit Natriumfluorid 1241

-, Schluckstörungen 334

Gesellschaft für Gastroenterologie in Bayern 687

Gesichtsfeld und Bauchlage 955

Gesundheitsamt, Aufbewahrung von Röntgenfilmen 581

-, Modell- 77

Gicht, Spironolacton und Thiabutazid, Wirkung auf Serumkonzentrationen von Harnsäure und Lipiden 11

-, primäre, Epidemiologie und klinisches Bild, 1948-1970 183

Glaukom und Anticholinergika 795

-, sekundäres, und Nebenhöhlenoperation 1049

Glibornurid, Therapie des Erwachsenendiabetes 915

Gliedmaßenarterien, Spasmen durch ergotamintartrathaltige Medikamente 825

Glioblastom und Herpes-simplex-Enzephalitis 1010

$\gamma$-Globulin zur Infektionsprophylaxe bei Diabetikern 634

-, Prophylaxe bei Bluttransfusionen 228

Glomus caroticum, maligner Tumor mit Katecholaminsekretion 993

Glucagon, Einfluß auf Druckprofil des unteren Osophagussphinkters 1059

Glucocorticoide zur Senkung der elektrischen Reizschwelle von Schrittmachern 858

Glucose, Bilanz- und Stoffwechselverhalten bei Gesunden und parenteraler Ernährung 602, 1006

-, Nebenwirkungen bei Infusion 839

-, parenteral, postoperative Verwertung 809

Glucosebelastung, orale 794

Glucosebestimmung im Blut, reflektometrische 400

Glucosekonzentration, Bestimmung im Reflektometer 122

Glucosetoleranz im Alter 908

Glucosewerte bei unterschiedlicher Blutentnahme 124

Gödecke-Forschungspreis 292

Gravidität und Budd-ChiariSyndrom 398

GRF, Growth-HormoneReleasing-Faktor, Mangel bei Minderwuchs 539

Grippeschutzimpfung und anaphylaktische Reaktionen 1238

Growth-Hormone-ReleasingFactor (GRF), Mangel bei Minderwuchs 539
Grundimmunisierung, -DPT, nach Wiederimpfung 74

Gumprechtsche Kernschatten bei chronischer Lymphadenose 289

Gutachten, ärztliche, und Einsichtnahme durch die begutachtete Person 176

-, amtsärztliches, Verwertung fremder Befunde 125

Gutachter, ärztlicher, Mitteilungspflicht bisher nicht bekannter Befunde 635

-, -, Schweigepflicht 286

\section{H}

Hämangiom 1246

Hämiglobincyanid-Methode zur Hämoglobinbestimmung 456

Hämodialyse, Heimbehandlung und -Training 641

-, Einfluß auf Hormonstatus bei terminaler Niereninsuffi. zienz 661

- mit Oberarmfistel 395

- und Parathyreoidektomie, subtotale $\mathbf{4 8 4}$

Hämoglobin, Bestimmung im Blut 456

Hämophilie, prophylaktische Behandlung 1240

-, Pseudotumoren der Knochen 206

Händedesinfektion auf Infektionsstationen 124

Hageman-Faktor-Mangel 267

Halswirbelsäule und chronische Polyarthritis, neurologische Komplikationen 988

Hans-Kleinschmidt-Preis 583

Hans-Klenk-Preis 1052

Hans-Theo-Schreus-Gedächtnispreis 34

Harnblase, Wandnekrose beim Neugeborenen durch Nabelkatheter $\mathbf{7 2 7}$

Harngewinnung zur bakteriologischen Untersuchung 845

Harnröhrenmündung, Desinfektion mit Sublimat 1275

Harnsäure im Serum, Abhängigkeit von Alter und $\mathrm{Ge}$ schlecht, bei Urica-quantTest $\mathbf{3 8 0}$

- - --, Einfluß von Spironolacton und Thiabutazid bei Gichtkranken und Stoffwechselgesunden 11

Harnstoff, Serum-, zur Diagnostik von Nierenfunktionsstörungen 684

Harnwegsinfektionen des Kindes und komplette und inkomplette Antikörper 904

Haschisch und Persönlichkeitsbild 214

Hausstaub-Allergie, Prophylaxe 1143

Hautdesinfektion 517

- vor Injektionen 73, 909

HB-Antigen, In-vitro-Stimulation der Lymphozyten von HR-Antikörper-Trägern 262

HB-Antikörper-Träger, Invitro-Stimulation der Lymphozyten durch HB-Antigen 262

Heimdialysebehandlung und -Training 641

Heinz-Karger-Preis 34

Hepatitis, Stuhlentseuchung mit Chlorkalk 1276

-, chronisch-aggressive, Differentialdiagnose und Therapie 580

-, Virus-, Desinfektionsmaßnahmen 176

Herpes-simplex-Enzephalitis und Glioblastom 1010

Herpes zoster, Therapie 1275

Herz, Indikationen zur chirurgischen Behandlung der koronaren Herzerkrankung 853

-, klinische Belastungsprïifungen bei koronarer Herz. erkrankung 891

-, Pilzendokarditis nach prothetischem Her klappenersatz 201

-, Sinusknotensyndrom 1

Herzerkrankung, koronare, chirurgische Behandlung 853

,,-- klinische Belastungsp riifungen 891

Herifehler, angeborene und erworbene, operative Rehabilitation $\mathbf{4 2 1}$

Herzinfarkt und Körperfert in Israel und Deutschland 637

Herzinfarktrezidiv und Training 1191

Herzkontusion und ventrilkuläre Extrasystolen 885

Herzrhythmusstörungen, schwere, Elektrotherapie 675

Herzschädigung, traumatische, und ventrikuläre Extrasysstolen 885

Hiatushernie, chirurgische Therapie 1131

Hilfeleistungsptlicht des Krankenhausarztes außerhalt, der Klinik 518

Hinterstrangreizung, elektrische, bei chronischen Schmerzzuständen $\mathbf{1 1 3 0}$

Hirndruck, gesteigerter, guitartiger, Diagnostik 17

,,,--- Therapie 19

Hirnkranke mit und ohne Aphasie und Sprachverst:ändnisstörungen 139

Hirnszintigraphie, Diagnositik der zerebrovaskulären Inısuffizienz 627

-, statische, zur Diagnostik zerebrovaskulärer Erkramkungen 973

Hirntumor, larvierte Symptromatik 714

Hochleistungssport, Myokard- 
Hodenfunktion, endokrine, und Lebensalter $\mathbf{1 2 8 1}$

Hormonregulation des Lipidstoffwechsels $\mathbf{7 8 7}$

Hormonstatus bei terminaler Niereninsuffizienz, Einfluß der Hämodialyse $\mathbf{6 6 1}$

Hüftgelenk, Reihenuntersuchungen bei Säuglingen und Strahlenschutz 402

Hüftgelenksfunktion und Bauchlage 955

Hufeland-Preis 1092

Hundespulwurm, Larveninvasion beim Menschen und Meningo-enzephalomyelitis 1175

Hydronephrose bei Peritonitis 127

Hydrothorax, hepatischer 669

Hyperaldosteronismus, primärer, Diagnose und Seitenlokalisation 506

Hypercalcämie 852

- -Krise bei HypercalcämieSyndrom 276

- -Syndrom und hypercalcämische Krise $\mathbf{2 7 6}$

Hypercalcurie, idiopathische 683

Hyperfunktion, biologisch frustrane, endokriner Drïsen, Induktion durch Immunisierung gegen das Effekthormon 469

Hyperhidrosis, Therapie 518

Hyperinsulinismus, Einfluß von Ernährungsfaktoren auf Entstehung 1256

Hyperkinesie, extrapyramidale, bei Langzeittherapie mit Mebhydrolin 1071

Hyperlipidämie und Hypogammaglobulinämie 399

Hyperlipoproteinämien bei ambulanten Patienten 463

-, Häufigkeit bei ambulanten Patienten 463

-, Typen II a, II b und IV, Therapie mit $\beta$-Pyridylcarbinol 1197

-, Typenverteilung bei ambulanten Patienten $\mathbf{4 6 3}$

Hyperoxalurie, Pathogenese und Therapie 633

Hyperparathyreoidismus, primärer, mit Cholelithiasis 426

-, -, mit Pankreatitis 426

Hy persplenismus, Pathogenese 388

Hypertonie, Pathogenese bei primärem Aldosteronismus 100

-, Senkung durch körperliche Betätigung 1193

-, essentielle, Blutdruck und Nierenfunktion $\mathbf{5 9 7}$

-, maligne, Nephrosklerose mit irreversiblem Nierenversagen nach Ovulationshemmern 757

-, nephrogene, Blutdruck und Nierenfunktion $\mathbf{5 9 7}$

Hypertrophie endokriner Drüsen durch aktive Immunisierung gegen das Effekthormon 469
Hyperurikämie und Oxalatsteine 1088, 1275, 1306

Hypogammaglobulinämie und Hyperlipidämie 399

Hypoglykämie, paraneoplastische, bei Leberzellkarzinom 322

Hypophysengeschwülste, kombiniertes offen-stereotaktisches transsphenoidales Operationsverfahren 646

Hysterektomie, zytologische Kontrolle 399

\section{I}

Ifosfamid und Vincristinsulfat zur zytostatischen Kombinationstherapie 1203

Immunabwehr bei granulomatöser Candidiasis, TransferFaktor-Therapie $\mathbf{4 1 5}$

Immunelektrophorese zur Diagnostik der Paraproteinosen 731

Immunfluoreszenz, simultaner Kern- und MitochondrienAntikörpernachweis $\mathbf{1 2 2 3}$

Immunfunktion und TransferFaktor 446

Immunhämolyse, Autozytotoxine und Anämie mit Leukopenie $\mathbf{5 3 2}$

Immunhistologie bei Arteriitis temporalis $\mathbf{2 8 3}$

- bei Riesenzellarteriitis $\mathbf{2 8 3}$

Immunisierung, aktive, gegen das Effekthormon und $\mathrm{Hy}$ pertrophie endokriner Drüsen 469

,,$-- \ldots+$ - und Induktion biologisch frustraner Hyperfunk tion endokriner Drüsen 469

-, intrauterine, gegen Medikamente 960

Immunologie, Sensibilisierung auf Phenacetin $\mathbf{7 6 2}$

Immunsuppressiva, Indikation zur Anwendung 167

Immuntherapie des Krebses 1179

Impferfolg, Beurteilung bei Pockenschutz-Erstimpfung 289

Induratio penis plastica, Therapie 1192

Infektionskrankheiten, meldeptlichtige, Häufigkeit in BRD 1971127

-, -, - - - III/1972 459

,,,----- IV/1972 687

-, -, - - - 19721010,1147

,,-----1 . Vierwochenperiode 1973849

,,-----2 . Vierwochenperiode 19731243

Infektionsprophylaxe, $\gamma$-Globulin bei Diabetikern 634

Infertilität und rundköpfige Spermatozoen 61

Injektionen und Hautdesinfektion 73

Innenohrschwerhörigkeit, Opticusatrophie und Diabe- tes mellitus, familiäres Vorkommen 243

Instand-Ringversuche, Qualitätskontrolle von Laborwerten 33

Insuffizienz, zerebrovaskuläre, akute, Therapie 123

Insult, ischämischer, und Schlafmittel 1089

-, zerebraler, Flüssigkeitszufuhr 122

International Health Foundation Award 34

Intoxikation, Bromcarbamid 398

Ischialgie durch Endometriose 179

\section{$\mathrm{J}$}

Jodamoeba bütschlii 581

Jubiläumspreis, Braun-Melsungen 1278

\section{K}

Kaltvernebler, bakteriologische Probleme 227

Kamel-Pockenvirus 963

Kammertachykardie durch Reentry-Mechanismus $\mathbf{8 8 1}$

Kammerwandaneurysma, verkalktes 1094

Kariesprophylaxe durch Fluorid 123, 751

Karl-Thomas-Preis 77

Karzinom, histologische Diagnose und Malignität 683

-, Differenzierungsgrad und Malignität 683

Katecholaminsekretion bei malignem Tumor des Glomus caroticum 993

Keratoakanthom 407

Kern- und MitochondrienAntikörpernachweis, simultaner, in der Immunfluoreszenz 1223

Kernschatten bei chronischer Lymphadenose 289

Kind, Anoxie-Syndrom, perinatales, morphologische Substrate 665

-, Antikörper des AB0-Systems im Nabelschnurblut, Immun spezifität $\mathbf{7 0 3}$

,,-- komplette und inkomplette, bei Harnwegsinfektionen 904

-, Aquaeductus cerebri, Größe 232

-, Bauchlage, Auswirkungen auf Entwicklung 955

-, Beeinflussung durch Medikamente in Spätschwangerschaft 949

-, Bilirubinenzephalopathie und medikamentöse Therapie $\mathbf{1 2 6 0}$

-, Depotpenicilline 1276

-, Enzephalitis 235

-, idiopathisches nephrotisches Syndrom, risikogerechte Therapie 1079

-, Immunisierung, intrauterine, gegen Medikamente 960

-, Nahrung, Verfügbarkeit des Brennwertes 901

-, Pockenvakzine-Virusinfektion 1292

- , Reihenuntersuchungen der Hüftgelenke und Strahlenschutz 402

-, Salmonellen-Infektionen, Therapie 456

-, Straßenverkehr, Zahl der tödlichen Unfälle in BRD, 1. Halbjahr 1972912

-, Varizen durch Infusionen bei Neugeborenen 1243

-, Wandnekrosen der Harnblase durch Nabelkatheter $\mathbf{7 2 7}$

-, Wiederimpfung nach DPTGrundimmunisierung 74

Klinefelter-Syndrom und Brustkrebs 1278

Klippel-Trenaunay-Syndrom 228,682

Koagulation, disseminierte intravaskuläre, bei Waterhouse-Friderichsen-Syndrom 542

Körperfett und Herzinfarkt in Israel und Deutschland 637

Kohlenhydrate, Bedeutung in vollsynthetischer fettfreier Diät 1156

Kohlenhydrate, parenteral verabreichte, Verwertung, postoperative 809

Kohlenhydratstoffwechsel bei parenteraler Ernährung 1238

- und orale Kontrazeptiva 829

- - Myokardinfarkt 270, 844

Kollagenpeptidase-Aktivität, Parameter des Therapieeffektes bei Sarkoidose 1253

Kolon, proximales, und endoskopische Polypektomie 219

- - Divertikulitis, Behandlungsergebnisse 1109

Kolonadenom, villöses 690)

Kontrazeptiva, Steroid-, Einfluls auf Fibroadenom der Mamma 698

Konzeptionen, voreheliche, Häufigkeit in BRD 1963-1968 232

Koronararterien, normale, und Myokardinfarkt bei Hochleistungssportlern $\mathbf{6 2 0}$

Koronarsklerose und Diät 797

Krankenhaus-Baedeker für Verbraucher, Manhattan 459

Krankenhausbehandlung, Rechte des Patienten in USA 747

Krankenhauspatienten und Wetter 924

-, Zahl in BRD 1971798

Krankenversicherung, Wechsel des Arbeitgebers 401

Krankenversicherung, private, Auskunftserteilung durch 
Kreislaufstillstand, Reanimation 561

Kristallzucker bei Dekubitalulkus 1091

Kunststoffe, Kontakt mit Lebensmitteln, Schädigungen 795

Kurpfuschertum und Parapsychologie 65

Kurzzeitfibrinolyse bei akutem Myokardinfarkt $\mathbf{8 6 1}$

\section{$\mathbf{L}$}

Laborwerte, Qualitätskontrolle durch Instand-Ringversuche 33

Längenwachstum, übermäßiges, Einfluß von Ovulationshemmern 1047

Lanataglykosie, Stoffwechsel und Pharmakokinetik bein Menschen 117

von-Langenbeck-Preis 1278

Larva migrans visceralis und Meningo-enzephalo-myelitis 1175

Laryngitis, chronische, und Präkanzerose 400

LE-Antiglobulinkonsumptionstest bei Lupus erythematodes 1048

Lebensalter und endokrine Funktion der Testes beim Erwachsenen $\mathbf{1 2 8 1}$

Lebensmittel, Kontakt mit Kunststoffen, Schädigungen 795

Leberfunktionsproben, pathologische, Häufigkeit bei anikterischen Drogenabhängigen 1022

Leberinsuffizienz, Àtiologie und Therapie 1076

Leberkeilexzision, pathologischanatomische Folgen $\mathbf{8 1}$

Leberkranke, chronisch, ergometrische Untersuchungen zur körperlichen Belastbarkeit $\mathbf{5 2 8}$

Leberschädigung, akute, durch Alkohol 983

Lebertoxizität von Tuberkulostatika 74

Leberzellkarzinom und paraneoplastische Hypoglykämie 322

Leberzirrhose mit Aszites und Hydrothorax 669

-, Differentialdiagnose, immunologische $\mathbf{4 7 2}$

-, -, morphologische 472

-, alkohol-toxische, Differentialdiagnose $\mathbf{4 7 2}$

-, hepatitische, Differentialdiagnose $\mathbf{4 7 2}$

-, primär-biliäre, Differentialdiagnostik 472

-, Virushepatitis, aufgepfropfte 1240

Leichtkettenplasmozytome unter dem Bild chronischer Nierenerkrankungen $\mathbf{1 2 8 9}$

Leukämie, Differentialdiagnose von Frühveränderungen $\mathbf{8 9 5}$
-, Frühbefunde 945

- und Infektiosität 1007

-, Plasmazellen-, Diagnose und Therapie $\mathbf{8 7 4}$

Leukozytopenie, chronische, bei immunhämolytischer Anämie mit Autozytotoxinen 532

Lichen planus 1093

Lipase, Bestimmung im Serum zur Diagnostik von Pankreaserkrankungen $\mathbf{3 6 4}$

Lipide im Serum, Einfluß von Spironolacton und Thiabutazid bei Gichtkranken und Stoffwechselgesunden $\mathbf{1 1}$

Lipidstoffwechsel, hormonale Regulation $\mathbf{7 8 7}$

Lipoidpneumonie durch Einatmung von verdampftem Fett 337

Lipomatose des exokrinen Pankreas nach D-Penicillamin bei Ratten unter Cholinmangeldiät $\mathbf{1 0 8 5}$

Lipome, submuköse, des Dickdarms 1064

Liquor cerebrospinalis, Porphyrinnachweis bei chronischer hepatischer Porphyrie 513

Ludolph-Brauer-Preis 850

Lübeck, Medizinische Hochschule 1309

Lungenalveolen, Oberfläche 794

Lungenamyloidose bei generalisierter Amyloidose mit Paraproteinämie, Knochenmarksplasmozytose $\mathbf{6 1 4}$

Lungenemphysem, juveniles, und $\alpha_{1}$-Antitrypsinmangel 255

Lungenfibrose, Nebenwirkung von Bleomycin 77

Lupus erythematodes und LEAntiglobulinkonsumptionstest 1048

- - -ähnliches Syndrom mit antimitochondrialen Antikörpern 131

Lyell-Syndrom 639

Lymphadenose, chronische, Bedeutung von Kernschatten 289

Lymphoblastenleukämie, akute 913

Lymphoblastom, großfollikuläres 335

Lymphogranulomatose, Diagnostik und Stadieneinteilung 836

- des Magens, Therapie 148

Lymphozyten, menschliche, Einfluß von Antilymphozytenglobulin $\mathbf{5 7 8}$

- von HB-Antikörper-Trägern, In-vitro-Stimulation durch HB-Antigen 262

Lymphozytose, akute infektiöse 749

$\mathrm{M}$

Magengeschwür, chirurgische Behandlung 114
Magenkarzinom und Pseudohyperparathyreoidismus als paraneoplastisches Syndrom 565

-, Antioxidantiengehalt des Frühstücks 33

- bei Japanern in Hawaii 179

- und Strahlenbelastung 1007

Magensekretionsanalyse, Durchführung und Beurteilung 938

Magen-Lymphom 234

Magen-Lymphosarkom 233

Magna Charta für Patienten in USA 747

Malaria-Ubertragung in New York 911

Maldigestion nach Pankreasresektion, therapeutische Beeinflußbarkeit 1212

Malignom des Glomus caroticum mit Katecholaminsekretion 993

- der Schilddrüse, Therapie 996

-, inoperables, und Aszites, Therapie 175

Mammagewebe, benigne verändertes, und B-Partikelähnliche Strukturen 162

Mammakarzinom, Risikofaktoren 583

Mammatumoren, gut- und bösartige, Diagnostik 691

Mamnographie, vermeidbare Irrtümer 272

Maus, Sozialordnung 911

Mebhydrolin, extrapyramidale Hyperkinesie bei Langzeittherapie 1071

Medikamente, Immunisierung, intrauterine 960

- in Spätschwangerschaft, Beeinflussung des Kindes 949

Medikinale Marburg 73

Medizingeschichte, Friedrich der Große und GeneralChirurgus Theden 906

Medizinische Hochschule Lübeck 1309

Medizinstudium, Zulassungschancen 583

Megaloblastenanämie 339

Melanom 1245

-, malignes 965

- -verdacht und Biopsie 1239

Membranoxygenatoren zur prolongierten extrakorporalen Zirkulation $\mathbf{5 0 8}$

Meningitis, eitrige, Therapie 776

Meningo-enzephalo-myelitis, eosinophile, und viszerales Syndrom durch Askaridenlarven des Hundes 1175

Meningokokken, chemotherapeutische Empfindlichkeit $\mathbf{8 6}$

Meningosis leucaemica, Therapie mit Methotrexat, intrathekal 259, 455

Menstruationsblutung, präoperative Unterdrückung 745

Methotrexat, intrathekal, bei Meningosis leucaemica 259 455

Metronidazol bei aufsteigender Trichomonaden-Infektion 455

- - Trichomonas vaginalis 375

Miconazole, Behandlung on Candida-albicans-Sepsis nach Nierentransplantation 1;

Mikro-Blutsenkungsmethoden 175

Mikrobiologie, Analyse von Befunden mit elektronisher Datenverarbeitung $\mathbf{4 4 1}$

Minderwuchs infolge Manzel an Thyrotropin-ReleasirgHormone (TRH) und Growth-Hormone-ReleasingFactor (GRF) 539

-, hypophysärer, Therapie 744

Mischinfektionen, Bacteroilesund Sphaerophorus-Keine, pathogenetische Bedeutung 350

Mitochondrien- und KernAntikörpernachweis, simultaner, in der Immunfluoreszenz 1223

Mitralstenose 294

Mittellappensyndrom der Lunge, Malignität 1095

Modellgesundheitsamt 77

Morbus Baastrup, Diagnose 1178

- Behçet 105

- Crohn des oberen Verdauungstrakts, Diagnose $\mathbf{4 8 1}$

- -, Therapie mit Azathioprin 1270

- Fröhlich, Therapie 31

- Hodgkin 341

- -, Diagnostik und

Stadieneinteilung 836

- - des Magens 148

- Ménétrier 408

- Ritter, Differentialdiagnose 959

Morphologische Grundlage von Blasenfunktionsstörungen bei Diabetes 1309

Mucoviscidose 1150

- und Zilienhemmfaktor 1277

Mumpsorchitis und Brustkrebs 1278

Myelitis, parainfektiöse, Ätiologie und Therapie 846

Myokardinfarkt und Fettsäuren 844

- bei Hochleistungssportlern mit normalen Koronararterien 620

- und Kohlenhydratstoffwechsel 270, 844

-, Pathogenese 963

- und Schenkelblock, inkompletter, bilateraler 409

-, akuter, Kurzzeitfibrinolyse 861

Myokarditis, diagnostische Wertigkeit von Enzymbestimmungen $\mathbf{1 2 9 7}$

Myositis ossificans localisata 653 
Nabelschnurblut, Antikörper des AB0-Systems, Immunspezifität $\mathbf{7 0 3}$

Nachtarbeit, Häufigkeit in BRD von Nov. 1971 bis Jan. 1972 638

Nagelmykose und chronischrezidivierendes Erysipel, Therapie 846

Nahrung, Verfügbarkeit des Brennwertes bei Säuglingen, Kindern und Erwachsenen 901

Nahrungsmittel, Natriumbestimmung 518

Narkose bei Tonsillektomie 745

Narkot:ka, Einfluß auf Blutgerinnung 226

Natriumbestimmung in $\mathrm{Nah}$ rungsmitteln 518

Natriumfluorid bei Altersostecporose 1241

Nebenhöhlenoperation und Sekundärglaukom 1049

Nephritis mit nephrotischem Einschlag und Blutsenkungsges.chwindigkeit 634

Nephrosklerose mit irreversiblem Nierenversagen und maligner Hypertonie nach Ovulationshemmern 757

Nerv enschädigung, periphere, und Dermatozoenwahn 1305

Neuriliemmon 800

Neurofibromatosis von Recklinghausen, operative $\mathrm{Be}$ ha:ndlung 548

Niere und Anämie, Pathogenese 217

-, Diabetes insipidus, Therapie 74

Nierendiagnostik, sonographische 361

Nierrendystopie, Ätiologie, Einteiilung, Diagnostik 1169

Nier enerkrankungen, chroniscthe:, Differentialdiagnose von Leichtkettenplasmozy'tcomen 1289

Nieremfunktion und Blutdruck besi nephrogener und essentiellier Hypertonie 597

Niereenfunktionsstörungen, Kure:atinin-Clearance zur Diia.gnostik 684

-, Serrumharnstoffbestimmung zurr Diagnostik 684

Nierre:ninsuffizienz und Anämic, Proophylaxe und Therapic 10410

-, alkute, bei Plasmozytom $\mathbf{3 1 8}$

-, chrronische, FurosemidWirkung 977

-, tezrminale, Einfluß der Hämodiia.lyse auf Hormonstatus 66611

Nierre:nkonservierung mit Peer:fusionsmaschine beim NAenschen 29

Niezrentransplantation, Erfahruungen in Zürich $\mathbf{1 0 5 5}$

-, Eirgebnisse 479

Niesrentraumen, Diagnostik 1:1:37
Nierenversagen, irreversibles, bei Nephrosklerose und maligner Hypertonie nach Ovulationshemmern $\mathbf{7 5 7}$ Noradrenalin bei Schock 1089 Notfalldienst, ärztlicher 231 Novothyral, Therapie der blanden Struma $\mathbf{5 2 5}$

\section{O}

Oberarmfistel zur Hämodialyse 395

Oberbauchsyndrom, Evokationstest mit Sekretin und Pankreozymin 8

Oberschenkelarterie, chronische Verschlußkrankheit, Typeneinteilung 593

Obliterationen, arterielle, Einfluß von Acetylsalicylsäure auf perkutane Rekanalisation nach Dotter $\mathbf{1 2 8 5}$

Osophagus, Funktionsstörungen bei Diabetikern 1151

Osophagussphinkter, unterer, Beeinflussung durch Caerulein bei Mensch und Hund $\mathbf{3 3 2}$

,,--- des Druckprofils durch Gastrin, Calcitonin und Glucagon 1059

Opticusatrophie, Innenohrschwerhörigkeit und Diabetes mellitus, familiäres Vorkommen 243

Osteopathie, rachitische, bei antiepileptischer Langzeittherapie 1036

Otto-Nägeli-Preis 1973850

Ovulationshemmer bei übermäßigem Längenwachstum 1047

-, Einfluß auf Fibroadenom der Mamma 698

- und Eiweilistoffwechsel 829

- - Fahrtüchtigkeit 1191

- - Fettstoffwechsel 829

- Kohlenhydratstoffwechsel 829

- - Nephrosklerose mit irreversiblem Nierenversagen und maligner Hypertonie $\mathbf{7 5 7}$

- - Pankreopathie 175

- - Stoffwechselveränderungen 829

- - Zentralvenenthrombose 744

Oxalatsteine bei Hyperurikämie 1088, 1275, 1306

Oxymetholon bei aplastischen Anämien 1026

I'

Paneth-Zellen, intestinale, funktionelle Bedeutung 220

Pankreas, Doppelradionuklidszintigraphie 1019

-, exokrine, Lipomatuse nach D-Penicillamin bei Ratten unter Cholinmangeldiät 1085

Pankreasdiagnostik und Evokationstest 579
Pankreaserkrankungen,

Diagnostik durch Lipasebestimmung in Serum 364

Pankreasfunktion, exkretorische, Einfluß von Cholezystektomie $\mathbf{9 3 0}$

- exokrine bei Chromenteropathie $\mathbf{1 2 6 8}$

Pankreasnekrose, sonographische Darstellung 429

Pankreasresektion und

Maldigestion, therapeutische Beeinflußbarkeit 1212

Pankreatitis und Cholelithiasis bei primärem Hyperparathyreoidismus $\mathbf{4 2 6}$

Pankreon zur Therapie von Maldigestion nach Pankreasresektion 1212

Pankreopathie und Ovulationshemmer 175

Pankreozymin zum Evokationstest beim Oberbauchsyndrom 8

Pappenheim-Preis 1194

Paraproteinämie bei generalisierter Amyloidose, Knochenmarksplasmozytose und Lungenamyloidose 614

-, Serumproteine, immunologische Bestimmung 309

Paraproteinosen, Diagnostik mit Immunelektrophorese 731

Parapsychologie und Kurpfuschertum 65

Parathyreoidektomie, subtotale, bei Hämodialysepatienten 484

Patient, Rechte bei Krankenhausbehandlung in USA 747

Paul-Schürmann-Plakette 128

Penicillin, Depot-, beim Kleinkind 1276

- G, bakterizider paradoxer Effekt auf Enterokokken $\mathbf{6 1 1}$

Perfusionsmaschine, Nierenkonservierung beim Menschen 29

Peritonitis und Hydronephrose 127

Persönlichkeitsbild und Haschisch 214

Phenacetin in Medikamenten und ärztliche Aufklärungspflicht 1008

-, Sensibilisierung, immunologische Aspekte $\mathbf{7 6 2}$

Pilzendokarditis nach prothetischem Hercklappenersatz 201

Pilzpneumonie, interstitielle, bei Candida-Sepsis, Therapie 1207

Plasmazellenleukämie 181

-, Diagnose und Therapie 874

Plasmozytom, Langzeittherapie mit Cyclophosphamid 496

-, akutes Nierenversagen 318

-, monostatisches, Therapie 1008

Plasmozytome, Leichtketten-, unter dem Bild chronischer Nierenerkrankungen 1289

Plasmozytose des Knochenmarks und generalisierte Amyloidose, Paraproteinämie und Lungenamyloidose $\mathbf{6 1 4}$

Pneumonie, Lipoid-, durch Einatmung von verdampftem Fett 337

Pneumocystis-cariniiPneumonie 851

Pockenerkrankungen in Hannover 1967 und $1972 \mathbf{5 8 7}$

Pockenimpfung nach Schädeltrauma 580

Pockenschutz-Erstimpfung, Beurteilung des Impferfolgs 289

Pockenvirus, Kamel- 963

Poliomyelitis in BRD durch importierte Poliowildviren 970

- -Schluckimpfung 476

- - in Schwangerschaft 1239

- und zerebrale Erkrankungen 1049

Poliowildviren, importierte, und Poliomyelitis in BRD 970

Polyarthritis, chronische, alternierende Corticoidtherapie 919

-, -, der Halswirbelsäule, neurologische Komplikationen 988

Polypektomie, endoskopische, im proximalen Kolon $\mathbf{2 1 9}$

-, koloskopische, bei Dickdarmpolypen $\mathbf{6 7 5}$

Porphyrie, chronische hepatische, Porphyrinnachweis im Liquor 513

Porphyrinnachweis im Liquor bei chronischer hepatischer Porphyrie $\mathbf{5 1 3}$

Poxvirus-officinale-Infektion beim Kind 1292

Präkanzerose und chronische Laryngitis 400

Präleukämie, Definition 895

-, Differentialdiagnose von leukämischen Frühveränderungen 895

Preis der Freunde der Medizinischen Hochschule Hannover zur Förderung der Krebsforschung 1194

Prolaps, ano-rektaler, chirurgische Therapie $\mathbf{1 1 2 5}$

Propanidid, Einfluß auf Blutgerinnung 226

Prophylaxe der renalen Anämie 1040

Propranolol bei Konditionstraining 288

Prostaglandine und Acetylsalicylsäure 521

Prostatasarkom 36

Pseudohyperparathy reoidismus als paraneoplastisches Syndrom bei Magenkarzinom 565

Pseudomonas-Infektion 293 
- von Knochen bei Hämophilie 206

Psychopharmaka und Adipositas 1306

-, anticholinergische, bei Glaukom 795

Psychosen und Arzt 637

- - Wetter 924

-, körperlich begründbare 967

Pulmonalarterienummauerung, tumoröse, mit subakutem Cor pulmonale, und EKG 1034

Pulmonalstenose 1196

Purpura, thrombotisch-thrombozytopenische 1011

Pyelonephritis, Therapie $\mathbf{1 2 2 5}$

Pyloroplastik und Vagotomie bei gastroduodenalen Ulkuskomplikationen 1104

$\beta$-Pyridylcarbinol zur Therapie von Hyperlipoproteinämien der Typen II a, II b und IV 1197

\section{Q}

Quadrantendystrophie mit Gefäßanomalien 682

Querschnittssymptomatik, Komplikation bei chronischer Polyarthritis der Halswirbelsäule 988

\section{$\mathbf{R}$}

Rachitis nach Langzeittherapie mit Antiepileptika 1036

Rachitissymptome, Vitamin-DTherapie 1191

Raucher, Entwöhnungsregeln 1242

Rauschgiftsucht und Arzt 637

- - EEG 1047

Rauschmittel in RheinlandPfalz 174

Reanimation nach Kreislaufstillstand 561

Recklinghausen von, Neurofibromatose, operative $\mathrm{Be}$ handlung 548

Reentry-Mechanismus und Kammertachykardie $\mathbf{8 8 1}$

Reflektometer zur Bestimmung von Glucosekonzentration 122

- Ames- zur Glucosebestimmung im Blut 400

Refluxkrankheit der Speiseröhre 63

Rehabilitation, operative, von angeborenen und erworbenen Herzfehlern 421

Reizschwelle, elektrische, von Schrittmachern, Senkung durch Glucocorticoide 858

Rekanalisation, perkutane, nach Dotter, arterieller Obliterationen, Einfluß von Acetylsalicylsäure $\mathbf{1 2 8 5}$

Rentenversicherung, operative Rehabilitation angeborener und erworbener Herzfehler 421
Rentenversicherungsträger, Zahl der beschäftigten

Ärzte, Januar 1972850

Rheumaknötchen 689

Rheumatische Erkrankungen, Fibel der 1309

Rhinomanometrie, Methodik und Normalwerte $\mathbf{7 1 9}$

Rhinosklerom mit tracheobronchialer Ausbreitung 499

Rieder-Medaille 1148

Riesenzellarteriitis, Immunhistologie 283

Risikofaktoren bei Brustkrebs 583

Robert-Feulgen-Preis 232

Robert-Koch-Medaille 179

Robert-Koch-Preis 179

Röntgenfilme, Aufbewahrung beim Gesundheitsamt 581

Röntgen-Plakette 1092

Röteln im zweiten Schwangerschaftsdrittel $\mathbf{5 7 0}$

Rote Liste 1973912

Ruktation und Bauchlage 955

\section{S}

Sachverständige, ärztliche, $\mathrm{Er}$ stattung von Unkosten für Benutzung fremder Einrichtungen 456

Säuglingssterblichkeit und Untergewicht 291

Salmonellen-Infektionen im Kindesalter, Therapie 456

Sarkoidose, KollagenpeptidaseAktivität als Parameter des Therapieeffektes $\mathbf{1 2 5 3}$

Schädeltrauma und Pockenimpfung 580

Schenkelblock, inkompletter bilateraler, bei Myokard infarkt 409

Schilddrüse, autonomes Adenom im Struma-Endemiegebiet 189

Schilddrüsenadenom, Stimulierbarkeit der TSH-Sekretion durch TRH 152

Schilddrüsendiagnostik und Achillessehnenreflexzeit 1048

Schilddrüsenhormon, endogenes, Inaktivierung durch aktive Selbstimmunisierung 469

-, synthetisches, Therapie der blanden Struma 525

Schilddrüsen-Malignome, Therapie 996

Schizophrenie und EEG 1074

Schlafmittel und ischämischer Insult 1089

Schlaganfälle, jahreszeitliche Häufung 1144

Schluckstörungen im Alter 334

Schmerzzustände, chronische, Behandlung durch elektrische Hinterstrangreicung $\mathbf{1 1 3 0}$

Schock, Therapie mit Noradrenalin 1089

Schocküberwachung durch kontinuierliche Registrierung der Sauerstoffaufnahme und andere Parameter 1227
Schöller-Junkmann-Preis 148

Schrittmacher, Senkung der elektrischen Reizschwelle durch Glucocorticoide $\mathbf{8 5 8}$

Schrittmacherfunktion, Kontrolle durch Schrittmachertester $\mathbf{8 8 9}$

Schrittmacherstimulation, kardiale, bei Carotissinus-Syndrom 558

Schrittmachertester 889

Schularzt, Zeugnisverweigerungsrecht nichtärztlicher Mitarbeiter 961

Schutzimpfungen und anaphylaktische Reaktionen 1047 1238

Schwangerschaft und Polioschluckimpfung 1239

- - Röteln 570

-, Spät-, Beeinflussung des Kindes durch Medikamente 949

Schwefeldioxid-Vergiftung 635

Schweigepflicht, ärztliche, und Auskunftspflicht gegenüber Berufsgenossenschaften 1307 ,,--- EDV 797

-, -, gegenüber nachbehandelnden Ärzten 1241

,-- , und Ubersendung von Entlassungsberichten an Krankenkassen 909

-, -, - private Krankenversicherungen 1049

,-- , gegenüber Werksärzten 847

- des ärztlichen Gutachters 286

Schwerhörigkeit und Telefonverstärker 456

Schwimmbad-Chlorung 580

Sekretin zum Evokationstest beim Oberbauchsyndrom 8

Sekretionsanalyse des Magens, Durchführung und Beurteilung 938

Sekundärglaukom nach Nebenhöhlenoperation 1049

Serumproteine bei Paraproteinämien, immunologische Bestimmung 309

Shunt-Operation, porto-cavale, und Pathophysiologie $\mathbf{1 1 4 0}$

Siegfried-Thannhauser-Goldmedaille 292

Sinusknotensyndrom 1

Skelettschmerzen und intermittierende Durchfälle als Leitsymptome $\mathbf{7 3 7}$

Sonographie der Nieren 361

- - Pankreasnekrose 429

Sozialordnung bei Mäusen 911

Spasmen der Extremitätenstammarterien nach ergotamintartrathaltigen Medikamenten 825

Speiseröhre, Achalasie, pneumatische Dilatation 814

-, Funktionsstörungen bei Diabetikern 1151

- Refluxkrankheit 63

Spermatozoen, rundköpfige, und Infertilität 61

Spermatozoennachweis, lang fristiger, nach Vasektomie 1221

Sphaerophorus-Keime, pathogenetische Bedeutung 350

Spironolacton, Wirkung auf die Serumkonzentration von Harnsäure und Lipiden bei Gichtkranken und Stoffwechselgesunden 11

Spontanpneumothorax, idiopathischer, Pathologie 801

Sprachverständnisstörungen bei aphasischen und nicht aphasischen Hirnkranken 139

Sputumbefunde bei chronischer Bronchitis 673

Statistik, Ärztezahl bei den Rentenversicherungsträgern Januar 1972850

-, Arzneispezialitäten, Zahl der Zulassungen in BRD 1972 1193

-, Bevölkerungsrückgang in BRD bis 1985748

-, Bierkonsum in BRD 1971 338

-, - - - 19721091

-, Geborene und Gestorbe ne im 1. Lebensjahr in BRD, DDR und Osterreich 291

-, Gicht, primäre, Epidemiologie und klinisches Bild 1948 bis 1970183

-, Infektionskrankheiten, meldepflichtige, in BRD 1971 127

$-,-,-,--111 / 1972459$

$\ldots-,--$ IV/1972 687

$-,-,-,--19721010,1147$

,,,----1 . Vierwochenperiode 1973849

,,,-----2 . Vierwochenperiode 19731243

-, der vorehelichen Konzep-tionen in BRD 1963-196i8 232

-, Zahl der Krankenhauspaitienten in BRD 1971798

-, Krankenhauspersonal in BRD 1971337

-, Nacht- und Feiertagsarbe:it, Häufigkeit in BRD Nov. 1971 bis Jan. 1972638

-, Zahl der Renten- und Pemsionsbezieher in BRD 1971 521

-, Säuglingssterblichkeit unıd Untergewicht 1970291

-, Straßenverkehr, Zahl der tödlichen Unfälle in BRD., 1. Halbjahr 1972912

-, Straßenverkehrsunfälle inı BRD 1972748

-, Tuberkulose-Infektionsraiten in Stuttgart 1961-1971 10166

-, Tabakverbrauch in BRD 1972583

-, Zigarettenpreis und-konsium 
Steroidhormon, endogenes, Inaktivierung durch aktive Selbstimmunisierung 469

-, Enzymdefekte bei der Biosynthese 1299

$\rightarrow$, Wirkungsmechanismus 831

Steroidkontrazeptiva, Einfluß auf Fibroadenom der Mamma 698

Stoffwechsel von Fructose, Glucose und Xylit bei Gesunden und parenteraler Ernährung 602

- - Kohlenhydraten bei parenteraler Ernährung 1238

Stoffwechselveränderungen durch hormonale Kontrazeptiva 829

Strahlenbelastung und Magenkrebs 1007

Strahlenquelle zur Telecurietherapie 1307

Strahlenschutz und Reihenuntersuchungen der Hüftgelenke bei Säuglingen 402

Straßenverkehr, Zahl der tödlichen Unfälle in BRD, 1. Halbjahr 1972912

-, Unfälle, Häufigkeit in BRD 1972748

Streckentauchen, Gefahren 634, 959

Stress bei Fluglotsen 1278

Strophanthintherapie, intravenöse, Dosierung 1144

-, orale 1006

Struma, blande, Therapie mit synthetischem Schilddrüsenhormon $\mathbf{5 2 5}$

- -Endemiegebiet, autonomes, Adenom der Schilddrüse 189

Stuhlentseuchung mit Chlorkalk bei Hepatitis 1276

Sublimat zur Desinfektion der Harnröhrenmündung 1275

Suchtstadien bei Jugendlichen 327

Südafrika, Ärztebedarf 1006

Sulfadiazin, Wirkung auf Memingokokken $\mathbf{8 6}$

Sulfafurozal-Panzytopenie 461

Syndrom, Bartter-, bei Erwachsenem $\mathbf{7 2 3}$

-, Budd-Chiari-, Diagnostik 48

-, -, nach Gravidität 398

-, Carotissinus-, Behandlung mit Schrittmacherstimulation 558

-, Cushing-, Pathologie 1272

-, Di-Guglielmo- 355

- Evans- 1163

-, härmolytisch-urämisches, beim Erwachsenen $\mathbf{5 4}$

-, Hypercalcämie-, und hypercal.cämische Krise $\mathbf{2 7 6}$

-, idiopathisches nephrotisches, bei:m Kind, risikogerechte Thierapie 1079

-, Kliinefelter-, und Brustkrebs 1278

-, Kliippel-Trenaunay- 228, 682

-, Luipus-erythematodes-ähn-

licthes, mit antimitochondrialen. Antikörpern 131
-, Mittellappen-, Malignität 1095

- , nephrotisches, Blutsenkungsgeschwindigkeit 634

-, paraneoplastisches, Pseudohyperparathyreoidismus bei Magenkarzinom 565

- Sinusknoten-1

-, Waterhouse-Friderichsen-, pathologische Anatomie 542

Szintigraphie des Gehirns bei zerebrovaskulärer Insuffizienz 627

-, statische, des Gehirns bei zerebrovaskulären Erkrankungen 973

-, Doppelradionuklid-, von Pankreas 1019

$\mathrm{T}$

Tabaksteuer, Anstieg in BRD 1972583

Tabakverbrauch 1972 in BRD 583

Tachykardie, Kammer-, durch Reentry-Mechanismus $\mathbf{8 8 1}$

Taubheit durch Arzneimittel 1309

Tauchen, Strecken- und Tief-, Gefahren 634, 959

Telecurietherapie, Strahlenquelle 1307

Telefonverstärker bei Schwerhörigkeit 456

Tertiärstruktur, Bestimmung bei einer Transfer-RNS 687

Testes, endokrine Funktion und Lebensaiter $\mathbf{1 2 8 1}$

Testosteronproduktion in verschiedenen Lebensjahren 1087

Teststreifen zum Nachweis von Urobilinogen im Harn 112

Tetanol, anaphylaktische Reaktion $\mathbf{1 1 0}$

Tetanus-Immunisierung, aktive, anaphylaktische Reaktion 110,517, 682

Theodor-Frerichs-Preis 1092

Thermalbäder und Trichomonas-Infektionen 960

Thiabutazid, Wirkung auf die Serumkonzentration von Harnsäure und Lipiden bei Gichtkranken und Stoffwech selgesunden 11

Thrombangiitis obliterans und Arteriosklerose, pathologisch-anatomische Abgrenzung 158

Thrombozyten-Aggregationshemmer, quantitative Bestimmung der antithrombogenen Wirkung 1004

Thrombozytenadhäsivität, Einfluß des Wetters 434, 1189

Thyrotropin-Releasing-Hormone (TRH), Mangel bei Minderwuchs 539

Tieftauchen, Gefahren 634, 959
Tonsillektomie und Narkose 745

- nach Sluder 745

Toxoplasmose, Epidemiologie 535

-, Therapie beim Erwachsenen 31

Training und Herzinfarktrezidiv 1191

- - Propranolol 288

Trampolin-Unfälle 684

Transfer-Faktor und Immunfunktion 446

- bei granulomatöser Candidiasis $\mathbf{4 1 5}$

Transfer-RNS, Bestimmung der Tertiärstruktur 687

Treppensteigen und Arbeitsbelastung 1008

TRH und Stimulierung der TSH-Sekretion bei Schilddrüsenadenomen 152

-, Thy rotropin-ReleasingHormone, Mangel bei Minderwuchs 539

Trichomonaden-Infektion, aufsteigende, beim Mann 455

,,-- Therapie mit Metronidazol 455

- in Thermalbädern 960

Trichomonas vaginalis und Blutungsanomalien 375

Trichophyton-rubrumInfektion 129

Trikuspidaldysplasie 1012

Trimethoprim-Sulfamethoxazol, Therapie des Typhus abdominalis $\mathbf{1 2 5 1}$

Trinkwasserfluoridierung, Toxikologie $\mathbf{7 7 8}$

Tripel-Diagnostik von Mammatumoren, gut- und bösartige 691

Tris-Puffer-Injektion in die Nabelgefäße, Organschäden 305

Trockensterilisation 456

Trometamol, Injektion in die Nabelgefäße, Organschäden 305

TSH-Sekretion, Stimulierung durch TRH bei Schilddrüsenadenomen 152

Tuberkulintest nach BCG-Impfung 125

Tuberkulose und BCG-Impfung 941

- -Infektionsraten in Stuttgart 1961-1971 1066

Tuberkulostatika, Lebertoxizität 74

Tumor, maligner, des Glomus caroticum mit Katecholaminsekretion 993

Tumoren, maligne, Immuntherapie $\mathbf{1 1 7 9}$

,,-- Kombinationstherapie mit Vincristinsulfat und Ifosfamid 1203

Typhus abdominalis, Therapie mit Trimethoprim-Sulfamethoxazol 1251
U

Uberträgerstoffe, falsche, im Gehirn 574

Ugen-Test, Nachweis von Urobilinogen im Harn 112

Ulkuskomplikationen, gastroduodenale, und Vagotomie und Pyloroplastik 1104

Ultraschalltomographie des Gehirns 1234

- der Pankreasregion 429

Ultraschallvernebler, bakteriologische Probleme 227

Untergewicht und Säuglingssterblichkeit 291

Urica-Quant-Test, Harnsäurefarbtest, enzymatischer 380

V

Vaccinia-Poxvirus-Infektion beim Kind 1292

Vagotomie und Pyloroplastik bei gastroduodenalen Ul kuskomplikationen 1104

Varikosis, Basler Studie II 343

Variola 587

Varizen durch Infusionen bei Neugeborenen 1243

Vasektomie und langfristiger Spermatozoennachweis $\mathbf{1 2 2 1}$

Verbrauchskoagulopathie 1195

Verein Medizinischer Dokumentationsassistenten 1309

Vergiftung, Blei-, Dauer der spezifischen Behandlung 747

-, Ciguatera- 1052

-, Schwefeldioxid- 635

Verschluß, akuter und chronischer, der Viszeralarterien, Behandlungsergebnisse 1112

Verschlußkrankheit, chronische arterielle, Typeneinteilung 593

Vincristinsulfat und Ifosfamid zur zytostatischen Kombinationstherapie 1203

Virushepatitis, Desinfektionsmaßnahmen 176

-, aufgepfropfte, bei Leberzirrhose 1240

Viszeralarterien, Verschlüsse, akute und chronische, $\mathrm{Be}$ handlungsergebnisse $\mathbf{1 1 1 2}$

Vitamin D bei Rachitis 1191

Vorderwandinfarkt 80,750

Vorhofflattern 182

Vorhofseptumdefekt 462

W

Waterhouse-Friderichsen-Syndrom, pathologische Anatomie 542

Wandnekrosen der Harnblase beim Neugeborenen durch Nabelkatheter $\mathbf{7 2 7}$

Weckamine und Psychodynamik des Drogenkonsums bei Jugendlichen 295 
Wellcome Trust, Stipendienprogramm 291

Weltgesundheitsorganisation 25 Jahre 638

Werner-Körte-Medaille 1278

Wetter und psychische Krankheit 924

- - Häufigkeit von Schlaganfällen 1144

- - Thrombozytenadhäsivität 434, 1189

Wirbelsäule, Fehlhaltungen, und Bauchlage 955

Wolff-Parkinson-WhiteSyndrom 640

\section{$\mathrm{X}$}

Xylit, Bilanz- und Stoffwechselverhalten bei Gesunden und parenteraler Ernährung 602, 1006

- , Nebenwirkungen bei Infusion 839

-, parenteral, postoperative Verwertung $\mathbf{8 0 9}$

\section{Z}

Zahnpasten mit Chloroformgehalt 849
Zellen, immunkompetente, Einfluß von Acetylsalicylsäureanhydrid $\mathbf{3 8 4}$

Zentralvenenthrombose und Ovulationshemmer 744

Zeugnisverweigerungsrecht von nichtärztlichen Schularzt-Mitarbeitern 961

Zigarren, "kleine «, Gefährdung im Vergleich zu Zigaretten 460

Zigaretten, Gefährdung im Vergleich $\mathrm{zu}$ »kleinen « $\mathrm{Zi}$ garren 460

Zigarettenkonsum und Zigarettenpreis 1091

\section{Zilienhemmfaktor bei} Mucoviscidose 1277

Zirkulation, extrakorporale prolongierte, mit Membranoxygenatoren 508

Zuckeraustauschstoffe, Nebenwirkungen bei Infusion $\mathbf{8 3 9}$, 1047

Zwölffingerdarmgeschwür, chirurgische Behandlung 114

Zytologie, Kontrolle nach Hysterektomie 399

Zytomegalievirus-Erkrankungen bei Erwachsenen 649

\section{Buchbesprechungen}

Adolfo Reccius, E.: Das deutsche Krankenhaus in Valpa raíso und seine Zeit. Deutsche Ärzte in Chile 404

Allert, M.-L., P. Dollfus: Neurogene Blasenstörungen. Aktuelle Probleme - Problèmes Actuels - Topical Problems 458

Bates, D. V., P. T. Macklem, R. V. Christie: Respiratory Function in Disease. An introduction to the integrated study of the lung 910

$v$. Bauereisen, E.: Physiologie des Kreislaufs. Band I: Arteriensystem, Capillarbett, Organkreisläufe, Fetal- und Placentarkreislauf 32

Bennett, M. R.: Autonomic Neuromuscular Transmission 1091

Berger, W., P. Waibel: Akrale Läsionen, Diabetes, Biguanide, Hyperlipidämie 686

Bleuler, M.: Die schizophrenen Geistesstörungen im Lichte langjähriger Kranken- und Familiengeschichten. Mit einem Beitrag von A. Uchtenhagen: Schizophrenieähnliche Rorschach-Befunde bei Blutsverwandten Schizophrener 402

Böcker, F.: Suizide und Suizidversuche in der Großstadt, dargestellt am Beispiel der Stadt Köln 685

Boyd, E. M.: Predictive Toxicometrics. Basic Methods for Estimating Poisonous Amounts of Foods, Drugs, and other Agents 403

Brehm, G.: Haut- und Geschlechtskrankheiten 1009

Brehm, H. K.: Frauenheilkunde und Geburtshilfe für das Krankenpflegepersonal 177

Britton, K. E., N. J. G. Brown: Clinical Renography 1193
Brock, D. J. H., O. Mayo: The Biochemical Genetics of Man 1277

Burri, C., D. Gasser: Der Vena-cava-Katheter 1145

Carrier, O.: Pharmacology of the Peripheral Autonomic Nervous System 403

Cherniack, R. M., L. Cherniack, A. Naimark: Respiration in Health and Disease 686

Chiappa, S., R. Musumeci, C. Uslenghi: Endolymphatic Radiotherapy in Malignant Lymphomas 402

Constam, G. R.: Leitfaden für Zuckerkranke 961

Cotta, H., W. Heipertz, H. Teirich-Leube: Lehrbuch der Krankengymnastik. In vier Bänden. Band III: Chirurgie, Unfallheilkunde, Orthopädie, Frauenheilkunde 1050

Coulston, F., F. Korte: Environmental Quality and Safety. Chemistry, Toxicology and Technology. Vol. 1: Global Aspects of Chemistry, Toxicology and Technology as Applied to the Environment 582

Cranley, J. J.: Vascular Surgery. Vol. 1: Peripheral Arterial Diseases 1146

Crowley, L. V.: Introductory Concepts in Pathology 797

Daniels, J., W. Hagen, H. Leh.mkubl, J. Posch, F. Pürckbauer, E. Schröder, J. Stralau, C. L. P. Trüb: Das öffentliche Gesundheitswesen. Band III: Hygiene und Seuchenbekämpfung. Teil A: Grundlagen/1. Ortshygiene und Allgemeine Hygiene. Teil A: Grundlagen/2. Verhütung und Bekämpfung übertragbarer Krankheiten 230
Debré, R., J. Celers: Clinical Virology. The Evaluation and Management of Human Viral Infections 1051

Demling, L.: Gastrointestinal Hormones 336

Doerr, W., G. Seifert, E. Uehlinger: Spezielle pathologische Anatomie. Band 2/Teil 1: Oesophagus - Magen 126

Elves, $M$. W.: The Lymphocytes 520

Emmelot, P., P. Bentvelzen: RNA Viruses and Host Genome in Oncogenesis 458

Feer, H.: Zwang und Schizophrenie 848

Frehner, H. U.: Diabetes-Fibel für Ärzte und Studierende 796

Frick, $P$.: Blut- und Knochenmarksmorphologie 1241

Gadamer, H.-G., P. Vogler: Neue Anthropologie. Band 3: Sozialanthropologie 847

Gädeke, R.: Diagnostische und therapeutische Techniken in der Pädiatrie 910

Gänshirt, H.: Der Hirnkreislauf. Physiologie - Pathologie - Klinik 290

Gastaut, H., R. Broughton: Epileptic Seizures. Clinical and Electrographic Features, Diagnosis and Treatment 1192

Geisler, L. S., H.-D. Rost: Hyperkapnie. Pathophysiologie, Klinik und Therapie $\operatorname{der} \mathrm{CO}_{2}$-Retention 32

Genest, J., E. Koiw: Hypertension - 1972746

Glauner, R., A. Rüttimann, $P$. Thurn, M. Viamonte, E. Vogler: Ergebnisse der medizinischen Radiologie. Band IV: Angiographie der abdominellen Organe. Chronische Verschlüsse der unpaaren Eingeweidearterien 796
Gödan, H.: Die sogenannte Wahrheit am Krankenbett 1051

Guyton, A. C.: Basic Human Physiology: Normal Function and Mechanism of Disease 1090

Guyton, A. C.: Organ Physiology: Structure and Function of the Nervous System 178

Haagensen, C. D., C. R. Feind, F. P. Herter, Ch. A. Slanetz, J. A. Weinberg: The Lymphatics in Cancer 1145

Haizmann, R., G. Krokou'ski: Rehabilitation. Gemeinschaftsaufgabe unserer Gesellschaft 126

Hand, I.: Pawlows Beitrag zur Psychiatrie. Entwicklungsund Strukturanalyse einer Forschungsrichtung 1090

Handa, J.: Dynamic Aspects of Brain Scanning 685

Handbuch der allgemeinen Pathologie. Band Ill: Zwischensubstanzen, Gewebe, Organe. Teil 6: Lymphgefäßsystem/Lymph Vessel System 848

Handbuch der experimentellen Pharmakologie. Hrsg. v. O. Eichler, A. Farah, H. Herken, A. D. Welch. Band XXVIII: Concepts in Biochemical Pharmacology. Teil 1 und 275

Handbuch der Kinderheilkunde. Hrsg. v. H. Opitz u. F. Schmid. Band VIII/Teil 2: Tumoren im Kindesalter 582

Haubrich, R.: Klinische Röntgendiagnostik innerer Krankheiten. Band 3: Skelett. Teil 1: Allgemeiner Teil. Teil 2: Spezieller Teil - Weichteile Gefäße 290

Hegglin, R.: Differentialdiagnose innerer Krankheiten 520 
Heinecker, R.: EKG-Quiz. Eine EKG-Auswahl zur Selbstprüfung 847

Heipertz, W.: Sportmedizin 636

Heiss, H.: Die künstliche Insemination der Frau. Medizin Theologie - Recht 403

Helwig, H.: Antibiotika - Chemotherapeutika. Grundlagen - Anwendung - Gefahren 1051

Henschler, D.: Gesundheitsschädliche Arbeitsstoffe. Toxikologisch-arbeitsmedizinische Begründungen von MAK-Werten (Maximale Arbeitsplatz-Konzentrationen) 178

Heuck, F.: Densitometrie in der Radiologie 1192

Hinz, P., R. Plaue: Die Begutachtung von Schleuder- und $\mathrm{Ab}$ knickverletzungen der Halswirbelsäule. Dreyer, J., P. Georgi: Möglichkeiten und Grenzen der SkelettSzintigraphie für die Orthopädie 582

Hötzel, D.: Kleine Ernährungslehre 1192

Holman, C. W., C. Muschenheim: Bronchopulmonary Diseases and Related Disorders. Vol. I and II 1009

Hülsmann, P.: Ärztliche Begutachtung der Leistungsfähigkeit von Arbeitslosen nach dem Arbeitsförderungsgesetz. Aufgaben, Grundlagen und Methoden 1308

Interaction of Alcohol and Other Drugs 796

Juchli, L., B. Högger: Umfassende Krankenpflege 336

Jucker, E.: Progress in Drug Research - Fortschritte der Arzneimittelforschung - Progrès des recherches pharmaceutiques. Vol. 15 und 16686

Keck, E. W.: Pädiatrische Kardiologie. Herzkrankheiten im Säuglings- und Kindesalter 178

Keidel, W. D.: Kurzgefaßtes Lehrbuch der Physiologie 636

Kiloh, L. G., A. J. McComas, J. W. Osselton: Clinical Electroencephalography 1308

Kinney, J. M., R. H. Egdabl, G. D. Zuidema: Manual of Preoperative and Postoperative Care. By the American College of Surgeons 1146 Klepzig, H.: Herz- und Gefäßkrankheiten. Grundbegriffe, Diagnostik, Therapie, Begutachtung, Ubersichtstabellen 910
Korting, G. W.: Hautkrankheiten bei Kindern und Jugendlichen. Ein Farbatlas für die Praxis 403

Kraus, E.: Immunophthalmologische Untersuchungen mit Hetero- und Autoantiseren. Ein kritischer Beitrag zur Autoimmunpathogenese von Augenerkrankungen 177

Krusen, F. H., F. J. Kottke, P. M. Ellwood: Handbook of Physical Medicine and Rehabilitation 33

Kucher, R., K. Steinbereithner: Intensivstation - Intensivpflege - Intensivtherapie. Möglichkeiten, Erfahrungen und Grenzen 402

Kügler, H.: Medizin-Meteorologie nach den Wetterphasen. Eine ärztliche Wetterkunde 458

Kühne, D., C.-G. Dässler: Leitfaden der gynäkologischen Endokrinologie 75

Kuschinsky, G.: Taschenbuch der modernen Arzneibehandlung. Angewandte Pharmakologie 519

Langen, D.: Kompendium der medizinischen Hypnose 291

Lutz, J.: Kinderpsychiatrie. Eine Anleitung zu Studium und Praxis für Ärzte, Erzieher, Fürsorger, Richter. Mit besonderer Berücksichtigung heilpädagogischer Probleme 1277

Markell, E. K., M. Voge: Medical Parasitology 76

Markwardt, F.: Allgemeine und spezielle Pharmakologie 1242

McDonald, G. A., T. C. Dodds, B. Cruickshank: Atlas der Hämatologie 961

McNair, T. J.: Hamilton Bailey's Emergency Surgery 179

Meyer, J.: Parenterale Ernährung und Infusionstherapie in der klinischen Medizin 961

Moberg, E.: Dringliche Handchirurgie 75

Mittelbach, H. R.: Die verletzte Hand 1090

Müller-Fablbusch, H. A.: Klinische und katamnestische Untersuchungen zum Parkinsonismus unter besonderer Berücksichtigung der Psychopathologie 125

Mumenthaler, M.: Neurologie. Ein kurzgefaßtes Lehrbuch für Ärzte und Studenten 1276

Naumann, H. H.: Kopf- und Hals-Chirurgie. Indikation -
Technik - Fehler und Gefahren. Operations-Manual in 3 Bänden. Band 1: Hals 177

Olitzki, A.: Enteric Fevers.

Causing Organisms and Host's Reactions 337

Orfanos, C. E.: Feinstrukturelle Morphologie und Histopathologie der verhornenden Epidermis 519

Overzier, C.: Systematik der Inneren Medizin. Für Mediziner und Zahnmediziner.

Daten - Fakten - Ubersichten 402

Popper, H., F. Schaffner: Progress in Liver Diseases. Vol. IV 962

Probst, C.: Frontobasale Verletzungen. Pathogenetische, diagnostische und therapeutische Probleme aus neurochirurgischer Sicht 1308

Raab, W.: Dermatologie. Grundlagen und Praxis. (Orientierung - Fortbildung - Praxis, Band 1) 230

Raab, W. P.: Natamycin (Pimaricin). Its Properties and Possibilities in Medicine 458

Raspé, G.: Advances in the Biosciences. Vol. 8. Workshop on Mechanisms and Prospects of Genetic Exchange, Berlin 19711308

Rørth, M., P. Astrup: Oxygen Affinity of Hemoglobin and Red Cell Acid Base Status 231

v. Rütte, B.: Die Reizblase der Frau, unter spezieller Berück. sichtigung funktioneller Untersuchungsmethoden 746

Saegesser, F., J. Pettavel: Surgical Oncology 231

Schärli, A. F.: Die angeborenen Mißbildungen des Rektums und Anus. (Aktuelle Probleme in der Chirurgie, Band 15.) 179, 746

Schettler, G.: Taschenbuch der praktischen Medizin 75

Schuchardt, K.: Fortschritte de Kiefer- und Gesichts-Chirurgie. Ein Jahrbuch. Band XV: Speicheldrüsentumoren Zentrale epitheliale Kiefertumoren 746

Schulte, W., R. Tölle: Psychiatrie 796

Schwetlick, W.: Orthopädische Erkrankungen des Säuglings und Kindes. Diagnose und Therapie unter besonderer Berücksichtigung der Vorsorgeuntersuchung 404
Siegenthaler, W.: Klinische Pathophysiologie 1009

Shirakabe, H.: Double Contrast Studies of the Stomach 910

Snapper, I., A. Kahn: Myelomatosis. Fundamentals and Clinical Features 33

Sökeland, J.: Urologie für Krankenschwestern und Krankenpfleger 636

Söling, H.-D., B. Willms: Regulation of Gluconeogenesis 290

Spiegelberg, H.: Phenomenology in Psychology and Psychiatry. A Historical Introduction 1242

Steigleder, G. K.: Dermatologie und Venerologie für Ärzte und Studenten 336

Theissing, H. J., W. Kumpf: Objektive Hörprüfung im Kindesalter. Veränderung des Atemgeräusches als Indikator für Hören. Untersuchungen der Phänomene und Anwendung zur Hörschwellenbestimmung 229

Timofeeff-Ressovsky, N. V., V. I. Ivanov, V. J. Korogodin: Die Anwendung des Trefferprinzips in der Strahlenbiologie 637

Tournay, R.: La Sclérose des Varices 962

Tweeddale, D. N., L. D. Dubilier: Cytopathology of $\mathrm{Fe}$ male Genital Tract Neoplasms 582

Volkbeimer, G.: Persorption (Gastroenterologie und Stoffwechsel, Band II) 290

Welch, C. E., J. D. Hardy: Advances in Surgery. Vol. 5, 126

Wells, C., J. Kyle: Wissenschaftliche Grundlagen der operativen Medizin 636

Wendt, G. G., D. Drohm: Die Huntingtonsche Chorea. Eine populationsgenetische Studie 1145

zum Winkel, K.: Lymphologie mit Radionukliden 126

Woitowitz, H.-J.: Arbeitsmedizinisch-epidemiologische Untersuchungen zu den unmittelbaren Gesundheitsgefahren durch Asbest 746

Zeumer, G.: Praxis der Handchirurgie in Operationsskizzen 520

Zimmer, S., M. Kübnert: Sputumzytologie des Lungenkrebses 910

Zinn, W. M.: Idiopathic Ischemic Necrosis of the Femoral Head in Adults 457 
Namenverzeichnis ${ }^{1}$

A

Abshage n, U. 117

Ackerman, H. S. $75^{*}$

Ackermann, R. 846

Adolfo Reccius, E. $404^{*}$

Albegger, K. W. 578

v. Albert, H.-H. 122

Allert, M.-L. 458*

Allgöwer, M. 1104

Amgwerd, R. 1169

Andrassy, K. 484

Angst, J. 402*, 1306

Arndt, H. 769

Arndt, H. J. 400

Astrup, P. 231*

\section{B}

Baas, E. U. 322

v. Babo, H. 272

Babucke, G. 183

Bachmann, A. 1275

Backe, W. 401

Bätzner, K. 325

Baldauf, G. 227

Bargfeld, D. 778

Barnes, T. 796"

Barth, V. 272

Bastian. H. P. 1306

Bates, D. V. $911^{\text {* }}$

Bauer, B. 309

v. Bauereisen, E. 32*

Baumgarten, H. G. 574

Bayer, H.-W. 72

Bechtelsheimer, H. 105

Beck, O. A. 409

Becker, F. 206

Becker, G. 148

Becker, H. 472

Becker, K. 398

Becker, V. 797*

Becker, W. 177"

Beisenherz, W. 539

Bellwinkel, S. 276

Benfer, J. 72

Benini, A. 17, 19

Bennett, M. R. $1091^{*}$

Bentvelzen, P. 458

Berg, G. 602, 961"

Berg, P. A. 1186

Berger, U. 86

Berger, W. 686"

Bernhard, A. 201

Bernsmeier, A. 290*

Bertram, E. 593

Bettendorf, U. 665

Beyer, J. 915

Bickel, H. 602, 809

Bierich, J. R. 31

Bindeballe, W. 661

Bingas, B. 284

Bitsch, Irmgard 1192*

Bläker, F. 194, 415, 446

Blauenstein, U. W. 429
Bleifeld, W. 858

Bleiker, M. A. 1066

Bleuler, M. 402*

Bloch, R. 20

Blumberg, A. 217

Bock, K. D. 751

Boeminghaus, F. 597

Böcker, F. 685*

Böhmer, D. 636*

Böke, W. 177*

Bohle, A. 757, 542

Bokermann, M. 1085

Bollinger, A. 825

Boquoi, E. 691

du Bosque, G. 398

Boyd, E. M. 403*, 797*

Braedel, H. U. 1136

Braun, A. 287, 1190

Braun-Falco, O. 519

Braveny, I. 535

Brech, W. 54

Breddin, K. 861

Brehm, G. 1009*

Brehm, H. K. $177^{*}$

Breining, H. $848^{*}$

Britton, K. E. 1193"

Brocher, J. E. W. 290*

Brock, D. J. H. $1277^{*}$

Brod, J. 1225

Brodie, B. B. $75^{*}$

Broughton, R. 1192*

Brown, N. J. G. 1193"

Brünner, H. 239, 426, 1064

Brunner, G. 472, 1085, 1223

Brunner, L. 558

Brunner, U. 158

Bruntsch, U. 148

Buchta, I. 769

Bünte, H. 809

Bürgi, H. 673

Büsser, E. 614, 719

Büttner, W. 751

Burger, J. 429

Burri, C. 1145*

Busch, E. W. 112, 380

C

Cano y Diaz, J. 162

Carrier, O. 403*

Caspary, W. F. 633

Castro, L. A. 641

Celers, J. 1051*

Chapchal, G. 404*

Cherniack, L. 686*

Cherniack, R. M. 686*

Chiappa, S. 402*

Chiari, H. 126"

Christie, R. V. 911"

Christl, H. L. 463

Chuiden, H. 243

Clagett, O. Th. $126^{*}$

Classen, M. 481

Coats, D. A. 809

Constam, G. R. 961*
Cotta, H. 1050*

Coulston, F. 582

Cranley, J. J. $1146^{*}$

Creutzfeldt, W. 228, 580, 908, 1085

Creutzig, H. 1019

Crowley, L. V. $797^{*}$

Cruickshank, B. 961*

D

Dässler, C.-G. $75^{*}$

Dammermann, R. 1251

Daniels, J. 230*

Dannenberg, H. 631

Debré, R. 1051*

Dehne, N. 558

Deicher, H. 93, 288

Deininger, H. K. 272

Delling, G. 1036

Delius, L. 126" 518

Demling, L. $336^{*}, 1076$

Denninger, K. 286, 1275

Deyhle, P. 219

Dienstl, F. 881

Dietrich, F. E. 1005

Dimou, E. 259

Disko, R. 535

Distler. A. 100

Dittberner, K.-H. 37

Dodds, T. C. $961^{*}$

Doerr, W. 126*

Dölle, W. 74

Döring, G. K. $746^{*}$

Dollfus, P. 458*

Drenkhahn, E. 661

Dreyer, J. 582*

Drings, P. 259

Drohm, D. $1145^{*}$

Dubach, U. C. 762

Dubilier, L. D. $582^{*}$

Dudziak, R. 1146*

E

Eberl, W. 597

Eckstein, H. B. 727

Edelmann, H. 175

Effert, S. 858

Egdahl, R. H. $1146^{*}$

Eggers, H. J. 1051*

Ehalt, W. 792

Ehlert, C. P. 1064

Ehrengut, W. 289, 580

Ehrly, A. M. 861

Eichler, O. 75*

Eigler, J. 74

Eisenberg, K. 112

Ellwood, P. M. 33*

Elster, Inge 635

Elves, M. W. 520*

Emmelot, P. 458*

Empt, J. 1192*
Erbe, R. 441

Erdmann, H. 1289

Erhardt, F. 152

Evers, K. G. 532

Ewald, W. 915

Ewe, K. 1212

Eyer, H. 580, 960

Eyrich, K. 959

\section{F}

Fabel, H. 32*

Falke, D. 458*, 1007

Farah, A. $75^{\circ}$

Fateh-Moghadam, A. 309

Faulhaber, J.-D. 1289

Fauser, U. 1207

Faust, V. 924

Fayers, P. M. 1066

Fechler, L. 861

Feer, H. $848^{*}$

Feind, C. R. 1145*

Feldmann, H. 499

Fernandez, E. 977

Filippini, L. 513

Fischer, D. 548

Fischer, K. 194

Fischer, R. 733

Fischer, S. 515

Flach, A. 727

Fleischer, K. 334, 456

Förster, H. 26, 290*, 742, 839,

1156, 1239

Forell, M. M. 930

Franken, F. H. 528

Frehner, H. U. $796^{*}$

Freitag, V. 1251

Frick, D. 861

Frick, P. $1241^{*}$

Frik, W. 1007

Fritsche, D. 350

Fröhlich, D. 276

Fröscher, W. 105

Fuchs, H.-F. 206, 481

Fülle, H. H. 874

Fünfgeld, E. W. 125*

Fuhrmann, W. $847^{*}$

Fumagalli, I. 219

Funke, H. D. 889

G

Gadamer, H.-G. 847"

Gädeke, R. $910^{*}$

Gänshirt, H. 290*, 1276*

Gahl, G. 641

Galvan, G. 189

Gasser, D. $1145^{*}$

Gastaut, H. 1192*

Gebert, G. 32*

Gehrmann, G. 1163

Geisler, L. S. $32^{*}, 686^{*}$

Geisthövel, W. 919

'Die fettgedruckten Zahlen bedeuten Originalarbeiten, die mit • versehenen Buchbesprechungen. 
Geißler, K.-H. $582^{*}$

Genest, J. 746"

Georgi, P. 582*

Geroulanos, S. 1095

Giessler, R. 1112

Gille, G. 967

Gillette, J. R. 75*

Gillmann, H. 33* $847^{*}, 1144$

Girndt, J. 977

Gladtke, E. 949

Glaser, E. 1227

Glaubitt, D. 284

Glauner, R. 796"

Glaus, L. 343

Glettner, M. A. 993

Gmeiner, R. 881

Gnauck, R. 737

Goerttler, U. 593

Göbel, U. 703, 1240

Gödan, H. 1051"

Görke, W. 284

Götze, W. 284

Gostomzyk, J. G. 175

Gottesbüren, H. 243, 398, 1151

Gottlob, R. 1004

Gottstein, U. 402*, 1089, 1144

Graef, V. 1299

Grase, E. U. 375

Greul, W. 496

Grewe, N. 885

Grob, P. J. 415, 446

Groher 684

Groop, L. C. 1178

Groscurth, P. 570

Gross, R. 783

Gruber, U. F. $179^{*}$

Grün, L. 73, 124, 456, 517

Grïner, J. 152

Grumme, Th. 1234

Grundmann, E. 683

Güller, R. 1268

Gullota, F. 105

Gundermann, K. O. 201

Gurd, F. N. 126*

Guyton, A. C. $178^{*}, 1090^{*}$

$\mathrm{H}$

Haagensen, C. D. $1145^{*}$

Haas, H. G. 683

Haas, R. 476, 649, 970, 1276

Haase, J. 178*

Haberich, F. J. 20

Hackelöhr, J. 398

Haering, M. 703

Haesen, D. 214

Häussler, S. 32

Hagemann, G. 1189

Hagen, W. 230"

Hahnloser, P. 1095

Haizmann, R. 126"

Halbfaß, H. J. 29, 479

Hall, R. 796*

Halsner, O. 421

Hamper, S. 1247

Hand, I. 1090*

Handa, J. 685"

Handrick, W. 1292

Hanrath, P. 858

Harbauer, H. 1277"

Hardy, J. D. $126^{*}$

Harms, D. 542

Hartje, W. 139
Hartwich, G. 1203

Haslbeck, M. 400

Hasse, H. E. 295, 327

Hassenstein, P. 48

Hasslacher, Ch. 301

Haubrich, R. 290*

Haupt, E. 915

Hausamen, T.-U. 169

Heberer, G. 1112

Heck, J. 1163

Hecker, W. Ch. $746^{*}$

Heesen, D. $4 \mathbf{4 4}$

Hegemann, G. 231*

Hegglin, R. 520*

Heilmann, K. 1022

Heiming, E. 305

Heimpel, H. 54, 289, 456, $1241^{*}$

Heinecke, G. 1040

Heinecker, R. 847*

Heinrich, K. $796^{*}$

Heinze, H. G. 152, 996

Heinze, V. 29, 479

Heipertz, W. 636", 582", 1050"

Heiss, H. 403*

Heitmann, P. 814, 1151

Helberg 795

Helbing, A. R. 112

Hell, K. 1104

Heller, A. 895

Heller, G. 1156

Hellriegel, W. 1307

Hellwege, H. H. 194, 415

Helmer, R. 214

Helpap, B. 81

Helwig, H. 1051*

Hennecke, A. 112, 934

Hennemann, H. H. 255

Henschler, D. 178", 403", 582", 751

Herken, H. $75^{*}$

Herms, W. 597

von Herrath, D. 1043

Herrmann, J. 469, 539

Herter, F. P. $1145^{*}$

Hertl, M. 336", 910"

Hesch, R.-D. 957

Heschl, R. 1047

Heuck, F. 1192*

Heuckenkamp, P.-U. 1006

Hey, D. 1227

Heyck, H. 404*

Hiemeyer, V. 267

Hilgard, P. 267

Hinz, P. 582*

Hirsch, H. A. 845

Hochrein, H. 409

Höfer, W. 801

Höffler, D. 684

Höffken, K. 148

Högger, B. $336^{* *}$

Höpken, W. 587

Hörtnagl, H. 993

Hötzel, D. 518, 1192*

Hoffmann, K. 1112

Hoffmeister, H. $\mathbf{3 8 0}$

Hohenfellner, R. 636*

Hohmann, G. 37

Hoigné, R. 1238

Holimann, W. 288

Hollwich, F. 458*

Holman, C. W. 1009*

Holstein, A. F. 61

Horn, H. J. 1013

Horn, K. 152

Hornung, G. 148
Horster, F. A. $\mathbf{5 2 5}$

Huber, Ch. 1026

Huber, E. G. 954

Huber, F. B. 671

Huber, H. 945, 1026

Hüllstrung, B. 1247

Hülsmann, P. 1308*

Huch, F. L. 744

Huhn, D. 355

Huland, H. 496

Humke, W. 1191

Hundeshagen, H. 1019

Hunger, J. 1125

Husmann, F. 451

\section{I}

Illig, Ruth 744

Ippen, H. 682, 686"

Irnich, W. 858

Irsigler, K. 741

Isermann, H. 714, 1074

Ivanov, V. I. $637^{\circ}$

Iwand, A. 441

Jacobi, E. 434, 1189

Janssen, H. 535

Jantzen, W. 210

Jennewein, H. M. 332, 1059

Jenny, M. 1095

Jenny, S. 219

Jontofsohn, R. 479

Jost, F. 1034

Juchli, L. 336*

Jucker, E. 686*

Judmaier, G. 1026

Jüsgen, W. 661

Junginger, Th. $\mathbf{3 4 7}$

Junkers, K. 479

Just, H. J. 100, 620

Just, I. 210

K

Kabelitz, H. J. 31

Kaboth, W. 355

Kaess, H. 283

Kahlau, G. 910"

Kahlstorf, J. 988

Kahn, A. 33"

Kaiser, H. 518

Kammerer, V. 627

Kapp, H. 1130

Karlson, P. 831

Kasper, H. 741

Kayasseh, L. 1268

Keck, E. W. 178*

Keidel, W. D. 636", 1090*

Keiser, G. 614

Keller, H.-P. 1292

Kelleter, R. 259, 499

Kepp, R. 403*, 745, 1047

Kerschensteiner, M. 139

Kessel, M. 641

Kienitz, M. 904

Kilch, L. G. 1308*

Kiloh, L. G. 1308*

Kinney, J. M. $1146^{*}$

Kirchberger, R. 272
Kirsch, W.-D. 1292

Kisker, K. P. $848^{*}$

Kistler, G. S. 570

Klausen, H. 634

Klein, E. 1189

Klein, W. 582*

Klepzig, H. $910^{*}$

Klemens, U. H. 1197

Kley, H. K. 469, 539

Knedel, M. 309

Knick, B. 568

Knocke, K.-W. 587

Knorr, D. 1087, 1278

Knoth, W. 230", 336"

Knothe, H. 904

Koch, H. 938

Koch, K. M. 484

Köhler, K.-H. 805

Kölmel, H. W. 259

König, H. 861

König, K. J. 934

Körner, H.-D. 1247

Koiw, E. 746

Koller, P. U. 380

Kollmeier, H. 421

Kommerell, B. 48, 983, 10:22

Konietzko, D. 1221

Konrad, M. 793

Kopsa, H. 15, 723

Korn, U. 733

Korogodin, V. J. 637"

Korsukewitz, J. 37

Korte, F. 582

Korting, G. W. 403:

Koszinowski, U. 262

Kottke, F. J. 33*

Kotzaurek, R. 15, 723

Kracht, J. 787

Krämer, W. 885

Kraft, D. 1043

Kraft, H. 861

Krainick, J.-U. 646, 1130

Kraus, E. 177*

Krause, H. 861

Krempien, B. 484

Kretschmer, V. 532

Kretschmer, W. 1090*

Kreuzer, G. 691

Krieg, H. 239

Krönig, B. 322

Krokowski, G. 126*

Kronenberg, K. H. 723

Krüskemper, H. L. 469, 5339 1281

Krull, P. 318

Krusen, F. H. 33"

Krzywanek, H. J. 861

Kucher, R. 402*

Kuibler, W. 853

Kügler, H. 458*

Kühn, K. 318

Kühnau, J. 684, 634, 794

Kühnau jr., J. 124

Kühne, D. $75^{*}$

Kühnert, M. $910^{*}$

Kümmerle, F. 1108

Kugler, J. 1047, 1308*

Kuhlencordt, F. 1241

Kuhnke, W. 434, 1189

Kumpf, W. 229*

Kuner, E. 1005

Kuschinsky, G. 519:

Kutschera, J. 861

Kutter, D. 112

Kyle, J. 636" 


\section{L}

Lachenmayer, L. 574

Lahrtz, Hg. 661

Lamerz, R. 309

Lamina, J. 1175

Landgraf, R. 787

Langen, D. 291*

Langloh, N. D. $457^{*}$

Largiadèr, F. 1055

Lasch, H. G. 1227

Laube, H. 1256

Laufs, R. 587

Lechelt, B. 930

Lehmann, D. 973

Lehmkuhl, H. $230^{*}$

Lehnhardt, E. 229*

Leithoff, H. 175

Leitritz, H. 178*

Lennert, K. $126^{*}, 335$

Leu, H. J. 158, 343

Leutenegger, H. 614

Leybold, K. 661

Leydhecker, W. 1049

Liebich, H. G. 384

Liehr, H. 1140

Liess, B. 587

Lindenschmidt, Th.-O. 636"

Linder, F. 1099

Lindner, H. 398

Linhart, P. 441, 983, 1022

Lischka, G. 1239

Loew, D. 1285

Löhr, E. 1192*

Löhr, J. 548

Löllgen, H. 620

Lösch, H. W. 861

v. Löwis of Menar, P. 1197

Lohrmann, H.-P. 54

Longmire, W. P. $126^{*}$

Loogen, F. 853

Loßnitzer, K. 885

Loth, R. 1064

Ludwig, O. 861

Lübbers, D. W. 231*

Lücking, Th. 1036

Lüllmann, H. 403* $1242^{*}$

Lutz, H. 361, 1203

Lutz, J. 1277"

\section{M}

Maas, D. 131

Macklem, P. T. 911*

Maess, J. 93

Märker, A. 1186

Makabe, R. 795

Malluche, H. H. 484

Maneke, M. 230*

Manke, H. G. 259

Marget, W. 456, 1276

Markell, E. K. $76^{*}$

Markoff, N. 962*

Markwardt, F. 1242*

Martin, H. 961*

Martini, G. A. 769, 998, 1151

Marx, H. H. $1308^{4}$

Maßhoff, W. 801

Mathes, P. 620

Mattes, P. 29

Matussek, P. 1242

Matzkies, F. 602, 1238

Mauß, J. 61

May, P. 1136
Mayo, O. $1277^{*}$

McComas, A. J. 1308*

McDonald, G. A. 961*

McNair, T. J. 179*

Medici, T. C. 947, $1009^{*}$

Meffert, O. 653

Mehnert, H. 26, 400, 742, 908, 915, 961", 1088

Meienberg, O. 973

Meiers, H. G. 210

Meiss, L. 1179

Mellin, P. 1275

Mertz, D. P. 11, 183

Meyer, D. 723

Meyer, J. 961*

Meyer, R.-D. 691

Meyer, W. 37

Meyer-Lindenberg, J. 105

Michlmayr, G. 945, 1026

Mihailova, K. 1260

Mikat, B. 861

Minne, H. 276

Misch, P. 809

Missmahl, H. P. 33*

Mitschke, H. 1272

Mittelbach, H. R. 1090*

Mittermayer, Ch. 593

Moberg, E. 75*

Mockwitz, J. 206

Möhring, K. 395

Mössner, G. 451

Mohr, P. 671

Mohr, W. 76*, 1088

Morgner, K. D. 539

Mueller-Eckhardt, Ch. $520^{*}$, 532, 1048

v. z. Mühlen, A. 539

Müller, G., Stuttgart 272

Müller, G., Ulm 267

Müller, H. E. 731

Müller, K. 226

Müller, R. 93

Müller, W. 1253

Müller-Fahlbusch, H. A. 125*

Müller-Hermelink, H. K. 201

Müller-Jensen, A. 1175

Muisebeck, M. 746*

Müting, D. 733

Mumenthaler, M. 1178, $1276^{*}$

Muschenheim, C. 1009*

Musumeci, R. 402*

Muth, H. 637*

von Mutzenbecher, Hilde 1239

\section{$\mathrm{N}$}

\section{Naber, K. 226}

Naimark, A. 686*

Nasemann, Th. 846, 1275

Naujoks, R. 123

Naumann, H. H. 177*

Naumann, P. 845

Nemeth, N. 915

Neuhäuser, G. 235

Neuhof, H. 1227

Neumann, E. 723

Neumann, G. 1066

Neumann-Haefelin, D. 476, 970

Neuwirth, R. 924

Niedermayer, W. 661

Nieschlag, E. 469, 1281

Nikolowski, W. 1192

Nobach, E. 162

Noth, J. $1091^{*}$

\section{$\mathrm{O}$}

Ober, K. G. 399

Oberhausen, E. 1136

Olberding, P. $\mathbf{5 8 7}$

Olbermann, M. 8, 579

Olbing, H. 1079

Olitzki, A. $337^{*}$

Opitz, H. 582*

Orfanos, C. E. $519^{*}$

Orgass, B. 139

Osselton, J. W. 1308*

Otte, M. 930

Ottenjann, R. 63, 677

Otto, H. F. 220

von Oudheusden, A. P. M. 112

Overzier, C. 402*

Oyelowo, J. P. 1212

\section{P}

Pache, H.-D. 582*

Pape, G. R. 542

Patz, J. 751

Peiper, H.-J. 1131

Pellnitz, D. 745

Perings, E. 1085

Peters, U. H. 967

Petersen, E. E. 476, 970

Pettavel, J. 231*

Petzold, K. 587

Pfeiffer, E. F. 1256, 1289

Philipp, Th. 100

pichlmaier, H. 347

Pickardt, C. R. 152

Piepgras, U. 627

Plaue, R. $582^{*}$

Poeck, K. 139

Pohl, G. 189

Polacsek, E. 796*

Poliwoda, H. 164

Popper, H. 962*

Posch, J. 230"

Prechtel, K. 698

Prellwitz, W. 8

Preter, B. 825

Pribilla, W. 874

Pringsheim, W. 1260

Probst, C. $1308^{*}$

Proß, E. 1108

Pürckhauer, F. 230*

Pulverer, G. 350

\section{Q}

Quellhorst, E. 977

$\mathrm{R}$

Raab, W. 230*

Raab, W. P. 458*

Rager, K. 727

Raith, L. 829

Ramanzadeh, R. 44

Raptis, S. 1256

Raspé, G. 1308*

Rau, H. 973

Raub, H. W. 587

v. Rauffer, L. 809

Rausch, F. 861

Recke, S. 8
Regli, F. 973

Rehbehn, W. 226

Rehder, H. 305

Reichel, G. 794, 1008

Reichel, H. 636*

Reichold, J. 1285

Reifferscheid, P. 727

Reikowski, J. 733

Reinecke, F. 1221

Reinwein, D. 1048

Renner, E. 634

Rettenmaier, G. 361

Rhomberg, W. 455

Riederer, J. 175

Riechert, T. 646, 1130

Riecken, E. O. 998

Riecker, G. 891, 1088

Rieger, H.-J. 125, 176, 287 , $401,518,456,635,685,847$, 581, 909, 961, 1008, 1307

Rietbrock, I. 561

Rietbrock, N. 117

Ringel, E. $685^{*}$

Ritter, U. 290*

Ritz, E. 395, 484

Riva, G. 399

Rob, Ch. 126*

Roder, O. 930

Roemer, G. B. 909

Röher, H. D. 484, 565

Rösch, W. 481

Rösler, H. 685*

Romieu, Cl. 1179

Rørth, M. 231*

Rosenblum, J. 582*

Rosenthal, P. 861

Rost, H.-D. 32*

Rothlin, M. 893

Rothmund, M. 426

Rudolph, P. 561

Rüegger, R. 762

v. Riitte, B. $746^{\circ}$

Rüttimann, A. 796*

Ruhrmann, G. 175

Rupp, M. 858

\section{S}

Saborowski, F. 675

Saeger, W. 1272

Saegesser, F. 231*

Salis-Samaden, R. 189

Sanwald, R. 301

Sarreither, P. 924

Sartory, S. 861

Satte's, H. $1145^{*}$

Sarvestani, M. 44

Sauer, H. 243, 686*, 796*, 1307

Sauerbruch, T. 283

Schaede, A. 37

Schaefer, J. 201, 519*

Schaefer, K. 1043

Schäfer, A. 503

Schäfer, H. J. 496

Schäfer, K. H. 1191

Schärli, A. F. 179*, 746"

Schaffner, F. 962*

Schall, J. 1175

Scheid, W. 685*

Scheler, F. 977

Schemmel, K. 661

Schenk, K. E. 270

Scherer, R. 1144

Scheurlen, P. G. 1008 
Schibli, R. A. 719

Schindler, E. 1136

Schink, W. 72, 520* $1090^{*}$

Schirren, C. 61, 455

Schirren, C. G. 61

Schlaak, M. 201

Schlage, C. 901

Schlegel, K. F. 229, 1050*

Schlierf, Chr. 463

Schlieter, F. 105

Schlosser, V. 593

Schmalzl, F. 355

Schmid, F. 582*

Schmidt, C. G. 148, 175, 836

Schmidt, C. L. 1130

Schmidt, E.-W. 458*

Schmidt, G. $75^{*}$

Schmidt, H. 579, 957, 1085

Schmidt, J. 636"

Schmidt, P. 15, 723

Schmitz, H. 649, 964

Schmitz-Valckenberg, D. 243

Schnack, H. 625

Schneider, K. W. 1297

Schneider, M. 343

Schnetter, Ch. 476

Schober, A. 262

Schoen, Imke 669

Schöffling, K. 469, 915

Schölmerich, P. 402" $520^{*}$

Schönhöfer, P. S. 295, 327

Schomerus, H. 769

Schoop, W. 1285

Schreiter, F. 1169

Schröder, E. 230

Schröder, E., Düsseldorf 597

Schröder, R. 1191

Schubothe, H. 131

Schuchardt, K. $746^{*}$

Schütz, E. 32*

Schütz, W. 122

Schulte, H. D. 508

Schulte, W. $796^{*}$

Schultheiss, H. R. 1104

Schultis, K. 364

Schulz, E. 1040

Schulz, K. H. 415, 446

Schulz, V. 503

Schulze, A. 37

Schumacher, K. 167

Schuman, L. 1104

Schwedes, U. 469

Schwemmle, K. 1125

Schwetlick, W. 404*

Schwick, M. 853

Schwille, P. O. 335

Schwinger, E. 227

Schwingshackl, H. 993

Scranowitz, P. 809

Scriba, P. C. 152, 787

Sebening, H. 1

Seeger, W. 1308

Seelig, H. P. $336^{*}$

Seeliger, H. $337^{*}$

Seidel, H. 698

Seifert, G. 126"

Seiffert, K. E. $75^{*}$

Sekeris, C. E. 831

Seitz, D. 243

Selmair, H. 472

Sennekamp, J. 1223

Senning, A. 1095

Serrou, B. 1179

Sheikh, M. 320

Shirakabe, H. $910^{*}$
Siegenthaler, W. $75^{\star}, 506,746^{*}$ $1009^{*}, 1051^{*}$

Siegert, R. 176

Siehr, U. 1034

Sietzen, W. 904

Siewert, J.-R. 1131

Simmler, F. 513

Simon, K. 942

Slanetz, Ch. A. $1145^{*}$

Snapper, I. 33*

So, C. S. $910^{*}$

Sökeland, J. 458*, 636

Söling, H.-D. 290

Solbach, H. G. 1281

zu Solms, Ingrid 291*

Sommer, B. 347

Spengler, H. 762

Spiegelberg, H. $1242^{*}$

Spiess, H. 74, 125, 682

Spillner, G. 593

Splitthoff, R. D. 441

Staak, M. 110, 517, 682

Staehelin, M. 1277*

Staemmler, H. J. 177*

Städtler, F. 1013

Stahlheher, H. 930

Staib, I. 29, 479

Stalder, G. A. 1268

Stauch, M. 885

Steer, H. 201

Steigleder, G. K. $336^{*}, 403^{*}$

Steinbereithner, K. 402*

Steiner, H. 189

Stelzner, F. $126^{*}, 179^{*}$

Stendel, A. 539

Stephan, K. 1009*

Stephan, W. 210

Sterzel, R. B. 318

Stetter, H. 1009*

Stille, W. 611

Stocker, W. G. 255

Stöhr, M. 1247

Stölzel, R. 284

Stioss, U. 1151

Stojan, B. 1253

Stoll, J. E. 175

Stralau, J. $230^{*}$

Straßburger, D. 210

Strauer, B. E. 558

Stroehmann, I. 1223

Strubelt, O. 778

Struck, H. 72

Stuhlinger, B. 283

Stutte, H. J. 388

Széplaki, F. 844

\section{$\mathrm{T}$}

Täube-Wunder, R. 214

Tariverdian, M. 1253

Taubert, H.-D. 75*

Teirich-Leube, H. 1050*

Terhorst, B. 1306

Thefeld, W. $\mathbf{3 8 0}$

Theissing, H. J. 229*

Thiel, H. 386

Thiele, K. G. 1270

Thiemiann, J. 1006

Thoden, U. 1130

Thomssen, R. 162, 262

Thurmayr, G. R. 930

Thurmayr, R. 930

Thurn, P. 796"

Til\%, G. P. 578, 1047
Timofeff-Ressovsky, N. V. $637^{*}$

Tölle, R. 796*

Töndury, G. 570

Tönne, J. 518

Tournay, R. $962^{*}$

Track, N. S. 1085

Traunecker, U. 1186

Tronnier, H. 960

Trüb, C. L. P. $230^{*}$

Tschätsch, W. 1203

Turner, N. 796*

Tweeddale, D. N. $582^{*}$

U

Uehlinger, E. $126^{*}$

Uffelmann, H. 611

Ulmer, W. T. 911*

Ulrich, G. 776

Ungeheuer, E. 114

Usadel, K. H. 469

Uslenghi, C. 402*

V

Valesky, A. 29

Vereschild, N. 983

Vetter, W. 506

Viamonte, M. $796^{*}$

Vido, I. 472

Vivell, O. 1049

Voge, M. $76^{*}$

Vogel, F. 1308

Vogelsang, H. 988

Vogler, E. $796^{\circ}$

Vogler, P. $847^{*}$

Voigt, G. 861

Volkheimer, G. $290^{*}$

Volles, E. 123

Vollmar, J. 380

Vollmar, J. F. $1146^{*}$

Voßköhler, E. 364

W

Wahl, A. R. 565

Wahl, P. 301

Wagner, C. 395

Wagner, E. 364

Wagner, J. 37

Waibel, P. $686^{\#}$

Waldeck, F. 332, 1059

Waldmann, H. 295, 327

Walter, P. 384

Wanitschke, R. 1212

Wanke, M. 126"

Weber, H.-G. 653

de W'eck, A. L. 762, 960

Wegmann, W. 614

Weichardt, H. 178*

Weidner, A. 988

Weinberg, J. A. 1145*

Weis, K. H. 561

Weise, C. 796*

Weiser, F. 1059

Weiser, G. 993

Weisner, B. 1175

Weissauer, W. 1049, 1241

Weissleder, H. 126"

Weitbrecht, H. J. 685"

Weitzel, G. 1051*
Weizel, A. 48, 1022

Welch, A. D. $75^{*}$

Welch, C. E. $126^{*}$

Wells, C. $636^{\star}$

Wendland, K.-L. 1305

Wendt, G. G. $1145^{*}$

Wenz, W. 796* $910^{*}$

Wessinghage, D. 44

Westphal, A. 581

Wetter, O. $1145^{*}$

Wetzels, E. 597

Wicklmayr, M. 915

Widmer, K. $\mathbf{5 4}$

Widmer, L. K. 343, 962"

Wiechers, B. $\mathbf{5 2 8}$

Wieck, H. H. 685* 776

Wiegelmann, W. 1281

Wiemers, K. 1145*

Wienbeck, M. 814

Wildhirt, E. 680, 1240

Wildmeister, W. 525

Wille, P. F.-C. 906

Willebrand, H. 548

Willers, H. 587

Wilk, F. 959

Willms, B. $290^{*}$

Wimmer, W. 65

Winckler, K. 957

Windorfer, A. 235

Windorfer jun., A. 1260

Wingen, A. M. 703

zum Winkel, K. 126* $402^{\star}$, i 193*

Winkelmann, W. 444

Winzeler, A. 614

Wirth, E. 110

Wirtzfeld, A. 1

Wittenborg, A. 919, 988

Witzel, L. 206

Wör , R 1071

Wohlenberg, H. 463

Woitowitz, H.-J. 746"

Wolf, H. 1227

Wolfram, G. 335

Wollenweber, J. 463, 737, 912

Wopfner, F. 809

Worth, G. $746^{*}$

Wüthrich, B. 1143

Wurm, K. 1253

Wylicil, P. 861

\section{Z}

Zazgornik, J. 15, 723

Zebe, H. 395

Zeidler, D. 1099

Zeidler, H. 919, 988

Zeidler, U. 539

Zeitler, E. 1285

Zeit\%, J. 942

Zekert, F. 1004

Zellmann, K. 214

Zerbst, E. 37

Zeumer, G. 520*

Ziegler, M. 395

Ziegier, R. 276

Zimmer, S. $910^{*}$

Zimmermann, W. 227

Zinn, W. M. 457*

Zobl, H. 318

Zollinger, R. M. $126^{*}$

Zuidema, G. D. 1146*

Zwirner, R. 1140 


\section{Personalnachrichten}

\section{Ernennungen, Berufungen, Lehraufträge}

Affolter, H. P. 1244

Ahnefeld, F. W. 128, 522, 1010

Althoff, H. 584

Ammon, H. 1309

Arnold, G., Aachen 850

Arnold, G., Düsseldorf 522

Bachmann, G.-W. 584

Bättig, K. 406

Baltzer, G. 292

Bargon, G. 128

Bartels, H. 522

Becker, F. 406

Behnke, H. 584

Benedum, J.-R. 338

Beneke, G. 522

van de Berg, A. 1194

Bernhardt, H. 1092

Beske, F. 1092

Bette, L. 406

Bidlingmaier, F. 292

Blank, M. 128

Blanke, K. 1092

Blauth, W. 850

Bleyl, U. 1148

Bloch, R. 1092

Blohmke, Maria 638

Bösenberg, H. 798

Brauser, B. 34

ten Bruggencate, G. 798

Brunner, L. 77

Bruns, W. 1148

Büchner, Ch. 638

Büchner, M. 688

Büchner, Th. 584

Büttner, W. 406

Burkhardt, R. 34

Busch, D. 584

Cremerius, J. 232

Cruchaud, A. 688

Daum, R. 638

Delachaux, A. 78

Dengler, H. J. 406

Dennhardt, R. 292

Dienstl, F. 912

Diete rich, H.-J. 1310

Dittrich, P. 912

Doden, W. 522

Döring, H.-J. 638

Dold, U. 584

Dombrowski, H. 292

Dreifuss, J.-J. 1194

Dudziak, R. 688

Eber hagen, D. 34

Eberle, H. 292

Egbring, R. 292

Ehle rs, K.-Th. 338

Eisenburg, J. 1310

Eißner, H. 1092

Engel, P. 292

Englhardt, Anneliese 1310

Engelking, R. 1148

Eschenbach, K. 292

Fabel, H. 1092

Federlin, K. 128
Fichsel, H. 128

Fiedler, F. 292

Finger, H. 688

Fischer, W. 522

Flad, H.-D. 1194

Fleischer-Peters, Annette 522

Forssmann, W. 688

Franz, H.-E. 522

Freundt, K. J. 406

Frick, E. 34

Frick, J. 912

Fridrich, R. 1052

Friehs, G. 798

Frischauf, J. 850

Fruhstorfer, H. 292

Full-Scharrer, Gabriele 1310

Gerhard, Lieselotte 688

Gerhardt, P. 78

Gerlach, U. 338

Geus, A. 1092

Gibbels, Ellen 1148

Girardet, P. 1194

Gleichmann, U. 688

Goebell, H. 1194

Görres, A. 1244

Goltz, Dietlinde 964

Gottesbüren, H. 1092

Graf, J. 78

Grasser, H. J. 1310

Gries, F. A. 77

Grimm, H. 292

Grözinger, K.-H. 638

Grosse-Brockhoff, F. 522

Grote, W. 77

Gruenagel, H. H. 688

Grundner, H. G. 292

Günther, R. 912

Haase, H.-J. 1092

Habermehl 292

Hachmeister, U. 338

Haim, G. 406

Harth, O. 1010

Haynal, A. 1194

Havsteen, D. B. 584

Hartung, W. 1244

Heberer, G. 584

Heene, R. 292

Heidsieck, C. 292

Heimann, K. 584

Heistracher, P. 748

Heitmann, H.-J. 584

Heitmann, P. 292

Heitmann, R. 584

Helmer, F. 748

Hengst, W. 798

Henschler, D. 78

Hertle, Hildegard 34

Hertting, G. 748

Heymann, H. 1194

Hickl, E.-J. 338

Hirschmann, J. 78

Hodler, J. 688

Höer, W. 1010

Hofer, G. 460

Hofmann, D. 406, 964

Hollwich, F. 406

Holstein, A. F. 1310

Holzknecht, F. 912
Horn, H.-J. 78

Huber, H. 912

Hubmer, G. 798

Hübner, L. 1092

Hürter, P. 1194

Hunziker, Nicole 1194

Hussl, G. 688

Intemann, Eleonore 798

Isler, W. 912

Jahnecke, J. 1010

Janz, D. 1010

Jellinger, K. 748

Jenny, M. E. 1244

Jochmus, Ingeborg 128

Jörgensen, G. 1309

Joseph, K. 292

Jungwirth, H. 78

Kaess, H. 638

Kaeßmann, H.-J. 1148

Kahr, E. 798

Kaiser, E. 850

Kalkschmid, W. 912

Keil, G. 798

Keller, R. 232

Kemper, F. 406

Keresztesi, K. 912

Ketterl, W. 1010

Keyl, H.-G. 128

Kirsch, W. 406

Kleihauer, E. 128

Klein, H. 638

Klein, P. 292

Kleinsasser, O. 1010

Kleinschmidt, A. K. 522

Klemin, J. 34

Klenk, H.-D. 1092

Klose, R. 584

Knolle, G. 522

Koberg, W. 688

Koch, H. 1010

Kochsiek, K. 292, 850

Kohlhage, H. 1092

Kornhuber, H.-H. 338

Kotscher, E. 522

Kovac, W. 748

Kovacicek, St. 77

Kratochwil, A. 688

Kraus, H. 964

Krayenbühl, Hugo 1194

Krenkel, W. 1148

Kriz, W' 798

Kubik, St. 1194

Kucsko, L. 850

Kübler, W'. 77

Kuhn, G.-G. 338

Kuni, H. 292

Landolt, E. 1194

Landsberger, A. 638

Lang, J. 1310

Lange, H. 292

Lange, H.-J. 912

Langendorf, H. 1010

Lauer, H.-H. 638

Lawin, P. 292

Lehmann, F. G. 292

Lehmann, G. 406

Lehnert, S. 798

Lelbach, W' K. 128
Lembeck, F. 1148

Lennartz, H. 688

Lensing, J. 798

Lichtlen, P. 1194

Liebaldt, G. 1244

Liebhardt, E. 292

Liesenhoff, H. 232

Lindner, J. 912

Lochner, W. 798

Loennecken, S. 584

Lösch, G. 522

Löweneck, H. 292

v. Loh, D. 850

Lohmeyer, H. H. 584

Ludwig, Gerlinde 292

Ludwig, H. 584

Ludwig, K. S. 292, 964

Ludwig, P. 522

Lütcke, A. 292

Lungershausen, E. 128

Maaß, G. 406

Machtens, E. 584, 1309

Maresch, W. 1148

Marghescu, S. 1310

Maroske, D. 292

Marquardt, P. 584

Matussek, N. 1310

Mauel, J. 1194

Mégevand, R. 522

Meigel, W. 34

Meinhof, W. 798

Meisner, J. 34, 292

Mester, H. 798

ter Meulen, V. 338

Michaelis, J. 460

Millesi, H. 460

Moeller, M. 1309

Morgenroth, K. 584

Müller, D. 1010

Müller, E. 1092

Müller, U. 1310

Müller-Ruchholtz, E. R. 522

Neiger, M. 688

Nemetschek, Th. 638

Nesswetha, W. 460

Neßler, Lore 77

Neurath, F. 232

Niessing, J. 292

Nissen, G. 1052

Nonner, W. 1194

Nowacki, P. 1148

Oberhoffer, G. 1148

Obiditsch-Mayer, Irmtraud 522

Oehlschlaegel, G. 338

Ohlenrodt, G. 1310

Ottenjann, R. 522

Palm, D. 584

Pateisky, K. 688

Peiper, H.-J. 1148

Petersen, P. 406

Petzoldt, D. 34

Pfeiffer, R. A. 128

Pfleiderer, Th. 638

Pichlmayr, Ina 292, 460

Pilz, H. 77

Plattig, K.-H. 1092

Plischka, G. 688

Pohlmeier, H. 522 
Poppe, H. 128

Pribilla, O. 1310

Priebe, L. 292

Prill, A. 1148

Prüll, G. 338

Raas, E. 688

Rabe, F. 77

Rakosi, Th. 584

Rapp, W. 638

Rassner, G. 798

Rassow, J. 584

Ravelli, A. 912

Rehder, K. 964

Reichenberger, Margot 584

Reidemeister, J.-Ch. 1092

Reinauer, H. 1309

Reinwein, D. 584

Renschler, H. 1148

Richter, K. 638

Rick, W. 688

Rickenbacher, J. 1194

Rimpler, M. 1310

Ringel, E. 522

Ritzerfeld, W. 1244

Röhrich, H. 1310

Rösli, R. 406

Rosenbauer, K. 77

Ross, W. 1244

Rossak, K. 638

Roth, H. 521

Rüegg, J. C. 292, 912

Runnebaum, B. 638

Ruska, Carla 522

Sack, H. 584

Sailer, S. 912

Santler, R. 912

Sasse, D. 78, 850

Satter, P. 522

Sauer, H. 912

Schäfer, W. D. 406

Schärer, K. 1148

Schamaun, H.-M. 232

Scheier, H. 1052

Schellong, G. 338, 964

Schenk, W. 1010

Schettler, D. 522, 1092

Schirmeister, J. 78, 406

Schlöndorff, G. 688, 1092

Schlorhaufer, W. 912

Schmid, K. 798

Schmidt, F.-C. 688

Schmidt, J. 798

Schmidt, M. 292

Schmidt-Wilcke, H. 292

Schönthal, H. 232

Schollmeyer, P. 688

Schreiber, G. 1010

Schrenk, M. 78

Schröder, E. 1092

Schröer, H. 688

Schröter, W. 34

Schübel, F. 1092

Schütz, R.-M. 522

Schultheis, Th. 232

Schwabe, H. 232

Schwalb, H. 798

Schwarze, C. 1148

Schweikert, C.-H. 1010

Schwerd, W. 798

Schwetz, F. 748

Schwille, P. 128

Seeger, Ruth 406

Seidel, W. 850

Selenka, F. 1010

Sewing, K.-F. 78
Simon, E. 1148

Sitzmann, C. 522

Slenczka, W. 292

Slezak, H. 748

Sodomann, C. P. 292

Sokolovski, A. 798

Soyka, D. 584

Speckmann, E.-J. 584

Spitzy, K. H. 748

Staak, M. 850

Stäcker, K. 798

Staib, W. 798

Stamm, D. 1148

Steding, G. 77

Steinbereithner, K. 460

Steingrüber, H.-J. 1092

Stoermer, J. 77, 584

Stoffel, W. 584

Stoicanu, N. 292

Stolze, Th. 522

Strik, W. 1244

Strohmeyer, G. 688

Struck, E. 292

Stücker, F.-J. 584

Stumpe, K. 1194

Stumpf, Ch. 748

Sturm, G. 292

Tarnow, G. 78

Tenhaeff, D. 584

Thalhammer, O. 460

Thoenen, H. 77

Tönnis, D. 128

Tornow, K. 1010

Triadan, H. 232

Tronnier, H. 748

von Uexküll, Thure 522

Veyrat, R. 688

Vido, I. 232

Viefhues, H. 1244

Vinnai, G. 232

Voss, D. 688

VOR, D. 522

Walcher, W. 1092

W/ecker, F. 405

Weghaupt, K. 522

Wegner, G. 584

W'eidtman, V. 1148

Weigel, W. 77

Weischer, Marieluise 128

Weise, W. 77

Wenner, J. 1310

Werchau, H. 688

Wernze, H. 1244

Wetzstein, R. 34

Wewalka, F. 180

Wienbeck, M. 292

Wilmanns, W. 78

Wilms, Gesine 1310

Winkler, H. 912

Wintersberger, E. 1310

Witt, E. 798

Wolf, E. 292

Wolf, F. 1309

Wolf, R. 1010

Wolff, K. 1244

Wollert, U. 1010

Wollheim, E. 78

Wïllenweber, R. 688

Wüstenfeld, E. 78, 406, 688

Wulf, K.-H. 1244

Wunderer, S. 912

Wundt, W. 232

Yasargil, M. G. 850

Zeidler, U. 406

Zeisberger, E. 406
Zelger, J. 912

Zimmermann, H. 688

Zimmermann, W. 78

Zühlke, D. 584

Zweymüller, E. 748

\section{Habilitationen, Umhabilitationen Dozenturen}

Adam, D. 34

Aguercif, M. 850

Albert, E. 798

Assal, G. 78

Atay, Z. 1310

Bachmann, F.-F. G. 850

Bachmann, W. 1010

Bandlow, G. 688

Baumann, G. 798

Becker, W. 638

Benakis, A. 850

Bergold, J. B. 748

Beyer, W. 798

Bock, K. W. 850

Börngen, U. 78

Brandau, H. 232

Braun, R. 78

Bregulla, K.-G. 1092

Brinkmann, P. 1310

Brückner, W. 292

Bruhn, H. D. 584

Bürgi, H. 338

Burger, A. 1310

Busch, Christiane 78

Buse, H. 1148

Caesar, K. 1148

Dauner, Iris 522

Denk, H. 1310

Dieterich, C. E. 78

Ditt, Jutta 338

Dörmer, P. 1310

Drews, U. 1010

Dufresne, J.-J. 406

Eisenbach, G. M. 638

Elsäßer, E. 1310

Engel, W. 798

Fichtner, H. J. 638

Finzen, A. 850

Föllmer, W. 1310

Frahm, Margarete 128

Frank, G. 78

Fuchs, K. 798

Gallmeier, W. 584

Gebhart, E. 292

Geiger, W. 522

Georghiu, Th. 584

Gloor, B. 912

Goebel, K. M. 78

Göbbeler, Th. 584

Grïn, Gisa 1052

Grünewald, W. 292

Gurland, J. 798

Hänze, S. 77

Hahn, K. J. 638

Hanselmaver, H. 1092

Harnoncourt, K. 688

Heißmeyer, H.-H. 1052

Hellmich, S. 798

Henrich, H. 128

Hertel, E. 798

Hilgermann, R. 522

Hindemann, P. 964

Hohenegger, M. 1278

Holzgreve, H. 292

Hupfauer, W. 584

Jeannet, M. 850

Jentsch, J. 688

Junghanns, K. 638

Kaiser, W. 34

Kalden, J. 460

Kallenbach, H.-H. 77

Kiwull, P. 292

Kleihues, P. 522

Klein, H. O. 522

Kleinhans, D. 638

Koch, G. 1092

Koch, R. 292

Köbberling, J. 77

Koob, E. 584

Koos, W. 460

von Kraft, A. 78

Kramar, R. 180

Krietsch, W. 1310

Kröger, E. 638

Krüger, J. 688

Krumhaar, D. 638

Krupke, H.-J. 964

Kümper, H. J. 798

Künzli, H. F. 964

Kunitsch, G. 232

Kunze, St. 292

Ladewig, D. R. 1194

Land, W'. 798

Latta, Elisabeth 78

Leber, H..W. 688

Lehmann, V. 688

Lesch, P. 688

Linnert, Doris 798

Livio, J.-J. 78

Löhrs, U. 1310

Ludin, H.-P. 338

Lüderitz, B. 338

Lozano-Tonkin, C. 128

Lux, H. D. 34

Mäusle, E. 1194

Martinius, J. 292

Marx, E. 77

Marx, P. 232

Maurer, P. K. 338

Mauß, J. 584

McGuigan, J. 748

Meinhof, W. 1309

Menge, H. 78

Merguet, P. 584

Meurer, K.-A. 1148

Meyer, J. 798

Meyer-Burgdorff, Ch. 77

Mittelbach, R. 232

Moayer, M. 584

Möhring, J. 638

Mönkemeier, D. 1310

Müller, H. 78

Müller, W. A. 798

Münzel, M. 798

Nejedlo, V. 34

Nier, K. 522

Obrecht, J.-P. 1194

Oepen, Irmgard 522

Otto, H. 798

Parwaresch, M. R. 584

Paumgartner, G. 748 
Raff, W.-K. 522

Ranft, Lore 78

Rebel, W. 1010

Regenburger, D. 688

Reichert, R. 798

Reinert, M. 1194

Renner, G. 798

Rettenmaier, G. 1092

Rohrbach, R. 1052

Rossipal, E. 912

Roth, F. J. 638

Rüdiger, H. 912

Ruile, K. 688

Sachtleben, P. 292

Schaal, K.-P. 522

Scheiber, V. 584

Schienbein, H. 522

Schildberg, F.-W. 522

Schimansky, K. H. 638

Schimpl, Anneliese 128

Schmidt-Habelmann, P. 34

Schneider, D. O. 78

Schöber, J. 1310

Schöll, A. 850

Schönberg, D. 78

Schrader, C.-P. 78

Schröder, F. H. 34

Schütz, J. 1310

Schulte-Hermann, R. 78

Schulz, E. 522

Schulze, E. 128

Schulze-Bergmann, G. 912

Seidel, G. 1310

Siegl, G. 748

Siewert, J.-R. 798

von Smekal, P. 522

Sonntag, H. 688

Souvatzoglou, A. 798

Spalke, G. 78

Spechtmeyer, H. 522

Spelsberg, E. 1310

Stamm, D. 338

Stellbrink, C. 798

Tauchert, M. 522

Taugner, G. 638

Thiebe, R. 1310

Thießen, G. 460

Thorn, Lieselotte 798

Tobiasch, V. 1194

Tripatzis 1310

Wadström, L. B. 964

Waldhäusl, W. 1310

Wallner, K. H. J. 338

Wawschinek, O. 688

Wehner, H. 850

Weigand, K.-H. 688

de Werra, P. 78

Wiesmann, U. 912

Wilhelm, K. 798

Willmen, H.-R. 460

Wolff, H. 34

Wolner, E. 1310

Wuttke, W. 688

Zerbin-Rüdin, Edith 292

Ehrenmitglieder, Korrespondierende Mitglieder, Gesellschaften, Auszeichnungen

Afting, E.-G. 292

Alexandridis, E. 34

Bamm, C. E.-P. 128

Bandlow, G. 583
Bargmann, W. 584

Bartels, H. 406

Berg, St. 338

Bernoulli, E. 77

Berrens, L. 179

Brocher, J. E. W. 1278

Bock, H.-E. 180

Brock 1052

Bücherl, E. S. 1309

Büchner, F. 522

Bühlau, V. 1278

Burckhardt, D. 34

Bushe, K.-A. 1092

Butenandt, A. 748

Dannheim, R. 850

Demling, L. 1194

Desselberger, U. 1194

Ellegast, H. 232

Fischer, E. 688

Fliedner, Th. M. 128

Frey, R. 78

Freyschmidt, P. 1092

Frommhold, W. 78, 128, 850

Fuchs, G. 128

Fürste, H.-O. 292

Gaubatz, E. 798

Gauger, D. 1194

Freiherr von Gebsattel, V. E. 638

Geiger, W. 1148

Geigy, R. 180, 1194

Georgii, A. 1194

Gercke, W. 78

Gloor, H. U. 180

Grschwend, N. 688

Gütgemann, A. 292

Habs, H. 338

Hauss, W. 128

Hecker, W. Ch. 34

Helmreich, E. 78

Henning, N. 128, 292

Hensel, H. 338

Hess, W., Basel 521

Hess, W., Zürich 964

Hilgenfeldt, O. 1278

Holle, F. 292, 1278

Hollwich, F. 584

Hopf, M. 1278

Ihli, M. 34

Ippen, H. 12.44

Jadassohn, W. 232

Junghanns, H. 1278

Jusatz, H. 128

Kaiser, G. 1194

Kettler, D. 77

Kielholz, P. 180

Knieriem, H.-J. 1052

Kornhuber, H.-H. 338

Krause, H.-P. 1194

Krayenbühl, Hugo 78, 180

Künzer, W. 1010

Kunlin, J. 34

Lang, W. 1194

Lauterbach, H. 1278

Lejeune, J. 521

Lempp, R. 78

Lesky, Erna 180, 1244

Loch, W. 850

Lochner, W. 1092

Loogen, F. 338

Losse, H. 584

Martin, H. 522

Maurer, G. 128

Mühlemann, H. R. 850, 1194

Müller, M. E. 180
Müller-Ruchholtz, E. 77

Mundinger, F. 584

Musaph, H. 34

Mutschelknauß, R. 128

Naujoks, R. 78

Nasemann, Th. 748

Nolte, J. 232

Nowicki, L. 522

Nyhus, L. M. 1278

Obwegeser, H. 180

Oehme, J. 1244

Osswald, H. 1194

Ostertag, H. 1194

Pässler, H. W. 34

Patry, R. 1278

Pette, D. 232

Pfaltz, C. R. 292

Pfeiffer, E. 1052

Plester, D. 78

Ploog, D. 34

Pribilla, W. 1244

Probst, V. 77

Quiring, K. 1194

Reich, H. 964

Rickham, P. P. 78

Riegel, K. 292

Rondez, R. 748

Rossi, E. 180

Sautter, H. 128

Schadewaldt, H. 128

Schettler, G. 232

Schick, P. 1194

Schmidt, C. G. 77

Schneider, W. 850

Schnyder, U. W. 180

Schrader, C.-P. 1278

Schulte, H.-D. 77

Schuster, J. 34

Siegenthaler, W. 748

Siegismund, G. 1194

Stephan, U. 77

Striebitz 1052

Stucke, K. 460

Theml, H. 1194

Thews, G. 180, 1278

Thiele, J. 1194

Töndury, G. 180

Trepel, F. 1194

Uehleke, H. 850

Verzár, F. 1278

Waller, H. D. 78

Watzka, M. 748

Weber, B. G. 180

Weber, H. H. 34

de Weck, A. L. 179

Weicker, H. 292

Weinig, E. 292

Wildhirt, E. 338

Windorfer, A. 128

Winterhalter, K. H. 1194

Wischnevskii, A. 1278

Wittig 1052

Wolf-Heidegger, G. 521

Wollheim, E. 78

Wüstenberg, J. 1092

Zenker, R. 1278

Zimmermann, G. 1278

Zobl, H. 1194

Zuppinger, A. 1148, 1278

\section{Entpflichtungen}

Becker, H. 688

Delius, L. 688

Engelhardt, H. 912

Gerlach, J. 1244

Kirchhoff, H. 1309

Klaus, E. J. 798

Nordmeyer, K. 584

Reploh, H. 964

Schade, H. 1244

Schober, H. 522

Schoen, H. 77

Strauss, F. 1194

Sunder-Plaßmann, P. 850

Wernsdörfer, R. 1244

\section{Rücktritte}

Nicole, R. 912

\section{Geburtstage}

Albers, H. 1148

Bahner, F. 460

Balters, W. 521

Bayer, J. M. 964

Beckermann, F. 1194

Berning, H. 1052

Block, W. 460

Brenner, W. 1010

Brosch, F. 1148

Büssow, H. 688

Buff, H.-U. 522

Butenandt, A. 631, 638

Custodis, E. 638

Denecke, K. 232

Deuticke, H. J. 460

Döderlein, G. 1052

Domanig, E. 584

Dotzauer, G. 798

Feneis, H. 748

Finger, G. H. 406

Fuchsig, P. 460

Freiherr v. Gebsattel, V. E. 232

Gerlach, J. 638

Goerttler, K. 1010

Goetze, E. 338

Gödan, Hans 688

Hagen, J. 638

Harms, H. 232

Harnapp, G. O. 1052

Hartmann, G. 584

Herfert, O. 406

Heupke, W. 1052

Hohenner, K. 1010

Holzer, F. J. 460

Horatz, K. 78

Jaeger, R. G. 964

Jarmer, K. 522

Jeckeln, E. 964

Jess, A. 460

Jung, F. 1148

Käser, O. 128

Katner, W. 1092

Kirch, E. 522

Klaesi, J. 1092

Koch, G. 232

Koller, S. 180

Korth, C. 128

Kuntzen, H. 34

Lehnartz, E. 1310

Leicher, H. 584

Leinbrock, A. 1052

Leinzinger, E. 1244

Leischner, A. 1052 
Lentrodt, K. W. 638

Linnen, H. J. 912

Lutz, J. 128

Markees, S. 338

Markwalder, H. 1052

Maßhoff, W. 1092

Merke, F. 232

Meyer, A. 688

Mittelstraß, H. 1244

Moers, H. 460

Mueller, B. 78

Müller, E. 128

Müller, P. 1194

Mündnich, K. 180

Musger, A. 638

Neubert, R. 180

Nicole, R. 912

Nißler, K. 292

Oberdisse, K. 584

Obiditsch-Mayer, Irmtraud 1310

Ortmann, R. 912

Patzelt, K. 78

Penzholz, H. 748

Pfefferkorn, G. 688 v. Reckow, J. F. 1148

Reindell, H. 584

Reiser, K.-A. 1052

Rieder, W. 1010

Rieger, H. 912

Ruska, H. 1148

Salzer, G. 912

Schaede, A. 460

Schleyer, F. 688

Schnelle, H.-H. 1092

Schönfeld, W. 1010

Schriever, H. 1052

Schütte, E. 1194

Schulemann, W. 964

Schulze, W. 1278

Schwarz, H. 1278

Siede, W. 1244

Siedek, H. 912

Sommer, F. 292

Spreter, Th. 460

Steinmann, B. 964

Stender, A. 748

Stodtmeister, R. 128

Störring, G. 688

Strauss, H. 522
Tönnis, W. 1244

Trostdorf, E. 34

von Uexküll, Thure 522

Walter, K. 1244

Walther-Büel, H. 180

Weber, G. 78

Wernsdörfer, R. 688

Wiskott, A. 460

Wüstenberg, J. 912

Zdansky, E. 1194

Zenker, R. 406

Zimmer, E.-A. 128

Zutt, J. 1309

\section{Todesfälle}

Amreich, I. A. 78

Böhler, L. 292, 792

Bragard, K. 1310

Dennig, H. 406

Fischer, L. 180, 454

Fleisch, A. 1244

Friemann, W. 34
Giese, W. 912

Gotsch, K. 180

Hammer, H. 522

Hasche, E. 1278

Heiß, J. 1310

Heuser, H. 338

Hoede, K. 1244

Hoeppli, R. J. C. 688

Hoessly, G.-F. 584

Huber, H. 964

Kalk, H. O. 406, 680

Kauffmann, F. 1244

Kirch, E. 850

Freiherr v. Kress, H. 638

Küntscher, G. 78, 515

Memmesheimer, A. M. 292

Rakov, A. I. 292

Richards, D. W. 748

Lord Rosenheim, M. 333

Schwarzenburg, Ch. 34

Seelemann, K. 34

Strnad, F.-J. 1092

Südhof, H. 1278

Sturm, A. 1278

Weber, G. 1310 
(23) Musshoff, K., K. H. Strickstrock, L. Boutis: Indikation zur Behandlung der Lymphogranulomatose. Strahlentherapie 133 (1967), 161.

(24) Naqvi, M. S., L. Burrows, A. E. Kark: Lymphoma of the gastrointestina tract: prognostic guides based on 162 cases. Ann. Surg. 170 (1969), 221

(25) Pomeranz, A. A.: Hodgkin's disease of the stomach. Mount Sinai J. Med. 18 (1952), 358.

(26) Portmann, U. V., E. F. Dunne, J. B. Hazard: Manifestations of Hodgkin's disease of the gastrointestinal tract. Amer. J. Roentgenol. 72 (1954), 772. (27) Prosnitz, L. R., S. B. Nuland, M. M. Kligerman: Role of laparotomy and splenectomy in the management of Hodgkin's disease. Cancer (Philad.) 29 (1972), 44.

(28) Reinhardt, M., G. Ehrhardt: Die
Manifestation lvmphatischer Tumoren am Magen. Dtsch. Z. Verdau.- u. Stoffwechselkr. 24 (1965), 185.

(29) Rösch, W., H. Fuchs: Diffuse lym phatische Hyperplasie, Lymphom und

Pseudolymphom des Magen-Darm Trakts. Dtsch. med. Wschr. 97 (1972), 878.

(30) Rösch, W., G. Hartwich, K. Elster, R. Ottenjann: Gastric lymphoma. Endoscopy 3 (1971), 28.

(31) Rosenberg, S. A., H. D. Diamond, B. Jaslowitz, L. F. Craver: Lymphosarcoma: a review of 1269 cases. Medicine (Baltimore) 40 (1961), 31.

(32) Rosenberg, S. A.: Report of the Committee on Staging of Hodgkin's disease. Cancer Res. 26 (1966), 1310

(33) Rosenberg, S. A.: A critique of the value of laparotomy and splenectomy in the evaluation of patients with
Hodgkin's disease. Cancer Res. 31 (1971), 1737.

(34) Rosenberg, S. A., M. Boiron, V. T DeVita, R. E. Johnson, B. J. Lee, J. E. Ultmann, M. Viamonte: Report of the Committee on Hodgkin's disease stagin procedures. Cancer Res. 31 (1971), 1862. (35) Sandick, H.: Hodgkin's disease involving the stomach. Gastroenterology 15 (1950), 135.

(36) Salmela, H.: Lymphosarcoma of the stomach. A clinical study of 39 cases. Acta chir. scand. 134 (1968), 567.

Dr. K. Höffken, Dr. G. Hornung, Dr. U. Bruntsch,

Prof. Dr. G. Becker, Prof. Dr. C. G. Schmidt

Innere Klinik und Poliklinik (Tumorforschung) der Ruhr-Universität, Klinikum Essen

43 Essen, Hufelandstr. 55
(37) Schembra, F. W : Uber Lymphogranulomatose des Magens. Fortschr. Röntgenstr. 84 (1956), 756

(38) Schmidt, C. G.: Klinik und Chemotherapie der Lymphogranulomatose.

Z. Krebsforsch., im Druck.

(39) Thorbjarnarson, B., J. M. Beal, J. M. Pearce: Primary malignant lymphoid tumors of the stomach. Cancer (Philad.) 9 (1956), 712

(40) Warren, S., C. R. Lulenski: Primary, solitary lymphoid tumors of the gastrointestinal tract. Ann. Surg. 115 (1942), 1.
Dtsch. med. Wschr. 98 (1973), 152-157

(c) Georg Thieme Verlag, Stuttgart

\section{Stimulierbarkeit der TSH-Sekretion durch TRH bei autonomen Adenomen der Schilddrüse*}

\author{
C. R. Pickardt, F. Erhardt, J. Grüner, H. G. Heinze, K. Horn und P. C. Scriba \\ II. Medizinische Klinik (Direktor: Prof. Dr. E. Buchborn) und Klinik und Poliklinik für Radiologie \\ (Direktor: Prof. Dr. J. Lissner) der Universität München
}

\section{Die Stimulierbarkeit der TSH-Sekretion durch $200 \mu \mathrm{g}$ TRH intravenös} wurde bei 31 Patienten mit autonomen Adenomen der Schilddrüse untersucht: Bei vier euthyreoten Patienten mit kompensierten autonomen Adenomen waren die Serum-TSH-Spiegel normal zu stimulieren. Bei sechs Patienten mit einem dekompensierten autonomen Adenom bestand eine Hyperthyreose mit erhöhten Serum- $\mathrm{T}_{4}$-Spiegeln. Die TSH-Sekretion war in Übereinstimmung mit dem szintigraphischen Bild supprimiert und durch TRH nicht stimulierbar. Vierzehn Patienten hatten dekompensierte autonome Adenome und normale $\mathrm{T}_{4}$-Spiegel. Die fehlende Stimulierbarkeit der TSH-Sekretion bestätigte in allen Fällen den indirekten szintigraphischen Hinweis auf die Suppression der endogenen TSH-Sekretion. Bei fünf Patienten dieser Gruppe bestand eine $T_{3}$-Thyreotoxikose; bei den verbleibenden neun Patienten könnte die Ursache für die Suppression der endogenen TSH-Sekretion eine phasenhafte Hyperthyreose oder die autonome Schilddrüsenhormonsekretion im euthyreoten Bereich sein. Bei sieben weiteren Patienten wurden Übergänge zwischen verschiedenen funktionellen Stadien des autonomen Adenoms der Schilddrüse beobachtet. Die Ergebnisse erlauben die Beschreibung eines funktionellen Zyklus des autonomen Adenoms, von der blanden Struma nodosa über das kompensierte autonome Adenom zu Übergangsformen und zum dekompensierten autonomen Adenom der Schilddrüse mit und "ohne " Hyperthyreose. Das Fehlen der Stimulierbarkeit der TSH-Sekretion ist ein wichtiges Kriterium für die Indikationsstellung zur Therapie des autonomen Adenoms.

* Mit Unterstützung der Deutschen Forschungsgemeinschaft (SFB 51)
Ability to stimulate TSH secretion by TRH in autonomous thyroid adenoma

The TSH response to stimulation with $200 \mu \mathrm{g}$ TRH, given intravenously, was studied in 31 patients with autonomous thyroid adenoma. In four patients thyroid hormone production by the autonomous nodule was normal and TSH secretion was not suppressed, as indicated by indirect scanning ( $T_{3}$ suppression test) and by direct radioimmunological determination of TSH. Six patients with hyperthyroidism had elevated $\mathrm{T}_{4}$ levels without ${ }^{131}$ I uptake in the extranodular tissue, the basal TSH levels were reduced, and there was no response to TRH stimulation. In 14 patients with toxic nodules and nonfunctioning extranodular tissue normal $\mathrm{T}_{4}$ levels were found. Absent response to TRH stimulation confirmed the indirect scanning evidence that endogenous TSH had been suppressed by the toxic nodule in all of the 14 patients. Five patients of this group were found to have $T_{3}$ thyrotoxicosis. It may be assumed that in the remaining nine patients the intermittent phases of

hyperthyroidism or TSH suppression was due to the autonomously sustained euthyroid hormone levels. In a further seven patients with autonomous adenoma there were transitional stages between different functional stages of the autonomous thyroid adenoma. These findings make it possible to describe a functional cycle of the autonomous adenoma. Absent TSH response to TRH stimulation is of practical importance when choosing suitable therapeutic measures for patients with "toxic" adenoma of the thyroid. 
Seit der Synthese des "thyrotropin releasing hormone " $=\mathrm{TRH}(2,3)$ und der Einführung der radioimmunologischen TSH-Bestimmung im Serum $(5,14,21)$ ist es möglich, nach TRH-Stimulation der endogenen TSHSekretion primäre Störungen der Schilddrüsenfunktion auf hypophysärer Ebene abzulesen (17). Da die TSHSpiegel bei primärer Hypothyreose um mehr als eine Zehnerpotenz erhöht sind und da die Schilddrüsenüberfunktion die hypophysäre TSH-Sekretion TRH-refraktär supprimiert, stellt die diagnostische TRH-Belastung ein analytisches Verstärkerprinzip zur Erkennung primärer Schilddrüsenfunktionsstörungen dar.

Beim autonomen Adenom der Schilddrüse erlaubten bisher nur indirekte szintigraphische Kriterien, die durch die autonome Schilddrüsenhormonsekretion veränderte TSH-Sekretion zu beurteilen. Definitionsgemäß gilt für das kompensierte autonome Adenom, daß die Radiojodaufnahme des TSH-unabhängigen Schilddrüisenareals im Gegensatz zum übrigen Schilddrüsengewebe durch exogene Trijodthyroninzufuhr nicht zu supprimieren ist ( 1 , 8). Das dekompensierte autonome Adenome stellt sich dagegen im szintigraphischen Bild als zirkumskripter radiojodspeichernder Knoten dar, neben dem das Restgewebe keine Isotopenspeicherung mehr zeigt. Dieser Befund ist ein indirekter nuklearmedizinischer Nachweis der Suppression der endogenen TSH-Sekretion, da die exogene TSH-Zufuhr zu einer Isotopenaufnahme auch im restlichen funktionsfähigen Schilddrüsengewebe führt (1).

Mit der Frage nach der Übereinstimmung von indirektem szintigraphischen Hinweis auf eine Suppression der endogenen TSH-Sekretion und fehlender Stimulierbarkeit der TSH-Sekretion bei direkter Bestimmung der Serum-TSH-Spiegel wurden von uns 31 Patienten mit autonomen Adenomen der Schilddrüse untersucht.

\section{Material und Methoden}

Synthetisches "thyrotropin releasing hormone " (TRH): Pyro-Glutamyl-Histidyl-Prolinamid der Hoechst AG (Hoe 500 11).

TRH-Belastungstest: Nach Entnahme einer Blutprobe zur Bestimmung der basalen TSH-Spiegel und der peripheren Schilddrüsenhormonspiegel wurden $200 \mu \mathrm{g}$ TRH schnell intravenös injiziert. Nach 30 Minuten erfolgte die zweite Blutentnahme zur Bestimmung des Anstiegs der Serum-TSH-Spiegel. Die Serumproben wurden bei $-37^{\circ} \mathrm{C}$ bis zur Bestimmung aufbewahrt.

Radioimmunologische Serum-TSH-Bestim.mung: Die TSH-Bestimmung erfolgte nach der Doppelantikörpermethode von Odell und Mitarbeitern $(14,15,21)$ mit den Modifikationen von Erhardt und Mitarbeitern (5) unter Verwendung von humanem Thyreotropin zur ${ }^{125} \mathrm{~J}$-Markierung und dem Antikörper vom Kaninchen gegen humanes TSH der National Pituitary Agency, National Institute of Health, Bethesda, USA, und unter Verwendung des "human thyrotropin research standard $A$ " (h-TSH-RSA) des National Institute for Medical Research, London.

Der Normalbereich der basalen TSH-Spiegel für diese Methode (16) liegt zwischen 1,4 und $7,1 \mu \mathrm{E} / \mathrm{ml}(\overline{\mathrm{x}} \pm 2 \mathrm{~s}, \log )$.

Der Normalberich des TSH-Anstiegs (16) nach Stimulation mit 200 แg TRH ( $\triangle \mathrm{TSH} 30 \mathrm{~min}=\mathrm{TSH} 30 \mathrm{~min}-\mathrm{TSH}$ basal $)$ beträgt 2,73 bis $23,6 \mu \mathrm{E} / \mathrm{ml}(\overline{\mathrm{x}} \pm 2 \mathrm{~s}, \log )$.

Gesamt-Thyroxin-Bestimmung im Serum $\left(\mathrm{T}_{4}\right)$ : Die Bestimmung der Gesamt- ${ }_{4}$-Spiegel erfolgte nach dem Prinzip der kompetitiven Proteinbindungsanalyse und wurde nach dem automatisierten Verfahren von Horn und Mitarbeitern $(7,9)$ durchgeführt. Der Normalbereich beträgt 3,1 bis $6,6 \mu \mathrm{g} \mathrm{T}_{4}-\mathrm{Jod} / 100 \mathrm{ml}(\overline{\mathrm{x}} \pm 2 \mathrm{~s}, \log$.) bzw.
4,7 bis $10,1 \mu \mathrm{g} \mathrm{T}_{4} / 100 \mathrm{ml}$. Um der besseren Vergleichbarkeit willen mit den $\mathrm{PB}^{127} \mathrm{I}$-Werten werden hier die $\mathrm{T}_{4}$-J-Spiegel angegeben.

$T_{3}$-in-vitro-Test: Der $\mathrm{T}_{3}$-in-vitro-Test wurde nach dem automatisierten Verfahren von Horn und Mitarbeitern (10) durchgeführt. Das Ergebnis wird als sogenanntes freies $\mathrm{T}_{3^{-125} \mathrm{~J}}$ in Prozent des zugesetzten ${ }^{125} \mathrm{~J}$-markierten Trijodthyronins angegeben. Normalbereich $=32$ bis $42 \%(\bar{x} \pm 2 s)$.

Index des freien Schilddrüsenhormons: Durch Multiplikation des Gesamt-Schilddrüsenhormon-Spiegels $\left(\mathrm{T}_{4}-\mathrm{J}\right)$ mit dem Ergebnis des $\mathrm{T}_{3}$-in-vitro-Tests erhält man einen Index, welcher der Konzentration an freiem Schilddrüsenhormon entspricht $(19,20)$. Errechneter Normalbereich $=1,33$ bis $2,50 \mu \mathrm{g} / 100 \mathrm{ml}(\overline{\mathrm{x}} \pm 2 \mathrm{~s})$.

Nuklearmedizinische Diagnostik: Nach Durchführung des üblichen Radiojodspeicherungstests mit Beurteilung von Speicherungshöhe und Radiojodumsatz wurde zum Nachweis eines kompensierten autonomen Adenoms der L-Trijodthyronin-Suppressionstest durchgeführt. Dabei erhielten die Patienten vor Beginn der Untersuchung 7 Tage lang dreimal $20 \mu g$ Trijodthyronin und die gleiche Dosis während der 3 nachfolgenden Untersuchungstage (8). Zum Nachweis eines dekompensierten autonomen Adenoms wurde die Radiojodspeicherungsdiagnostik nach zwei- bis dreitägiger Stimulation der Schilddrüse durch exogenes TSH (Thyreostimulin ${ }^{\circledR}$, Organon) mit täglich 5 bis $10 \mathrm{IE}$ intramuskulär wiederholt $(1,4,20)$.

In Einzelfällen, bei denen die Radiojodspeicherungskinetik nicht von diagnostischem Interesse war, wurde nach intravenöser Verabreichung von Technetiumpertechnetat $\left(^{99 m} \mathrm{TcO}_{4}{ }^{-}\right)$die Schilddrüsenszintigraphie durchgeführt. Dabei wurde die $\mathrm{T}_{3}$-Suppression bzw. die TSH-Stimulation in oben beschriebener Weise vorgenommen. In die Bewertung ging neben der qualitativen Beurteilung der Szintigraphie auch die quantitative Verschiebung des Aktivitätsverhältnisses vom autonomen Adenom zum normal regulierten Schilddrüsengewebe ein.

Tab. 1. Stimulation der Serum-TSH-Spiegel bei 4 Patienten mit kompensierten autonomen Adenomen. Serum-TSH-Spiegel vor und nach Stimulation durch TRH, TSH-Anstieg zur 30. Minute ( $\triangle \mathrm{TSH}$ $30 \mathrm{~min})$ und Schilddrüsenhormonspiegel $\left(\mathrm{T}_{4}-\mathrm{J}, \mathrm{T}_{3}\right.$-in-vitro- $\Gamma$ est, Index des freien Schilddrüsenhormons)

\begin{tabular}{|c|c|c|c|c|c|c|}
\hline Patienten & basal & $30 \mathrm{~min}$ & $\begin{array}{l}\vec{I} \cdot \Xi \\
\tilde{E} \\
<0\end{array}$ & 5 & 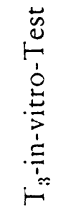 & 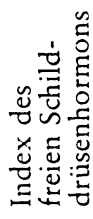 \\
\hline R.K. ठ̀ & 1,1 & 6,0 & 4,9 & 4,0 & 31,6 & $.1,27$ \\
\hline Z.E. $\delta$ & 1,9 & 8,3 & 6,4 & 3,6 & 28,0 & 1,01 \\
\hline S.M. q & 2,1 & 9,4 & 7,3 & 3,0 & 27,9 & 0,84 \\
\hline v. L.B. $q$. & 1,2 & 5,6 & 4,4 & 3,7 & 28,8 & 1,07 \\
\hline
\end{tabular}

\section{Ergebnisse}

Kompensierte autonome Adenome. Bei vier Patienten mit einem kompensierten autonomen Adenom der Schilddrüse (Tabelle 1) waren die $\mathrm{T}_{4^{-}}$J-Spiegel im Serum mit einem Mittelwert von 3,58 $\mathrm{gg} / 100 \mathrm{ml}$ normal. Definitionsgemäß ergab die nuklearmedizinische Diagnostik des kompensierten autonomen Adenoms der Schilddrüse keinen Hinweis auf eine endogene Suppression der TSHSekretion. Dementsprechend waren die TSH-Spiegel durch TRH zur 30. Minute normal stimulierbar.

Dekompensierte autonome Adenome. Bei den dekompensierten autonomen Adenomen $(n=20)$ ergab sich durch die Berücksichtigung der $\mathrm{T}_{4}$-J-Spiegel im Serum und des Ergebnisses des $\mathrm{T}_{3}$-in-vitro-Tests die Unterteilung in zwei Gruppen (12): dekompensierte autonome 
Adenome mit Hyperthyreose $(n=6)$ und dekompensierte autonome Adenome »ohne Hyperthyreose" $(\mathrm{n}=$ 14).

Tab. 2. Stimulation der Serum-TSH-Spiegel bei 6 Patienten mit dekompensierten autonomen Adenomen mit Hyperthyreose. SerumTSH-Spiegel vor und nach Stimulation durch TRH, TSH-Anstieg zur 30 . Minute ( $\triangle \mathrm{TSH} 30 \mathrm{~min}$ ) und Schilddrüsenhormonspiegel ( $\mathrm{T}_{4}-\mathrm{J}, \mathrm{T}_{3}$-in-vitro-Test, Index des freien Schilddrüsenhormons)

\begin{tabular}{|c|c|c|c|c|c|c|}
\hline Patienten & basal & $30 \mathrm{~min}$ & 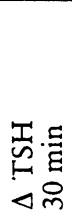 & $\stackrel{F}{F}$ & 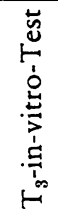 & 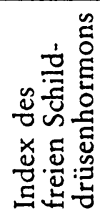 \\
\hline G. J. $q$ & $<1,0$ & 1,2 & 0,2 & 9,0 & 69,9 & 6,29 \\
\hline B.R. $q$ & $<1,0$ & $<1,0$ & 0 & 7,8 & 50,5 & 3,94 \\
\hline F. G. $\hat{\sigma}$ & $<1,0$ & $<1,0$ & 0 & 7,5 & 45,5 & 3,41 \\
\hline G. A. $\quad \hat{o}$ & 1,1 & 1,0 & 0 & 11,0 & 41,7 & 4,59 \\
\hline 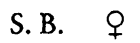 & $<1,0$ & $<1,0$ & 0 & 8,3 & 48,4 & 4,02 \\
\hline 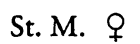 & 1,6 & 1,8 & 0,2 & 6,6 & 41,6 & 2,75 \\
\hline
\end{tabular}

1. Dekompensierte autonome Adenome mit Hyperthyreose. - Bei sechs Patienten mit dekompensiertem autonomen Adenom der Schilddrüse (Tabelle 2) waren die $\mathrm{T}_{4}$-J-Spiegel im Mittel auf $8,25 \mu \mathrm{g} / 100 \mathrm{ml}(\mathrm{x}, \mathrm{log})$ erhöht. Die basalen TSH-Spiegel dieser Patienten lagen in vier Fällen unter der Nachweisbarkeitsgrenze der $\mathrm{Me}$ thode $(<1,0 \mu \mathrm{E} / \mathrm{ml})$ und waren in zwei Fällen mit 1,1 bzw. 1,6 $\mu \mathrm{E} / \mathrm{ml}$ niedrig-normal. Entsprechend der Hyperthyreose waren die TSH-Spiegel in allen Fällen durch TRH praktisch nicht stimulierbar. Die fehlende Stimu-

Tab. 3. Stimulation der Serum-TSH-Spiegel bei 14 Patienten mit dekompensierten autonomen Adenomen ohne Hyperthyreose. Serum-TSH-Spiegel vor und nach Stimulation durch TRH, TSH-Anstieg zur 30 . Minute ( $\triangle$ TSH $30 \mathrm{~min}$ ) und Schilddrüsenhormonspiegel $\left(T_{4}-J\right.$ bzw. PB $^{127} I, T_{3}$-in-vitro-Test, Index des freien Schilddrüsenhormons)

\begin{tabular}{|c|c|c|c|c|c|c|}
\hline Patienten & basal & $30 \mathrm{~min}$ & $\begin{array}{l}\vec{T} \cdot E \\
\stackrel{H}{H} \\
\triangleleft 0\end{array}$ & 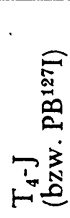 & 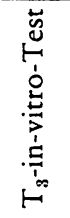 & 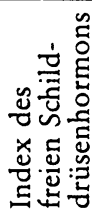 \\
\hline H.E. $\quad$ & $<1,0$ & $<1,0$ & 0 & 4,9 & 44,2 & 2,17 \\
\hline D.F. $\widehat{\sigma}$ & $<1,0$ & $<1,0$ & 0 & 3,8 & 35,5 & 1,35 \\
\hline B. H. $\hat{\sigma}$ & $<1,0$ & $<1,0$ & 0 & 3,1 & 48,3 & 1,50 \\
\hline B. M. 우 & 1,1 & 1,2 & 0,1 & 5,0 & 39,2 & 1,96 \\
\hline M.E. $\delta \hat{~}$ & $<1,0$ & $<1,0$ & 0 & 4,0 & 35,1 & 1,40 \\
\hline S.P. $\delta$ & $<1,0$ & $<1,0$ & 0 & $(5,4)$ & 37,3 & $(2,01)$ \\
\hline W. G. $q$ & $<1,0$ & $<1,0$ & 0 & 3,6 & 42,5 & 1,53 \\
\hline M.E. $q$ & 3,7 & 4,6 & 0,9 & $(6,8)$ & 26,0 & $(1,77)$ \\
\hline S.E. $\quad$ ㅇ & $<1,0$ & $<1,0$ & 0 & 4,4 & 38,7 & 1,70 \\
\hline W.M. ㅇ & 2,3 & 1,5 & 0 & 3,8 & 34,9 & 1,33 \\
\hline B. A. $q$ & 1,5 & $<1,0$ & 0 & 6,0 & 31,6 & 1,90 \\
\hline O.A. 우 & 1,1 & 1,1 & 0 & 4,6 & 32,4 & 1,49 \\
\hline S.B. $q$ & 1,9 & 1,8 & 0 & 5,2 & 35,9 & 1,87 \\
\hline Z.H. $q$ & $<1,0$ & $<1,0$ & 0 & 3,7 & 26,2 & 0,97 \\
\hline
\end{tabular}

lierbarkeit der TSH-Spiegel bei peripherem Schilddrüsenhormonüberschuß deckt sich mit dem indirekten szintigraphischen Hinweis auf die Suppression der endogenen TSH-Sekretion.

2. Dekompensierte autonome Adenome "ohne Hyperthyreose«. - Bei 14 Patienten mit szintigraphisch dekompensierten autonomen Adenomen (Tabelle 3) konnte an den konventionellen Laboratoriumsbefunden (17) keine Schilddrüsenüberfunktion abgelesen werden. Die $\mathrm{T}_{4}$-J-Spiegel waren mit einem Mittelwert von $4,13 \mu \mathrm{g}$ pro $100 \mathrm{ml}$ normal, desgleichen der Index des freien Schilddrüsenhormons mit $1,64 \pm 0,37 \mu \mathrm{g} / 100 \mathrm{ml}$. Diese Patienten waren jedoch wegen ihrer Beschwerden zur Behandlung eingewiesen worden, so daß sich hier bereits eine Diskrepanz zwischen der Symptomatik und den gemessenen peripheren Schilddrüsenhormonspiegeln abzeichnete.

Die basalen TSH-Spiegel dieser 14 Patienten lagen im Mittel unter der Nachweisbarkeitsgrenze $(<1,0 \mu \mathrm{E} / \mathrm{ml})$ und waren bei allen Kranken durch TRH nicht zu stimulieren. Die Befunde der radio-immunologischen SerumTSH-Bestimmung nach TRH-Stimulation entsprechen in diesen Fällen also ebenfalls dem indirekten szintigraphischen Hinweis auf eine Suppression der endogenen TSHSpiegel.

Sonderfälle und Übergangsformen (Tabeile 4). Bei P. E., S. S. und M. A. zeigte das szintigraphische Bild der Schilddrüse nur eine schüttere Radiojodspeicherung des Restgewebes, so daß hier szintigraphisch bereits der Verdacht auf ein fast dekompensiertes autonomes Adenom bestand. Die Schilddrüsenhormonwerte dieser Patienten waren normal. Die radioimmunologische TSH-Bestimmung mit fehlender Stimulierbarkeit der TSH-Spiegel bestätigte den szintigraphischen Verdacht und ließ ein Übergangsstadium von einem kompensierten in ein dekompensiertes autonomes Adenom vermuten.

Bei Z. H. fanden sich multilokuläre autonome Adenome in einer schütter speichernden Schilddrüse. Die Schilddrüsenhormonwerte waren erhöht, die TSH-Spiegel durch TRH nicht stimulierbar. Dieser Befund wies ebenfalls auf eine beginnende Dekompensation der autonomen Adenome hin, die schon eine Hyperthyreose verursachten.

Bei F. I. und B. T. war szintigraphisch ein dekompensiertes autonomes Adenom nachgewiesen worden. Bei F. I. war der Index des freien Schilddrüsenhormons erniedrigt, bei B. T. normal. Bei beiden Patienten waren die TSH-Spiegel durch TRH normal zu stimulieren. Diese Befunde lassen vermuten, daß im ersten Fall die TRHBelastung zu einem Zeitpunkt durchgeführt wurde, an dem bei peripherem Schilddrüsenhormonmangel die pharmakologische TRH-Dosis die endogene TSH-Suppression nach phasenhafter $\mathrm{Hy}-$ perthyreose durchbrechen konnte, und daß im zweiten Fall die spontane endogene TSH-Sekretion jedoch noch nicht wieder ausreichend war, um die Restschilddrüse zu stimulieren.

Bei P. R. wurde bei der ersten Untersuchung szintigraphisch ein dekompensiertes autonomes Adenom festgestellt, die peripheren Schilddrüsenhormonspiegel waren zu diesem Zeitpunkt erniedrigt, die TSH-Spiegel wurden nicht untersucht. Vier Monate später zeigte sich szintigraphisch eine homogen speichernde Struma nodosa. Die TSH-Spiegel waren jetzt in Ubereinstimmung mit dem Szintigramm normal stimulierbar (Abbildung 1). Durch Suppressionstest konnte das zu diesem Zeitpunkt maskierte, voll kompensierte autonome Adenom szintigraphisch dargestellt werden ${ }^{1}$.

1 Wir danken Dr. L. Schmid, Stiftsklinik Augustinum, München, für die Úberweisung der Patientin und für die zur Verfügung gestellten Untersuchungsergebnisse. 
Tab. 4. Sonderfälle und Ubergangsformen der autonomen Adenome der Schilddrüse bei 7 Patienten. Serum-TSH-Spiegel vor und nach Stimulation durch TRH, TSH-Anstieg zur 30. Minute ( $\Delta$ TSH $30 \mathrm{~min}$ ) und Schilddrüsenhormonspiegel $\left(\mathrm{PB}^{127} \mathrm{I}\right.$ bzw. $\mathrm{T}_{4}-\mathrm{J}, \mathrm{T}_{3}$-in-vitro-Test, Index des freien Schilddrüsenhormons)

\begin{tabular}{|c|c|c|c|c|c|c|c|}
\hline Patienten & \multicolumn{2}{|c|}{$\mathrm{TSH} \mu \mathrm{E} / \mathrm{ml}$} & $\begin{array}{l}\Delta \mathrm{TSH} \\
30 \mathrm{~min}\end{array}$ & $\begin{array}{c}\mathrm{PB}^{127} \mathrm{I} \\
\left(\text { bzw. } \mathrm{T}_{4}-\mathrm{J}\right)\end{array}$ & $\begin{array}{l}T_{3} \text {-in-vitro- } \\
\text { Test }\end{array}$ & $\begin{array}{l}\text { Index des } \\
\text { freien } \\
\text { Schilddrüsen- } \\
\text { hormons }\end{array}$ & szintigraphische Diagnose \\
\hline P.E. $\quad$ Q & 2,8 & 1,6 & 0 & 3,3 & 31,6 & 1,04 & fast dekompensiertes autonomes Adenom \\
\hline S.S. & 2,2 & 2,0 & 0 & 4,9 & 43,4 & 2,13 & $\begin{array}{l}\text { fast dekompensiertes multilokuläres } \\
\text { autonomes Adenom }\end{array}$ \\
\hline M.A. $q$ & $<1,0$ & $<1,0$ & 0 & 4,5 & 31,3 & 1,41 & fast dekompensiertes autonomes Adenom \\
\hline Z.H. ठ̀ & $<1,0$ & $<1,0$ & 0,3 & 10,3 & 41,2 & 4,24 & $\begin{array}{l}\text { fast dekompensiertes multilokuläres } \\
\text { autonomes Adenom }\end{array}$ \\
\hline F.I. $\quad$ q & 1,9 & 8,4 & 6,5 & 2,8 & 29,6 & 0,83 & dekompensiertes autonomes Adenom \\
\hline B. T. $\delta$ & 2,2 & 9,6 & 7,4 & 3,7 & 39,7 & 1,47 & dekompensiertes autonomes Adenom \\
\hline P.R. $\quad q$ & & & & $(2,0)$ & 30,8 & 0,62 & dekompensiertes autonomes Adenom \\
\hline & 0,8 & 5,9 & 5,1 & $(2,2)$ & 32,9 & 0,72 & $\begin{array}{l}\text { vier Monate später: } \\
\text { homogen speichernde Struma nodosa, } \\
\text { autonomes Adenom aber durch } \\
\mathrm{T}_{3} \text {-Suppression nachweisbar }\end{array}$ \\
\hline
\end{tabular}

\section{Diskussion}

Die hier untersuchten Patienten mit kompensiertem autonomen Adenom der Schilddrüse waren euthyreot und ihre TSH-Spiegel durch TRH normal zu stimulieren. Entsprechend dem szintigraphischen Bild ist die autonome Schilddrüsenhormonbildung in dem TSH-unabhängigen Areal offenbar zu gering, um bereits oder noch eine Suppression der endogenen TSH-Spiegel zu bewirken.

Bei autonomen Adenomen, die nach dem szintigraphischen Bild Hinweise auf eine beginnende Dekompensation zeigten, waren entsprechend dem szintigraphischen Bild die TSH-Spiegel nicht mehr zu stimulieren, ein Befund, der für Patienten sowohl mit erhöhten als auch mit normalen, konventionell gemessenen Schilddrüsenhormonspiegeln gilt. Die fehlende Stimulierbarkeit der TSH-Spiegel durch TRH bei autonomen Adenomen mit Hyperthyreose (12), das heißt mit erhöhtem Schilddrüsenhormonspiegel nach konventioneller Messung (17), zeigte in allen untersuchten Fällen eine präzise Ưberein- stimmung mit dem szintigraphischen Bild des dekompensierten autonomen Adenoms.

Die Beurteilung der Schilddrüsenfunktion bei dekompensierten autonomen Adenomen "ohne Hyperthyreose " bereitet bekanntlich Schwierigkeiten. Bei unseren $14 \mathrm{~Pa}$ tienten waren die TSH-Spiegel in allen Fällen in Úbereinstimmung mit dem szintigraphischen Bild nicht stimulierbar. Eine Hyperthyreose war anhand der $\mathrm{T}_{4}$-J-Spiegel und nach dem Index des freien Schilddrüsenhormons in keinem dieser Fälle festzustellen. Bei fünf von zehn dieser Patienten waren aber erhöhte Trijodthyroninspiegel (6, 11) nachzuweisen. Diese fünf Patienten sind also doch als hyperthyreot anzusehen ( $T_{3}$-Hyperthyreose). Bei den übrigen neun Patienten, von denen fünf keinen nachweisbar erhöhten Trijodthyroninspiegel hatten, muß offenbleiben, ob eine phasenhafte Hyperthyreose zu einer Suppression der TSH-Spiegel geführt hatte. Für die Annahme eines phasenhaften Verlaufs der Hyperthyreose bei dekompensierten autonomen Adenomen spricht tatsächlich in vielen Fällen die klinische Beobachtung $(1,17,22)$ : Die
Abb. 1. Spontaner Übergang eines dekompensierten autonomen Adenoms in ein maskiertes kompensiertes autonomes Adenom der Schilddrüse (Patientin P. R.). 17.2. 1972: dekompensiertes autonomes Adenom, gesichert durch exogenen TSH-Stimulationstest (14. 4. 1972). Vier Monate

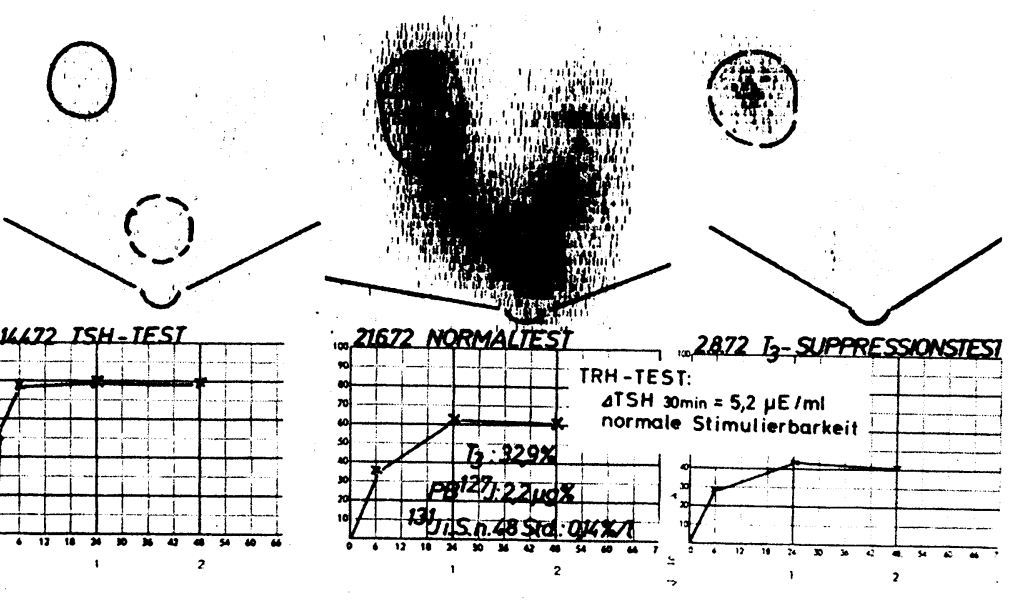

später homogene Speicherung in einer Struma nodosa mit Schilddrüsenhormonmangel. Nachweis des (maskierten) kompensierten autonomen Adenoms durch den Trijodthyronin-Suppressionstest. Die TSH-Spiegel waren durch TRH normal stimulierbar. (Ein weiteres, sich entwickelndes autonomes Adenom im unteren rechten Schilddrüsenpol ist nicht auszuschließen.) 
Patienten beschreiben zum Teil deutliche Phasen mit Zeichen einer vermehrten peripheren Schilddrüsenhormonwirkung (zum Beispiel Tachykardie, Gewichtsabnahme). Möglicherweise blieb die TSH-Sekretion dann durch die autonome Schilddrüsenhormonsekretion im euthyreoten Bereich weiterhin supprimiert, da der physiologische Sekretionsreiz für TSH (Absinken der Schilddrüsenhormonspiegel unter die Norm) fehlt. - Eine andere Erklärungsmöglichkeit für die endogene TSH-Suppression wäre eine Ruhigstellung der hypophysären thyreotropen Funktion durch eine autonome Schilddrüsenhormonsekretion, die immer im euthyreoten Bereich blieb, aber ebenfalls einen Fortfall des physiologischen Sekretionsreizes für TSH bewirken könnte.

\section{Entwicklungsmöglichkeiten des autonomen Adenoms}

Eine schematische Darstellung der Entwicklungsmöglichkeiten des autonomen Adenoms gibt Abbildung 2. Bei der Mehrzahl der Patienten mit blander Struma nodosa (18) sind die peripheren Schilddrüsenhormonspiegel und die TSH-Spiegel nach TRH-Stimulation normal (Stadium 1). Der erste Schritt zur Entstehung eines autonomen Adenoms aus der Struma nodosa ist die TSH-unabhängige Schilddrüsenhormonbildung in einem oder mehreren Strumaknoten, das heißt die Autonomisierung eines zirkumskripten Schilddrüsenareals. Der Úbergang von der blanden Struma nodosa zum autonomen Adenom wurde von Miller und Mitarbeitern (13) beschrieben. Im Stadium des unkomplizierten kompensierten autonomen Adenoms sind die Schilddrüsenhormonspiegel noch normal, und die TSH-Sekretion ist durch TRH ebenfalls normal stimulierbar; die Patienten sind euthyreot (Stadium 2).

Das Verhalten der Schilddrüsenhormonspiegel und der TSH-Spiegel im Übergang vom kompensierten zum dekompensierten autonomen Adenom läßt sich wegen der Zufälligkeit des Untersuchungszeitpunktes am besten an Einzelfällen darstellen. Die Untersuchungsergebnisse bei Patienten mit dekompensiertem autonomen Adenom legen die Vermutung nahe, daß eine autonome Schilddrüsenhormonsekretion bereits im euthyreoten Bereich zu einer endogenen Suppression der TSH-Sekretion führen kann, da der physiologische Sekretionsreiz für TSH fortfällt. In anderen Fällen ist der Anstieg der peripheren Schilddrüsenhormone in den hyperthyreoten Bereich die Ursache für die Suppression der TSH-Sekretion. Folglich sind im Ubergang vom kompensierten zum dekompen- sierten autonomen Adenom in Abhängigkeit vom Untersuchungszeitpunkt verschiedene Befundkonstellationen zu erwarten:

1. Bei szintigraphisch weitgehend dekompensiertem autonomem Adenom fanden wir klinisch eine Euthyreose und normale Schilddrüsenhormonspiegel im Serum, während die TSH-Sekretion durch TRH nicht mehr stimulierbar war. Die schüttere Radionuklidspeicherung in der Restschilddrüse muß in diesen Fällen ohne endogene TSH-Stimulation noch möglich sein (Stadium 3 a).

2. Daneben beobachteten wir jedoch einen Kranken, bei dem das szintigraphische Bild der übrigen Schilddrüse noch eine schüttere ${ }^{131} \mathrm{~J}$-Speicherung aufwies (noch kompensiertes autonomes Adenom). Als Ausdruck der Hyperthyreose waren die peripheren Schilddrüsenhormonspiegel aber bereits erhöht und die TSH-Spiegel nicht mehr stimulierbar (Stadium 3 b).

3. Denkbar ist ferner ein Stadium im Übergang vom kompensierten zum dekompensierten autonomen Adenom (Stadium $3 \mathrm{a}^{\prime}$ ), in dem die Schilddrüsenhormonspiegel schon erhöht sind, die TSH-Sekretion durch TRH aber in Übereinstimmung mit dem szintigraphischen Bild noch stimulierbar ist. Diese Konstellation wäre nur bei einer sehr schnellen Entstehung der Hyperthyreose, zum Beispiel durch Jodifizierung, erklärbar und würde dem Stadium 3 b vorausgehen.

Das Stadium 4 stellt das bekannte szintigraphisch dekompensierte autonome Adenom mit Hyperthyreose und Suppression der endogenen TSH-Sekretion dar.

Wenn die autonome Schilddrüsenhormon-Freisetzung wieder in den euthyreoten Bereich absinkt (Stadium 5), kann die TSH-Sekretion infolge des Fehlens des physiologischen Sekretionsreizes (Absinken der peripheren Schilddrüsenhormonspiegel) weiterhin supprimiert bleiben. Bei einem weiteren Abfall des peripheren Schilddrüsenhormonspiegels in den unteren Normalbereich oder unter die Norm, zum Beispiel durch Jodmangel, kann mit exogener TRH-Stimulation wieder ein Anstieg der TSH-Spiegel erzielt werden (Stadium 6).

Wenn die TSH-Sekretion schließlich nicht nur durch exogenes TRH stimulierbar ist, sondern sich auch die Regulation zwischen peripherem Schilddrüsenhormonspiegel und TSH-Sekretion im euthyreoten Bereich normalisiert, wird das szintigraphische Bild wieder das eines (maskierten) kompensierten autonomen Adenoms sein, also ein Übergang vom Stadium 6 zum Stadium 2 statt-

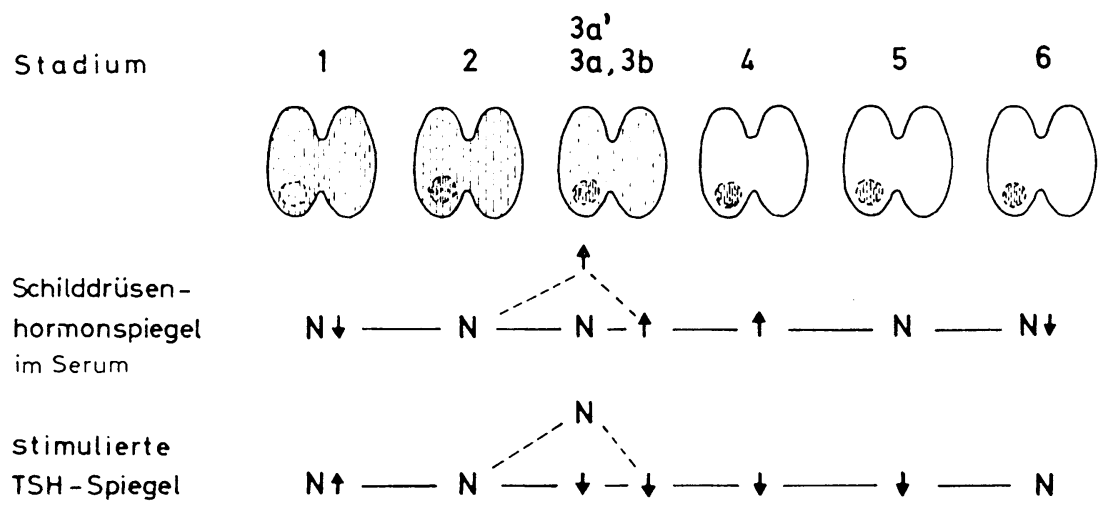

Abb. 2. Funktioneller Zyklus des autonomen Adenoms der Schilddrüse. Die Einteilung in die Stadien 1-6 enispricht den Ubergängen von der blanden Struma nodosa zum kompensierten und zum dekompensierten autonomen Adenom mit und ohne Hyperthyreose und zu Rückbildungsstadien. Diese Einteilung berücksichtigt die Schilddrüsenhormonspiegel im Serum und die Stimulierbarkeit der TSHSekretion durch TRH. $\mathrm{N}=$ normal, $\uparrow=$ erhöht, $\downarrow=$ erniedrigt. Der Úbergang von $3 \mathrm{a}$ ' nach $3 \mathrm{~b}$ ist durch eine gestrichelte Linie dargestellt. 
finden. Spontane rückläufige Veränderungen werden in Abhängigkeit von der Schilddrüsenhormonbildung im autonomen Areal aus dem Stadium 3 nach Stadium 2 ebenfalls möglich sein, ohne daß die Stadien 4 bis 6 vorher durchlaufen werden müssen. Diese rückläufigen Veränderungen werden durch die klinischen Untersuchungsmethoden jedoch nur in Einzelfällen diagnostiziert werden können.

\section{Folgerungen}

Die Beschreibung des funktionellen Zyklus der autonomen Adenome gibt noch keine Erklärung für die Ursache etwa des Uberganges eines kompensierten in ein dekompensiertes autonomes Adenom. Hier spielt vielleicht eine zufällige plötzliche hohe Jodzufuhr eine Rolle. Die einzelnen Stadien des funktionellen Zyklus lassen sich durch die angegebenen Methoden heute genau charakterisieren. Praktisch wichtig ist, daß zum Beispiel beim dekompensierten autonomen Adenom "ohne Hyperthyreose « der Ubergang in eine Hyperthyreose, etwa nach Applikation jodhaltiger Kontrastmittel, jederzeit zu befürchten ist, da die TSH-unabhängige Schilddrüsenhormonsekretion keiner physiologischen Regulation unterliegt. Daher liegt die diagnostische Bedeutung der TRH-Belastung mit dem Ergebnis der fehlenden Stimulierbarkeit der TSH-Spiegel in der daraus abzuleitenden therapeutischen Konsequenz: Ein autonomes Adenom sollte auch "ohne Nachweis einer Hyperthyreose " durch Operation oder Radiojod-Behandlung ausgeschaltet werden.

Wir danken Fräulein G. Madlener, Fräulein S. Trimborn und Fräulein I. zur Hrost für die sorgfältige technische Assistenz.

\section{Litcratur}

(1) Börner, W., E. Moll, E. Rauh, A. Pohner, S. Grehn, G. Ruppert: Diagnostik des autonomen Adenoms der Schilddrüse. Disch. med. Wschr. 96 (1971), 1707

(2) Boler, J., F. Enzmann, K. Folkers,

C. Y. Bowers, A. V Schally: The identity releasing factor (TRF). Nature (Lond.) $226(1970), 321$.

(4) Emrich, D.: Jodstoffwechsel. In: Emrich, D. (ed.): Nuklearmedizin, Funktionsdiagnostik (Thieme: Stuttgart 1971), 148.

(5) Erhardt, F., J. Grüner, 1. Marschner C. R. Pickardt, P. C. Scriba: Optimicrte radioimmunologische TSH-Bestimmung im Serum: Methode und Interpretation. In Vorbereitung.

(6) Habermann, J.: Kompetitive Protein bindungsanalyse für $T_{3}$ und $T_{4}$, Anwendung für die getrennte Bestimmung von $T_{3}$ und $T_{4}$ im Serum. Dissertation, München. In Vorbercitung.

(7) Habermann, J., J. Henner, K. Horn I. zur Horst, P. C. Scriba: Automatization of serum thyroxine determination and of $T_{3}$-uptake test. Acta endocr.

(Kbh.) Suppl. 159 (1972), 7

(8) Heinze, H. G., H. W. Pabst, J. Klemm, G. Hör: 1-TrijodthyroninSuppressionstest der Schilddrüse. (Ergebnisse von 395 ausgewerteten Testen.)

Ther. Umsch. 24 (1967), 397.

(9) Horn, K., J. Habermann, J. Henner, I. zur Horst, P. C. Scriba: Automatisierte Schilddrüsenhormonanalytik in Serum: $T_{3}$-in-vitro-Test und GesamtThyroxin (CPB). Z. anal. Chem. 259 Thyroxin (CP1
(1972), 222.

(10) Horn, K., J. Henner, P. C. Scriba Klinisch-chemische Schilddrüsenfunktionsdiagnostik. II. Automatisierter $\mathrm{T}_{3}$. in-vitro-Test. Disch. Ges. klin. Chem., Mittcilung No. 2 (1971), 29.

(11) Horn, K., T. Ruhl, P. C. Scriba: Semiautomatic method for the separation and determination of total triiodothyronine and thyroxine in serum. Z. klin. Chem. 10 (1972), 99.

(12) Klein, E., H.-L. Krï̈skemper, D. Reinwein, K. Schwarz, P. C. Scriba: Klassifikation der Schilddrïsenkrankheiten. Disch. med. Wschr. 96 (1971), 752
(13) Miller, J. M., R. C. Horn, M. A Block: The autonomous functioning thyroid nodule in the evolution of nodular goiter. J. clin. Endocr. 27 (1967), 1266

(14) Odell, W. D., J. F. Wilber, W. E. Patul: Radioimmunoassay of thyrotropin in human serum. J. clin. Endocr. 25 (1965), 1179.

(15) Odell, W. D., J. F. Wilber, R. D. Utiger: Studies of thyreotropin physiology by means of radioimmunoassay. Rec. Progr. Horm. Res. 23 (1967), 47.

(16) Pickardt, C. R.: Stimulation der TSH-Sekretion durch TRH (Thyrotropin Releasing Hormone): Diagnostische Bedeutung und pathophysiologische Folgerungen. Habilitationsschrift, München 1972.

(17) Pickardt, C. R., K. Horn, P. C. Scriba: Moderne Aspekte der Schilddrüsenfunktionsdiagnostik. Internist (Bcrlin) 13 (1972), 133

18) Pickardt, C. R., F. Erhardt, J. Grüner, K. Horn, P. C. Scriba: Stimulation der TSH-Sekretion durch TRH bei blander Struma: Diagnostische Bedeutung und pathophysiologische Folgerungen. Klin. Wschr. 50 (1972), 1134.

(19) Scriba, P. C.: Die diagnostische Wertigkeit des Trijodthyronin-Tests. Disch. med. Wschr. 94 (1969), 1455.

(20) Scriba, P. C.: Schilddrüsenkrankheiten. In: Schwarz, K., P. C. Scriba (ed.): Endokrinologie für die Praxis, Teil I A (Lehmann: München 1969).

(21) Utiger, R. D.: Radioimmunoassay of human plasma thyrotropin. J. clin. Invest. 44 (1965), 1277.

(22) Zeidler, U., H. L. Krüskemper. H. J. Dowidat, H. Fritz: Das autonome Adenom der Schilddrüse. Med. Klin. 64 (1969), 1963.
Dr. C. Renate Pickardt, Dr. Dr. rer nat. F. Erhardt, cand. med. Jutta Grüner, Dr. K. Horn, Prof. Dr. P. C. Scriba Il. Medizinische Klinik der Universität 8 München 2, Ziemssenstr. 1

Privatdozent Dr. H.-G. Heinze

Klinik und Poliklinik für Radiologie der Universität 8 München 2, Ziemssenstr. 1 